University of Louisville

ThinkIR: The University of Louisville's Institutional Repository

Electronic Theses and Dissertations

$12-2020$

\title{
The ball is in your court: a phenomenological study examining college athletes with learning disabilities and/or ADHD on college campuses.
}

Stephanie Thea O'Donnell

University of Louisville

Follow this and additional works at: https://ir.library.louisville.edu/etd

Part of the Higher Education Commons

\section{Recommended Citation}

O'Donnell, Stephanie Thea, "The ball is in your court: a phenomenological study examining college athletes with learning disabilities and/or ADHD on college campuses." (2020). Electronic Theses and Dissertations. Paper 3551.

https://doi.org/10.18297/etd/3551

This Doctoral Dissertation is brought to you for free and open access by ThinkIR: The University of Louisville's Institutional Repository. It has been accepted for inclusion in Electronic Theses and Dissertations by an authorized administrator of ThinkIR: The University of Louisville's Institutional Repository. This title appears here courtesy of the author, who has retained all other copyrights. For more information, please contact thinkir@louisville.edu. 
THE BALL IS IN YOUR COURT: A PHENOMENOLOGICAL STUDY EXAMINING COLLEGE ATHLETES WITH LEARNING DISABILITIES AND/OR ADHD ON COLLEGE CAMPUSES

\author{
By \\ Stephanie Thea O'Donnell \\ B.A. \& B.S., Keene State College, 2013 \\ M.A., The University of Alabama, 2016 \& 2017
}

\begin{abstract}
A Dissertation
Submitted to the faculty of the College of Education and Human Development of the University of Louisville in Partial Fulfillment of the Requirements for the degree of
\end{abstract}

Doctor of Philosophy in Counseling and Personnel Services

Department of Counseling and Personnel Services

University of Louisville

Louisville, Kentucky

December 2020 
Copyright (C) 2020 by Stephanie Thea O’Donnell

All rights reserved 

THE BALL IS IN YOUR COURT: A PHENOMENOLOGICAL STUDY EXAMINING COLLEGE ATHLETES WITH LEARNING DISABILITIES AND/OR ADHD ON COLLEGE CAMPUSES

\author{
By \\ Stephanie Thea O'Donnell \\ B.A. \& B.S., Keene State College, 2013 \\ M.A., The University of Alabama, 2016 \& 2017
}

A Dissertation Approved on

November 16, 2020

By the following Dissertation Committee

Dr. Amy Hirschy

Dr. Meera Alagaraja

Dr. Meg Hancock

Dr. Eddie Comeaux 


\section{ACKNOWLEDGEMENTS}

Throughout my educational journey from the age of three to the age of 30 , there have been several influential educators and coaches throughout each monumental milestone. Everyone I have had the pleasure of interacting with has left an impact on the student and professional I am today. The dissertation process is no different. The process of dissertating is unlike any other educational experience and a sense of academic, professional, and personal community was what got me through this journey.

First, this research would not have been possible without the resilient and gifted students who participated. These students not only shared their narratives and vulnerable personal experiences but also committed their time and perspective throughout several aspects of the research process. I hope I did justice conveying each of your individual and collective experiences.

Without the consistent guidance and commitment of my committee members, I would not be the same learner, writer, or researcher I am at the end of this process. Dr. Amy Hirschy, thank you for your consistent support and time commitment, ensuring every items on my "to do" list was always discussed and thoroughly answering all of the questions I had throughout my doctoral program. I could not have asked for a better faculty member to engage with and collaborate in this process. I appreciate your perspective and engaging in intellectual brainstorming and investing in my research and 
personal growth. You advocated for me along this journey in numerous ways and I am thankful for your mentorship and expertise.

To my methodologist, Dr. Meera Alagaraja, you have taught me everything I know about qualitative research, from the different approaches, to the process of coding and data analysis. Thank you for being a critical aspect in my development of skills and confidence. You took several hours of your time to mentor me as an emergent qualitative researcher and elevating my research. To Dr. Meg Hancock, from the moment I enrolled in your athletic academic support services graduate course, I knew your knowledge and dedication to student athlete development and support services aligned with this study. I appreciate you taking the time to serve and provide you input throughout the process.

Dr. Eddie Comeaux, thank you for challenging my intellectual growth and development, to view social justice within athletics from a different perspective than the "norm". I reached out to you via email when in the process of writing my proposal and wanted your high regarded perspective on collegiate athletics and disabilities. I am honored to have you serve on my committee and push this research to the next level. Thank you for engaging in deep conversations around athletics and social justice.

Finally, this process would not have been possible without my colleagues, mentors', dearest friends, and family members. To everyone who listened to me anxiously ramble about my research, provided words of encouragement, proof read this manuscript, or helped by properly formatting the final product, I could not have done this without your continuous support, love, expertise, and feedback. Thank you all for playing an integral role towards my success. I am walking away from this experience with lifelong friends, professional mentors, and a new perspective on education. 


\title{
ABSTRACT \\ THE BALL IS IN YOUR COURT: A PHENOMENOLOGICAL STUDY EXAMINING COLLEGE ATHLETES WITH LEARNING DISABILITIES AND/OR ADHD ON COLLEGE CAMPUSES
}

\author{
Stephanie Thea O'Donnell
}

November 16, 2020

Approximately only $1 \%$ of scholarly top-tier higher education published research focuses on the experiences of students with disabilities since the passing of the ADA in 1990 (Pena, 2014). Even fewer studies have explored the learning-disabled collegiate athlete experience. The purpose of this emerging phenomenological study is to understand the lived experiences of college athletes with learning disabilities and/or ADHD at NCAA Division 1 FBS institutions, giving voice to the untold stories, and commonalities amongst this population. This study provides findings grounded in student perspective by examining their experiences related to disability disclosure, self-advocacy, and academic support within the college environment. Five college athletes with ADHD and/or a learning disability participated in 90-minutes interviews. Three major themes emerged throughout the data including reactions and perceptions of others, being vocal and persistent, and building rapport and relationships. The results of this study help inform practitioners on best practices individually and systemically.

Keywords: Academic Support Services, ADHD, College Athletes, Learning Disabilities, NCAA, Self-Advocacy, Self-Disclosure 
TABLE OF CONTENTS

PAGE

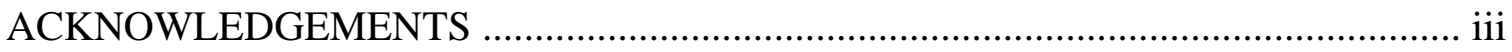

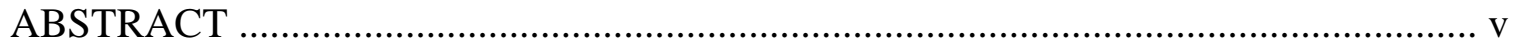

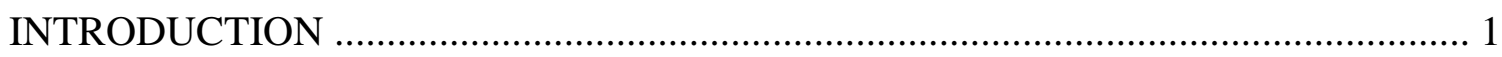

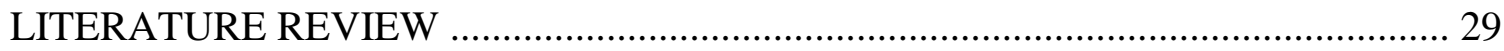

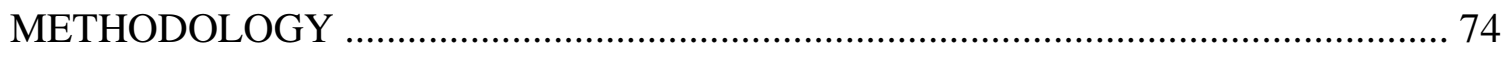

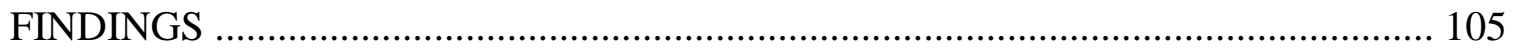

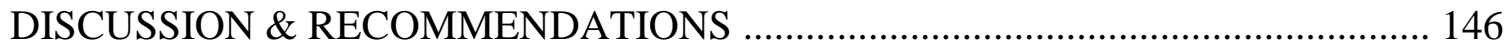

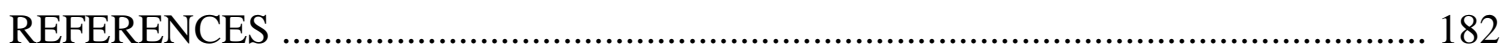

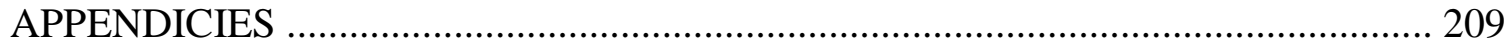

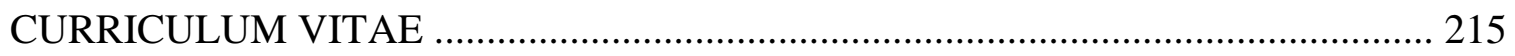




\section{CHAPTER 1}

\section{INTRODUCTION}

The word disability can hold a lot of meaning and can vary based on "... social, geographical, theoretical, or historical context..." (Evans, Broido, Brown, \& Wilke, 2017, p. 4). In addition to context, every disabled person has their own unique perspective and preference when it comes to language choice. The term disability differs on who is defining the word and which disability model approach they choose to subscribe to. Disability can be viewed from a social justice framework as "the way in which people's activities are restricted by their environments (and thus, as a synonym for handicap), and disability as the noun form of disabled" (Evans, Broido, Brown, \& Wilke, 2017, p. 5). As far as naming the specific condition, Evans, Broido, Brown and Wilke (2017) suggest using the word impairment which means, "the ways in which people's bodies or minds differ from what society deems 'normal' or 'typical'. Impairment therefore refers to specific physical, psychological, sensory, cognitive or health conditions whether present at birth or acquired later" (pp. 4-5).

Many things within the disability community vary on the individual, from the type of impairment, to the ways in which an individual views their environment and circumstances. Similarly, each disabled person will have a different perspective and view on how they prefer to be addressed. Some individuals may promote person-first language whereas others subscribe to disability-first language, which is a contemporary perspective 
within American society (Evans, Broido, Brown, \& Wilke, 2017). There is power in using disability first-language. For example, Collier (2012) stated "sticking a word in the shadow of a noun can create the impression that there is something inherently wrong with it, that it should be hidden" (p. E939). The United Kingdom has been using disability first-language as the norm since the beginning of the disability rights movement (Evans, Broido, Brown \& Wilke, 2017). For the purposes of this paper, both usages of the language (person-first and disability-first language) will be utilized to speak to numerous audiences.

The research presented throughout this manuscript aims to provide a glimpse into the learning disabled college athletes' experience, beyond athletic expectations, examining academic support and the development of self-advocacy skills. The voice of college athletes with learning disabilities and ADHD is almost non-existent within the literature. It is important to develop research grounded in lived experiences. In addition, this research provides an innovative social justice lens to understanding disability perspective, which is a large undertaking for a research project, as very few designs have taken a similar approach (Evans, Broido, Brown, \& Wilke, 2017). This phenomenological study seeks to describe the lived experiences of learning or ADHD disabled students who participate in intercollegiate athletics within National Collegiate Athletic Association (NCAA), Division I (D1) athletic programs. Student perspective will inform practitioners on how to support this population through academic support, disclosure decisions, and self-advocacy strategies. Furthermore, the interactionist model of disability helps guide the research, understanding that an individual's experience of a 
disability is a combination of the environment, the person's choices, and the person's impairment.

\section{Defining Learning Disability and/or ADHD}

Since the passing of the American with Disabilities Act (ADA) in 1990, learning impairments have raised significantly to the topmost reported disability on college campuses (Burroughs, 1997; Walker, 2004; Wolverton, 2016). The first definition of a learning disability was published in 1962; prior to this date, lack of achievement in the classroom was attributed to cognitive limitations or lack of motivation (Gordon \& Keiser, 2000; Walker, 2004). The passing of the ADA allowed for more individuals on college campuses to qualify for educational accommodations.

A widely accepted definition of learning disabilities stems from the National Joint Committee on Learning Disabilities (NJCLD). The NJCLD states,

Learning disabilities is a general term that refers to a heterogeneous group of disorders manifested by significant disorders in the acquisition and use of listening, speaking, reading, writing, reasoning, or mathematical skills (National Joint Commission on Learning Disabilities, 1990, p. 3).

This definition is still used present day within educational settings (Fletcher, Lyon, \& Fuchs, 2006). However, it is not backed by medical professionals as a definition for diagnosis or by the federal government.

According to the Diagnostic and Statistical Manual of Mental Disorders (DSM-V) learning impairments and ADHD are classified as neurodevelopmental disorders. The DSM-V is used by professional doctors and healthcare providers to diagnose some nationally recognized non-apparent disabilities such as ADHD and other psychological conditions. The DSM-V defines specific learning disorders as "difficulties learning and using academic skills" (American Psychiatric Association, 2013, p. 66). These difficulties 
must be considered long-term and cannot be resolved through interventions. The criteria listed to qualify for a specific learning disorder can be related to reading or mathematical comprehension, phonics, written communication, and spelling. Furthermore, the diagnosis can be categorized as mild, moderate, or severe. The most common learning disorders are linked to learning challenges in reading, math, and written communication (Cortilla \& Horowitz, 2014).

Attention Deficit Hyperactivity Disorder (ADHD) is classified in the DSM-V under neurodevelopmental disorders and has three categories. Group one is predominantly inattentive, group two is predominantly hyperactive-impulsive, and group three is combined (American Psychiatric Association, 2013). Hyperactivity symptoms widely vary when diagnosing a child compared to an adult. Adults with hyperactivity may experience symptoms of "extreme restlessness or wearing others out with their activity" (American Psychiatric Association, 2013, p. 61). Whereas inattentive behaviors may include the inability to process behaviors beforehand, lack of social awareness, and not considering long-term consequences for one's own actions (American Psychiatric Association, 2013). Symptoms in adults with ADHD may include difficulties with focusing, following through on tasks, organization, personal relationships, regulation of emotions, and impulsivity (Maher, 2014).

Learning impairments and ADHD are often considered hidden or invisible disabilities, not easily detected by physical appearance. ADHD and other learning impairments are typically diagnosed using psychoeducational evaluations, because they are cognitive in nature. Research focused on self-disclosure or stereotypes may be best examined by grouping students with visible and non-apparent disabilities (Vaccara, 
Kimball, \& Wells, 2015). This is due to the different experiences that may vary based on impairments. Disabled students may grapple with the positives and negatives to disclosing their condition and may encounter resistance to sharing this aspect of their identity, especially if the student has not come to terms with their own impairment.

\section{The College Experience for Students with a Learning Disability and/or ADHD}

Approximately $11 \%$ of undergraduate students enrolled in higher education in the United States have a disability (U.S. Department of Education. National Center for Education Statistics, 2013, 2014; U.S. Government Accountability Office, 2009). Furthermore, approximately $64 \%$ of disabled students enrolled in undergraduate coursework have an invisible impairment. Hidden impairments are often classified as learning disabilities, ADHD, and mental illness or psychological concerns (Lux, 2016). Additionally, about $33 \%$ of disabled students on college campuses report having a learning disability and $18 \%$ report having ADHD (Raue \& Lewis, 2011). It is suggested that between $25 \%$ and $50 \%$ of individuals who are diagnosed with a learning disability also have ADHD (Goldstein, 2007; Silver, 2006)

Transitioning from secondary education to higher education can be difficult for many learning disabled student as the academic rigor and curriculum shift drastically. Students with disabilities are more likely to encounter obstacles and barriers to their academic and educational success compared to students without disabilities. Furthermore, a radical transition occurs between high school and higher education where the responsibility to advocate and self-disclose an individual's disability shifts from educators and parents, to the students (Brinckerhoff, Shaw, \& McGuire, 1992; Vaccara, Kimball, \& Wells, 2015). This also implies that published literature and data on disabled 
students prior to entering higher education may not be truly accurate on depicting the full experiences of a college student. Therefore, the majority of research throughout this study focuses on literature geared towards students in postsecondary learning environments.

Students in K-12 education are protected under different federal laws, requiring different expectations. In the K-12 sector, students with disabilities are protected under the Individuals with Disabilities Education Improvement Act (IDEIA) of 2004 (Hadley, 2011). When students enter postsecondary education, students are protected by Section 504 of the Rehabilitation Act of 1973 and the Americans with Disabilities Act (ADA) of 1990 (Hadley, 2011). Not only do the laws change from secondary education to higher education, but the responsibility shifts to the student navigating the accommodation and advocacy process. Students are expected to take initiative and self-disclose their disability, contact the office of disability services, provide official paperwork about their qualifying disability, and self-advocate to their faculty and others who will support their academic endeavors (Hadley, 2011).

When students enter college, it is a preconceived notion that students should have developed academic skills and strategies throughout their primary and secondary education--. These skills include the ability to interpret lectures, take notes, read, write, and have fine-tuned study skills (Mason \& Mason, 2005). However, students with learning disabilities often find these academic tasks challenging, having difficulties in one or more areas which include reading, mathematics, written language, memory, and metacognition (Mason \& Mason, 2005). It is important to note that learning disabilities, just like all disabilities, are unique to each individual, however, educators typically lump 
all students with learning disabilities into one category attempting to prescribe a socially constructed concept (Mason \& Mason, 2005).

In relation to learning about an individual's learning disability, parents are often the first to share information with children or adolescents (Mason \& Mason, 2005). As a child, parents are typically responsible for advocacy. However, when a child continues onto college, parents who do not transition advocacy into the child's ownership may find their child to struggle. The student may view themselves as being underprepared and lack the ability to articulate their own needs (Mason \& Mason, 2005). Raskind, Goldberg, Higgins, and Herman (1999) believe the best strategies to be used by successful people specifically with learning disabilities are the ability to be self-aware, proactive, persevere, set goals, use support systems, and develop coping skills.

As the enrollment of students with disabilities increases on college campuses, the graduation rate of this population demonstrates a lack of successful completion (Quick, Lehmann, \& Deniston, 2003). There is a lack of literature surrounding the lived experiences of disabled students on college campuses (Lux, 2016). In order to better support this population of students, that is steadily increasing, more research must be conducted to understand the holistic experience. By understanding and seeking student voice, educators can create collegiate level support services that emphasize the needs of this group of students. A deeper dive into the literature will point to an understudied perspective, the college athlete with a learning disability or ADHD.

\section{Defining College Athlete}

The term student-athlete comes with a great deal of historical context. At first glance the term student-athlete would appear to sound student centered however, it is 
quite the opposite. Several authors claim the word student-athlete was first coined in 1964 by Walter Byers in a courtroom to protect the NCAA from paying workers compensation. A football player by the name of Kent Waldrop at Texas Christian University was paralyzed during a game against the University of Alabama and sued for workers compensation benefits (Byers, \& Hammer 1997; Shropshire \& Williams, 2017). By using the phrase student-athlete, the NCAA was placing emphasis on the concept that the individual was a student, not an employee (Byers, \& Hammer 1997; Shropshire \& Williams, 2017). This promotes the idea that academics come prior to athletic commitment. However, Staurowsky and Sack (2005) argue that the term traces back even further, to the formation of the NCAA in 1906. Academic scholarships were a political topic and using the term student in front of athlete painted a picture for the general public that student-athletes were solely enrolled in higher education institutions to earn a degree (Staurowsky \& Sack, 2005).

One common issue within higher education is the misrepresentation that college athletes are not typical students. For example, Zimbalist (2001) eloquently stated,

The term college athlete itself tells you they are not normal students...If studentathletes were normal students, then either the term would not be necessary, or it would be joined by other terms like student-musician, student-artist, or studentengineer (p. 37).

Everyone enrolled in higher education is a student, therefore it is argued that this term student-athlete is unnecessary and college athlete is a more appropriate term (Shulman \& Bowen, 2001; Staurowsky \& Sack, 2005; Zimbalist, 1999). To this day, the word studentathlete has been used in scholarly literature, streamed through the media, written into policies, and spoken across college campuses, yet the term is not defined within the dictionary (Staurowsky \& Sack, 2005). 
For the purpose of this research, the term college athlete will be used to represent a college student who participates in an intercollegiate sport officially recognized by the NCAA. By neglecting to use the term student-athlete, which is fueled by propaganda and a misleading historical origin, this paper serves to take a new direction grounded in social justice, equity, and advocacy defined in multiple contexts beyond disability. Additionally, this paper will focus on the experiences and prior research grounded in NCAA D1 student experiences from Football Bowl Subdivision (FBS) conferences unless otherwise noted. It is essential to remember college athletes encounter the same transition and adjustment concerns as students who are not athletes, but a college athlete requires different support services and necessities for their overall success compared to a noncollege athlete.

\section{The College Athletic Experience}

One of the most well-known organizations in collegiate athletics is the NCAA known for setting standards and regulations for college athletes and higher education institutions to abide. A little less than half a million college students participate in collegiate athletics in 24 different NCAA recognized sports each year (NCAA, 2019d). The NCAA is composed of three specific divisions with varying regulations and bylaws. DI institutions form the largest division which include institutions who offer seven or more sports for both men and women college athletes (Bailey, 2017).

The five most powerful conferences that dominate athletics due to their societal popularity are the Atlantic Coast Conference (ACC), Big 12, Big Ten, Pac-12 and Southeastern Conference (SEC) (Sanderson \& Siegfried, 2015; Siegfried \& Burba, 2004). Most revenue producing athletic programs come from these NCAA D1, Power 5 
conferences. The Football Bowl Subdivision (FBS) is comprised of the Power 5 and five additional athletic conferences, which consist of 130 of the largest, competitive colleges in the United States. There are several requirements an athletic program must meet to maintain eligibility under FBS guidelines, but the most common is a school must offer a minimum of 16 varsity sports, which must include football (NCAA, 2014). A revenue producing sport is a high-profile athletic program and are typically associated with football or basketball (Treme \& Burrus, 2006; Menke, 2016). Black men who participate in revenue producing sports account for more than half of the football roster at most of the Power 5 conference institutions, and this number is higher when analyzing men's basketball team rosters (Harper, 2016).

Once a college athlete has graduated high school, been recruited by an institution, and been approved as NCAA eligible, the student begins their collegiate experience. Some college athletes specifically within revenue producing sports enter college with the goal to become a professional athlete (Beamon, 2012; Rishe, 2003; Snyder, 1996). Others typically in Olympic competing sports use the opportunity to gain an education to propel them into a career of their choice. First year college athletes typically struggle academically due to their athletic obligations (Lally \& Kerr, 2005). Balancing schoolwork and outside extracurricular activities are difficult for any first-year student, but the structured and rigorous nature of athletics adds an additional challenge to the college transition.

The three largest concerns college athletes at the collegiate level grapple with include new academic expectations, transitioning from a secondary to post-secondary environment, and time management (Hodes, James, Martin, \& Milliner, 2015). These are 
similar challenges all students at the collegiate level experience, but college athletes require more assistance due to their athletic obligations (Hodes, James, Martin, \& Milliner, 2015). Where the non-college athlete has the ability to independently socialize and autonomy to create their own schedules, college athletes often find their time consumed by mandatory obligations such as academic tutoring or study hall, team practices, and appearances at a variety of campus or NCAA sponsored events (Hodes, James, Martin, \& Milliner, 2015). College athletes are also placed under unique expectations as they not only represent themselves and their team, but also symbolize their entire institutional reputation (Hill, 2001).

College athletes have two competing identities; they are in school for educational purposes, but they are also asked to meet high physical demands in their athletic performance (Watt \& Moore, 2001). College athletes face the same challenges as noncollege athletes, such as major and career exploration, social adjustments, continuous holistic development, and the pressure of academic demands (Carodin, Almond, \& Ratto, 2001; Watt \& Moore, 2001). In addition to the student academic role, college athletes are placed under athletic constraints such as team trainings or conditioning, practice, competition, and traveling to away games (Watt \& Moore, 2001; Carodin, Almond, \& Ratto, 2001).

Participating as a NCAA D1 athlete, comes with additional pressure to perform athletically and maintain NCAA academic eligibility (Watt \& Moore, 2001; Jolly, 2008; Ferris, Finster, \& McDonald, 2004). College athletes encounter high standards from media and consumers which is unique to the NCAA D1 college athlete experience (Howard-Hamilton, \& Sina, 2001; Rishe, 2003; Watt \& Moore, 2001). In addition, 
college athletes not only answer to faculty but are consistently facing pressures to achieve high expectations set forth by athletic coaches, administrators, and academic support staff (Huml, Hancock, \& Bergman, 2014). As pressures to win athletically on the field drive increases in revenue, the expectation to maintain student-athletic eligibility is heightened specifically around academics. This can lead to academic misconduct and lack of judgement in upholding integrity, as seen in recent NCAA investigations at the University of Mississippi and University of Missouri (NCAA, 2017c; NCAA, 2019c).

There is a common debate on the positive and negative implications of participating in intercollegiate athletics, especially at the NCAA D1 competition level. One argument is the positive influence and societal values that are instilled through athletic participation (Menke, 2016; Melendez, 2006; Wolniak, Pierson, \& Pascarella, 2001). Other critics emphasize the negative perspectives to athletic participation which includes lack of education endeavors and exploitation of the college athlete (Menke, 2016; Comeaux, 2011; Pascarella \& Terenzini, 2005; Simons, Bosworth, \& Fujita, 2007). Additional consequences specifically within revenue producing sports include lower graduation rates, negative stereotypes, and beliefs about athletes on college campuses, and slower cognitive development of college athletes (Menke, 2016).

The NCAA only allows athletes to practice 20 hours a week, to help create boundaries between athletics and education. However, college athletes and coaches are known to push this limit (Benford, 2007; Huml, Hancock, \& Bergman, 2014). The general student body on college campuses have the freedom and control to arrange their time commitments surrounding academics and social engagements independently (Jolly, 2008). However, college athletes specifically competing at the NCAA D1 level have 
prescribed schedules involving their academic obligations, to athletic priorities and demands (Jordan \& Denson, 1990; Watt \& Moore, 2001; Jolly, 2008).When surveyed, a half of NCAA D1 collegiate athlete participants admitted that they were unable to spend as much time on their academics as they would prefer and $80 \%$ of participants correlated the reasoning back to participation in athletics (Potuto \& O’Hanlon, 2007). Juggling these two competing identities of student and athlete is difficult. However, college athletes who have learning challenges may experience further struggles within their academic pursuits.

\section{The Learning Disabled College Athletic Experience}

The NCAA coined the term "education-impacting disabilities" (EID) to define college athletes who have a "current impairment that has a substantial educational impact on a student's academic performance and requires accommodations" in 2008 (NCAA, 2019b). According to the NCAA, some of the most commonly reported EIDs are learning disabilities, ADHD, mental health disorders, and medical conditions (NCAA, 2019b). Students who qualify under the NCAA EID legislation are accommodated with exceptions for eligibility standards on core courses, meeting the student's unique educational needs, and these rules differ between Division I, Division II and Division III institutions (NCAA, 2019b). There is a lack of information on EID beyond what is provided on the NCAA website.

It was reported over two decades ago that learning disabled college athletes made up $2.7 \%$ of the college athlete population (N4A, 1998). This number was expected to increase when the NCAA implemented lower admission requirements in 2001 (Clark \& Parette, 2002). Although there has been no scholarly statistics published since 1998, Stowkowski and Huffman (2014) found that out of 477 NCAA D1 college athlete survey 
responses, $4 \%$ of the sample reported having a learning disability. It is also argued that this number is much higher upwards of $25 \%$, reported through media outlets (“College Teams Exploit”, 2009). Although there are no population specific statistics available, some sample sizes suggest the number is much higher than $2.7 \%$. For example, at the University of Louisiana it was published in 2016 that approximately $40 \%$ of the football team qualified for academic accommodations for a learning disability (Wolverton, 2016). The Ohio State University has one in every five football players on scholarship receiving academic services for a learning impairment (Wolverton, 2016). These numbers appear to be similar across Power 5 conferences and revenue producing athletic programs.

Evident from the lack of clarity on the exact number of college athletes with learning impairments or ADHD, research and literature on this population is scarce. The majority of available literature in the early 2000's derives from law journals on the discrimination of college athletes with learning disabilities surrounding NCAA academic eligibility requirements (Weston, 1998; Denbo, 2003; Walker, 2005; Weston, 2005). The NCAA has since changed their requirements to align with federal ADA guidelines allowing remedial courses to satisfy academic course requirements for students with a qualifying education-impacting disability in 2008 (NCAA, 2019b).

Another growing body of literature examining college athletes with ADHD stems from recent research on concussion testing (Kelly, Ketcham, Patel, \& Hall, 2018; Iaccarino, Fitzgerald, Pulli, Woodworth, Spencer, Zafonte, \& Biederman, 2018; Manderino, Zachman, \& Gunstad, 2018). This literature does not address or focus on the academic demands, identity development or strategies and best practices to support college athletes with learning disabilities and ADHD on college campuses or in the 
classroom. Although concussion testing is important within athletic training and the healthcare profession, it does not provide any tangible strategies for the classroom or academic context. A dissertation completed twenty years ago examined college athletes with learning disabilities from one NCAA D1 institution and the transitional support services available. This study briefly analyzed the participant's beliefs of self-advocacy (Graham, 1999). Words such as "assertive", "intimidating", and "unaccustomed" were provided throughout the participants narratives. This outdated information focuses on Schlossberg's transition theory and further research must examine the experiences of college athletes with a theoretical lens grounded in self-advocacy and the interactionist model of disability.

One prevalent dissertation focusing on college athletes with learning disabilities and ADHD surrounding academics and higher education examines NCAA D1 football players and their perceptions on learning (Stokowski, 2013). This study found that five out of the nine participants interviewed were unaware of their specific learning impairment. Additionally, each of these interviews averaged 17 minutes in length and were conducted at one institution. During their dissertation, Stokowski (2013) found that all students used academic support services provided to them such as tutoring and the learning specialists, but only a few students used classroom accommodations. Furthermore, the research showed that most learning disabled college athletes did not take advantage of their classroom accommodations which could be contributed to the fact the majority of students were unaware of their specific disability diagnosis. In addition, the disabling environment filled with negative stereotypes and unaccommodating institutional processes could have played a role. 
A study conducted in 2017 at a NCAA D1 institution focused on learning disabled college athletes (Friedensen, McCrae, \& Kimball, 2017). This qualitative study found that college athletes with non-apparent disabilities used athletics as a coping strategy as athletics provided "support and structure" (p.58). Athletics helped this group of students understand their world and time commitment to their athletic obligations serving as both a positive and negative experience (Friedensen, McCrae, \& Kimball, 2017). One recommendation that derived from this research was embedded in rethinking the term disability, as the term stems beyond physical capabilities. It is suggested that institutional services that serve students with disabilities, and more specifically college athletes, consider using physical activity to teach different strategies related to time management (Friedensen, McCrae, \& Kimball, 2017).

In 2020, Stokowski and colleagues continue to research and publish articles on college athletes with education-impacting disabilities. These studies include examining the effect football has on students with EIDs and the stereotypes Black football students with EIDs experience (Stokowski, Goldsmith, Croft, Hutchens, \& Fridley, 2020; Stokowski \& Ferguson, 2020). Other than these studies indicated above, the college athlete perspective surrounding the lived experiences of navigating campus culture and academic experience with a learning impairment or ADHD are almost non-existent. With a lack of literature on this population of students in higher education, this emergent design will aim to focus on the academic support provided to college athletes with learning challenges. In addition, disability disclosure and self-advocacy skill development will be used to direct the research. In order to enhance a deeper 
understanding and implementation into the higher education context, research must begin with a basic understanding of these experiences.

\section{Problem Statement}

Since the 1970's, a growing number of athletic academic support centers have formed and multiplied their efforts toward supporting athletic academic success on college campuses (Benson, 1994; Rishe, 2003). Evidently, since the passing of the Americans with Disabilities Act (ADA), learning disabilities have become the most reported disability on college campuses (Burroughs, 1997; Walker, 2004). The combination of expanding support services and increased reports of learning disabilities on college campuses has produced the emerging trend and crucial need for learning specialists (Steinberg, Walther, Herbst, West, Zamagias, \& Smith, 2018). Learning specialists utilize strategies and techniques to best support college athletes with learning challenges in their academic success and goals (Weiss, 2011).

As college administrators begin hiring more learning specialists to support college athletes with learning disabilities and other learning concerns, it is critical for their interactions to be grounded in research. Limited pedagogical or practical strategy implementations within higher education can lead to consequences.

A lack of critical inquiry about students with disabilities in all realms of higher education leads practitioners to create policies and services that do not consider the needs of this growing group of students. Such exclusions have not only ethical but also potentially legal ramifications for higher education institutions (Vaccara, Kimball, \& Wells, 2015, p. 36).

This research has the ability to not only emphasize the importance of understanding this ignored population of students on college campuses, but can create lasting informed decision-making policies, and processes that are backed by student perspectives. 
In regard to policies and regulations involving the NCAA bylaws and ADA federal law, history has shown that the NCAA failed to address or incorporate equitable standards for students requiring accommodations based on an individuals' impairment for over 15 years (Weston, 1998; Denbo, 2003; Walker, 2005; Weston, 2005). As the NCAA has recently shifted towards supporting and researching the needs of mental health concerns within intercollegiate athletics, one thing remains untouched and underdeveloped, the importance of supporting college athletes with learning disabilities and/or ADHD.

One of the best ways to understand the difference between equality and equity is through an example based in athletics. Shropshire and Williams (2017) demonstrate that equality is providing an entire athletic team with the same size sneaker. Equality is the idea that everyone got the same, but equity takes this idea a step further. Equity is where everyone not only receives a pair of sneakers, but they are adjusted to meet the specific shoe size of each individual's feet. This allows each athlete to play to the best of their ability. By ignoring disabled college athletes and their experience, the NCAA, other athletic conferences, and institutions of higher education are perpetuating the idea that disability should be hidden (Collier, 2012). Disabled students who compete in intercollegiate athletics are not provided an equitable experience that meets their individualized needs.

Although the NCAA (2017a) published a resource on best practices in regards to mental health which incorporated a section on disability support services, this document does not allow athletic programs to take ownership of becoming more aware of invisible disability and putting best practices into action. Learning disabilities and ADHD are both 
listed in the DSM V, however, most people would not categorize these impairments as mental illness but rather invisible, or cognitive impairments, as the NCAA has also ignored specific best practices relating to academics and athletics in regards to learning disabilities and ADHD. The resource guide suggests best practices consisting of crisis management surrounding mental health concerns, and health-promoting environments that support well-being and resilience, but it neglects to address how athletic departments should better meet the needs of their students who have learning disabilities or ADHD (NCAA, 2017a). The NCAA has taken a stance on destigmatizing and incorporating a specific stance on informing and educating coaches, athletic staff, and departments, however, disability is still hidden, invisible, and ignored. It should be the institutional leaders main goal and objective to educate all students, and a shared responsibility of all personnel on campus to understand differentiated learning techniques, incorporate universal design, and pursue opportunities to gain knowledge and learn how to better support all students and their individualized needs on their educational journey.

Disabled students on college campuses tend to have minimal focus in research and practice when compared to other minoritized groups (Herbert, Welsh, Hong, SooYong, Byun, Atkinson, \& Kurz, 2014; Pena, 2014). Only 1\% of all scholarly work published in top-tier higher education journals since the passing of the ADA in 1990 center around topics relating to disability (Pena, 2014). Furthermore, when examining the motivation of students with disabilities and the disclosing process, limited research has explored the experience of student's decision-making, and choice to seeking disability services on college campuses (O’Shea \& Meyer, 2016). In addition, the research that is relatively available lacks in providing student voice and absence of best practices for 
learning or ADHD disabled students surrounding the effectiveness of accommodations (Lux, 2016).

Students with learning disabilities are more likely to encounter obstacles and barriers to their academic and educational success compared to non-disabled students (Cawthon \& Cole, 2010). The lack of education focused on teaching students how to advocate for their needs and guiding students through transitions into post-secondary education is contributing to the obstacles and barriers faced by disabled students in higher education (Cawthon \& Cole, 2010). Empirical research grounded in student experiences would provide professionals opportunities to foster development and support the navigation of academic independent agency among college athletes with learning disabilities.

In addition to the lack of scholarly research focused on disabled students within higher education, it has been argued that more emphasis needs to be placed on the challenge's intercollegiate college students experience (Comeaux \& Harrison, 2011). When combining these two identities, there is an absence of awareness and focus on this specific population of college athlete with learning disabilities and/or ADHD (Hishinuma \& Fremstad, 1997; Friedensen, McCrae, \& Kimball, 2017). It is essential that further research focuses on this population of students to not only provide deepened perspective, but it enhances the support and needs of the student from an institutional standpoint (Monda, 2011; Stokowski, Blunt-Vinti, Hardin, Goss, \& Turk, 2017).

\section{Significance of Study}

This study has four main goals. By adding student voice and perspective to a minority group on college campuses, this study aims to bring awareness to the lived 
experiences of learning and disabled college athletes. Additionally, this study seeks to bridge gaps in an unexplored population within the literature. A greater understanding of college athletes with learning disabilities and/or ADHD surrounding disability disclosure, self-advocacy and academic support are essential.

Failure to fully understand the distinct experiences of college athletes can have a significant impact on the extent to which we understand the need for specific forms of campus assistance and can affect questions of policy in higher education (Comeaux \& Harrison, 2011, p. 235).

This concept can also be applied to disability and the combination of both identity facets. Comprehending the experiences of learning or ADHD disabled college athletes can provide awareness to college student personnel who have direct contact with this population in the classroom, through athletic academic support centers, and program development across student support offices.

The second goal is to provide professionals, staff, and faculty, informed best practices and recommendations on how to best support college athletes with learning disabilities or ADHD. With limited research to help guide this profession, further research is crucial. Focusing on academic support, disability disclosure, and selfadvocacy can help learning specialists understand the population of students they serve. Faculty and staff can navigate interactions and implement support geared toward the specific needs of college athletes who choose to disclose their specific impairment(s). Emerging from student perspectives, this research can assist several diverse stakeholders on college campuses to create support for this growing yet overlooked population of students.

The third goal is to contribute research and bring more awareness to this group of students on college campuses. Gaston-Gayles (2009) stated, "In order for colleges and 
universities to make sound decisions concerning the welfare of college athletes, longitudinal data sources are needed" (p. 36). This is in response to the lack of studies that focus on the college athlete experience at multiple institutions, as many studies only focus on one or two higher education establishments to conduct research (Gaston-Gayles, 2009). This research aims to collect data from students at multiple institutions. When conducting research on the larger population (college athletes or disabled students), the literature suggests a quantitative approach, but when examining a subgroup within the larger population (college athletes with learning disabilities) the majority of research has applied a qualitative approach.

The final contribution that will be significant to this study is the application of the social justice and interactionist models of disability. Most of the research conducted on disabled students is written in person-first language and typically perpetuates and endorses a medical model approach to disability. The medical model approach views disability as an individualistic problem, whereas the social justice model places the problem within a societal context. This means that if society made all environments accessible to all impairments, there would be no "disability", as the environment is the disabling context. This research prescribes to the interactionist model of disability which incorporates three main factors into disability interactions which include the person's impairment, person's choices, and the environment. This eclectic approach allows for disability to be viewed from several different perspectives and also allows for participants to share which philosophy they subscribe to within the disability community, if they choose to identify as disabled at all. 


\section{Conceptual Framework}

With a lack of theoretical frameworks and conceptual models within higher education surrounding disability, it is suggested that scholars examine other disciplinary models and theories that are relevant to the research (Vaccaro, Kimball, \& Wells, 2015). One conceptual model used throughout this research derives from special education scholars. This conceptual model presented by Test, Fowler, Wood, Brewer, and Eddy (2005) provides a framework for self-advocacy for individuals with disabilities. The second conceptual model is known as the Interactionist Model of Disability, related to the experience of disabled students. This model derives from Evans and Broido (2011), within the field of higher education. These frameworks which will be explored further indepth in the literature review, inform the research questions, and are designed to be used when analyzing the data and synthesizing the findings

\section{Purpose Statement}

The purpose of this phenomenological study is to understand the lived experiences of college athletes with learning disabilities and/or ADHD at NCAA D1 institutions within Football Bowl Subdivision (FBS) conferences. A closer lens will examine disability disclosure, self-advocacy, and academic support within the college environment.

Central Question: What are the lived experiences of college athletes with learning disabilities and/or ADHD surrounding disability disclosure advocacy and academic support at NCAA D1 institutions?

RQ1: What does the process of disability disclosure look like for college athletes with learning disabilities and/or ADHD? 
RQ2: How do college athletes with learning disabilities and/or ADHD advocate for their academic success?

RQ3: In what ways do college athletes with learning disabilities and/or ADHD describe academic support within their campus community?

Working towards answering these questions will help promote a voice that is lacking in current higher education research. In order to best inform practices occurring in higher education, a student perspective is required to set forth recommendations and strategies on how to best support college athletes with learning disabilities and/or ADHD. Every individual on a college campus plays a significant role in the formation of campus climate. The purpose of this research is to provide direction and recommendations for athletic administrators, faculty, and student affairs staff, synthesizing findings, and application of these strategies into practice.

\section{Definitions}

The following is a list of words or terms used throughout this manuscript that sets clear definitions and descriptions.

Academic Support Services: Various programs and facilities that are available at individual institution to help students academically succeed and foster development through a variety of activities and interactions with administrators, staff, and peers. Academic support services refer to specific programs that are geared towards supporting students academically outside of the classroom towards retention and graduation (Gansemer-Topf \& Schuh, 2006). For the purposes of this study, academic support 
services include but are not limited to disability support services and athletic academic support services.

Accommodation: The Americans with Disabilities Act of 1990 requires all higher education institutions receiving federal funding to provide students with disabilities reasonable accommodations (Americas with Disabilities Act, 1990). Accommodations in an academic environment are known as removing barriers and making modifications for individuals to fully participate in their education.

Attention Deficit Hyperactivity Disorder (ADHD): One of several disorders classified under neurodevelopment within the DSM-V. ADHD can be diagnosed in early childhood, adolescence, or adulthood (American Psychiatric Association, 2013). The disorder can be diagnosed under one of three categories which include inattentive, hyperactive, or a combination. ADHD is "characterized by developmental deficits that produce impairments of personal, social, academic, or occupational functioning” (American Psychiatric Association, 2013, p. 31).

College Athlete: A college student who participate in an intercollegiate sport officially recognized by the NCAA. Irick (2011) defines college athlete by providing the following requirements. "For the purposes of this report, a participant at an NCAA member institution is defined as a student who, as of the day of the varsity team's first scheduled contest: (a) is listed as a team member; (b) practices with the varsity team and receives coaching from one or more varsity coaches; or (c) received athletically-related student aid. Any student who satisfies one or more of the above criteria is a participant, including a student on a team the institution designates or defines as junior varsity, freshman, or 
novice, or a student who does not play in a scheduled contest, whether for medical reasons or to preserve eligibility (i.e., a redshirt)" (p. 7).

Disability: According to the ADA of 1990, a disability is defined as "a physical or mental impairment that substantially limits one or more major life activities of such individual; a record of such an impairment; or being regarded as having such an impairment" (Americans with Disabilities Act, 1990, sec. 12102). Federal law requires postsecondary educational institutions "to provide both access and accommodations for students whose disabilities meet the laws' definitions" (Kaplin \& Lee, 2013, p. 1042). However, this research seeks to change the perspective of disability from a legal medical model point of view to a social justice, interactionist model perspective. Therefore, disability is defined as “the way in which people's activities are restricted by their environments (and thus, as a synonym for handicap), and disability as the noun form of disabled" (Evans, Broido, Brown, \& Wilke, 2017, p. 5).

Impairment: Evans, Broido, Brown, and Wilke (2017), define impairment as, "the ways in which people's bodies or minds differ from what society deems 'normal' or 'typical'. Impairment therefore refers to specific physical, psychological, sensory, cognitive or health conditions whether present at birth or acquired later" (pp. 4-5). Taking this approach means that the impairment would be ADHD or learning difficulties or challenges rather than the disability.

Learning Disabilities: This study takes an inclusive approach by defining a learning disability as "a general term that refers to a heterogeneous group of disorders manifested by significant difficulties in the acquisition and use of listening, speaking, reading, 
writing, reasoning, or mathematical abilities" (National Joint Commission on Learning Disabilities, 1990, p. 3).

Learning Specialist: A growing profession within athletic academic support services. This student support personnel is intended to support college athlete who are academically "at-risk", demonstrate learning challenges or difficulties, or have an impairment that affects their academic potential or success (Steinberg, Walther, Herbst, West, Zamagias \& Smith, 2018).

National Collegiate Athletic Association (NCAA): The NCAA is the largest governing body in the United States associated with intercollegiate athletics. "Nearly half a million college athletes make up the 19,750 team that send more than 52,500 participants to compete each year in the NCAA's 90 championships in 24 sports across the 3 division" (NCAA, 2019e). This study focuses on NCAA Division 1 college athletes. The NCAA is categorized into three collegiate sport divisions with different regulations which outline the extent of the athletic program, level of competition, and financial aid. NCAA D1 programs are the highest level of intercollegiate athletics authorized by the NCAA. Self-Advocacy: For the purposes of this study, self-advocacy is defined as "an individual's ability to effectively communicate, convey, negotiate, or assert his or her own interests, desires, needs, and rights. It involves making informed decisions and taking responsibility for these decisions (VanReusen, Bos, Schumaker, \& Deschler, 1994)" (Clark \& Parette, 2002, p. 54).

Self-Disclosure: Refers to a disabled student choosing to reveal or communicate information about their impairment to a faculty member, staff, or administrator for the 
purpose of requesting accommodations to support their disability through academics, educational attainment, or campus events and activities. 


\section{CHAPTER 2}

\section{LITERATURE REVIEW}

To understand the necessity of this research, it is essential to review what is considered noteworthy in prior literature. In the literature, a learning or ADHD impaired college athletes is a population lacking attention and voice. Due to the lack of literature and focus on this salient population of students, a wider range in approach is applicable. This section will emphasize the college experience of learning disabled students and literature around disability disclosure and stigmatization. The second section focuses on self-advocacy skills which will be included as these are facets that arise within the disability community. In addition, exploration of academic support services available to college athletes through athletic academic support centers and disability support services will be provided. The final section of this review will explain in-depth the conceptual models that will be applied throughout the research and data analysis.

\section{Disability Self-Disclosure}

As previously established, to receive accommodations at the post-secondary level, students must self-disclose their disability. The process of discussing or choosing to disclose a disability looks different depending on the type of impairment. For example, students with nonvisible or "hidden" impairments have the ability to voluntarily withhold sharing information about their disability compared to an individual with a physical or visible impairment, who may find hiding their disability impossible 
(Barnard Brak, Lechtenberger, \& Lan, 2010; Forman, Baker, Pater, \& Smith, 2011; Olney \& Kim, 2001). Self-disclosure of a disability is defined as the moment in which a student communicates with another individual that they have a disability (Lynch \& Gussel, 1996; De Cesarei, 2014). This can look different based on the individual and situation. When contemplating self-disclosure, individuals may consider the benefits and challenges associated with this vulnerable decision (Corrigan \& Matthews, 2003; Smart, 2001; Barnard-Brak, Lechtenberger, \& Lan 2010). Sharing extremely personal and private information about oneself is an ongoing process in which an individual must consider and learn to navigate the relationship and context (Petronio, 2002).

Deciding to self-disclose is considered a "complex, multilayered, and highly correlated to the climate and disability environment on campus" (Trammell \& Hathaway, 2007, p. 6). Self-disclosing a disability at any stage in the higher education process (application, enrollment, or first year of college and beyond) comes with both benefits and disadvantages (Gerber \& Price, 2003; Hughs \& Graham, 1994). Asking a student to share extremely privileged and personal information to staff and instructors can cause hesitation for some students. In many cases handing an instructor an accommodation letter can lead to the student being asked several questions about their disability. Questions can include "highly personal (e.g., asking specific questions about a person's disability) to the impersonal relating only to satisfying a request for accommodations (e.g., asking questions only in order to satisfy a request for accommodations)" (Marshak, Van Wieren, Farrell, Swiss, \& Dugan, 2010, p. 413). From either perspective there can be some level of discomfort felt by both participants in this exchange. 
There are three essential questions that students with disabilities contemplate before deciding to self-disclose their disability.

- Who do I tell?

- How much do I tell?

- When do I tell?

Students who can internalize and think through these questions are typically more capable of managing their ability to disclose information and find a process that works for their needs and comfort level (Trammel, 2009). There are four main factors that influence the self-disclosure process for disabled students (Petronio, Martin, \& Littlefield, 1984). First, is the relationship with the individual in which they are contemplating self-disclosure. Second, is the context of the situation and environment. The third factor is the individual's response to the student with a disabilities selfdisclosure. The final influencing factor is the individuals own beliefs, thoughts, and feelings about their own disability.

Identity development and exploration are essential dynamics during the college experience (Riddell \& Weedon, 2014). Identity issues that cause barriers to disclosing a disability on college campuses include a need to feel independent, the need to remove the stigmatized identity that is present from secondary education, and the hesitation in disclosing their identity as a disabled individual in their collegiate identity (Marshak, Wiernen, Ferrell, Swiss, \& Dugan, 2010). A second barrier is the need to remove negative social barriers such as being isolated. Additionally, insufficient knowledge or understanding on the student's own impairment or explanation of their accommodations can cause fear and feelings of worry (Marshak, Wiernen, Ferrell, Swiss, \& Dugan, 2010). 
Furthermore, negative interactions with professors lead to resisting disclosure of a disability. There appears to be several barriers that influence a student's decision to selfdisclose their impairment to receive disability related accommodations.

Choosing to self-disclose comes with both some benefits and several perceived negatives which can include discrimination and stereotyping (Crawford, 2002; Hartmann, 2003; Trammel, 2009). The term disability in itself can be a set-back for some students who need accommodations, since students have to visit the universities disability support services, which forces labels onto a student before the student even begins the process of seeking accommodations (Trammel, 2009). Stigma around the word disability can cause students to avoid self-identification on college campuses (Clark \& Parette, 2002; Walling, 1996). When a student chooses not to disclose their impairment, they are choosing not to be stigmatized but also not to benefit from the accommodations that could provide academic support (Baldridge \& Veiga, 2001). If requesting accommodations will benefit a student's academic abilities and success, but hinder their identity or public image, students will choose to opt into social identity rather than selfseeking behaviors (Baldridge \& Veiga, 2001; Madaus, 2008).

\section{Identity Stereotypes Affecting Self-Disclosure}

Defining the word stereotype through prior literature is difficult as the definition appears several times since the early 1920's but the literature cannot seem to agree on a working definition (Judd \& Park, 1993; Kanahara, 2006). Judd and Park (1993) conclude that "a stereotype is an individual's set of beliefs about the characteristics or attributes of a group" (p. 110). Similarly, Brauer, Judd, and Jacquelin (2001) define the term as “...a stereotype consists of an individual's beliefs about a group of people (p. 453). The two 
common words used throughout both definitions are belief and group (Kanahara, 2006). College athletes are typically generalized as a group and held to specific beliefs amongst faculty, peers, administrators, and sports fans.

Stereotyping has proven to negatively influence college athletes' academic success. The negative influence on academic performance is associated with stereotype threats, which is defined as "the anxiety people experience when they risk confirming a negative stereotype of their group" (Yopyk \& Prentice, 2005, p. 329). According to Steele (1997), college athletes are negatively stereotyped as being less academically engaged and competent than their peers. This could explain the lower academic scores on tests and exams. The most well-known stereotyping of college athletes is the "dumb jock" stereotype. Students are not held to high standards in the classroom, as professors buy into the stereotype that college athletes are incapable of academic abilities and therefore are not challenged to excel (Engstrom \& Sedlacek, 1991; Shropshire \& Williams, 2017). Stereotypes on a college campus bleed into the self-esteem and mental image of college athletes and their identity formation.

When it comes to interacting with faculty members, athletic stigma on college campuses is actively present, shown through remarks from professors about missed class due to athletic traveling or about college athlete's academic habits (Parsons, 2013). Engstrom, Sedlacek, and McEwen (1995) reported that faculty members hold specific stereotyping against two specific groups of college athletes. The first group are those who receive full athletic scholarships, the second group applying to those who are admitted with low standardized test scores. Having low standardized test scores resulted in the belief that students are underqualified or not deserving of admissions to the institution. 
Black college athletes face even further stereotyping. There has been an abundance of literature on the Black male college athlete experience in different college environments and experiences (Bennett III, Hodge, Graham, \& Moore III, 2015; Cooper \& Hawkins, 2014; Comeaux, 2008; Comeaux \& Harrison, 2007; Harrison, Comeaux, \& Plecha, 2006). There is a large amount of literature focusing on racism and the exploitation of men of color at predominantly white institutions (PWIs) (Beamon, 2014; Cooper, 2012; Harper, 2009; Hawkins, 2010; Murty \& Roebuck, 2015; Simiyu, 2012; Singer, 2005). This research is warranted and necessary to understanding a larger complex issue. Many students in revenue producing sports (football and basketball) are Black men who are considered academically "at-risk" (Harmon, 2010). There are many barriers college athletes of color can experience attending a PWI, where their coaches, support staff, and student body lack the ability to comprehend the Black experience (Harmon, 2010). Furthermore, isolation from the rest of the student body due to high demands to their athletic commitment hinders racial and other identity development (Ferrante, Etzel, \& Lantz, 2002; Harmon, 2010).

There are perpetuated academic stereotypes of Black college athletes held by faculty (Simiya, 2012). Black college athletes report feelings of being treated differently from a non-college athlete and White students (Njororai, 2012). Black male college athlete enrolled in Power 5 institutions express feelings associated with proving their worth of being enrolled at an academic institution based on merit beyond their athletic and physical abilities (Martin, Harrison, Stone, \& Lawrence, 2010). Furthermore, students experience being a perceived threat to society, which is further perpetuated through challenges surrounding stereotypes in the academic environment (Martin, 
Harrison, Stone, \& Lawrence, 2010). Black male college athlete may utilize faculty less as a support system due to stereotyping or previous negative experiences in faculty interaction.

Engaging with disabled students provides further stereotypes that interfere with a student's academic success. Faculty members perceive themselves to be advocates throughout the accommodation process for students with disabilities, especially within their courses, but learning disabled students report the opposite (Cawthon \& Cole, 2010; Debrand \& Salzberg, 2005; Murray, Flannery, \& Wren, 2008). Additionally, faculty want to be more informed on learning disabilities and the support procedures, referrals process, and accommodations that can be provided to students (Houck, Asselin, Troutman, \& Arrington, 1992).

Despite faculty members' perceptions of positive interactions with learning disabled students, students believe the opposite and struggle to find a sense of belonging within the classroom environment (Kurth \& Mellard, 2002; Hadley, 2011). Students with learning disabilities felt as though they were perceived as incompetent, or the student should not be enrolled in the course at all (Cawthon \& Cole, 2010). There are incongruences between the way faculty perceive their attitudes towards learning disabled students within the classroom and the lived experiences of student with learning disabilities in college learning environments. It is important for student affairs practitioners and faculty to remember that interactions between faculty and the campus community help increase academic commitment and involvement (Hadley, 2011).

Students on college campuses are faced with a two-way dilemma; if a student is to disclose their impairment in order to receive accommodations, the student risks 
discrimination and stigmatization (Crawford, 2002; Hartmann, 2003; Trammell, 2009).

Literature on learning disabilities reveal two specific types of attitudes, which are stereotyping and segregation (May \& Stone, 2010). Stereotyping threats include students with learning disabilities being perceived as "too lazy" (May \& Stone, 2010). This is a harmful stereotype, as students with learning disabilities already encounter deficits in specific areas of learning, to add the label of lazy impedes on the students overall academic success.

There are two types of stigmas that prevent disabled students from self-disclosing their identity which include public and self. Public stigma is societal decimation, whereas self-stigma is the individual's behaviors and responses (Corrigan \& Kleinlein, 2005; Kranke, Jackson, Taylor, Anderson-Fye, \& Floersch, 2013). According to disability support staff, stigmatization and fear of disclosure are considered the largest barrier to seeking disability support services (Collins \& Mowbray, 2005). Disabled students can also appear embarrassed and stigmatized when informing faculty members of nonapparent impairments (Salzer, Wick, \& Rogers, 2008). When interacting with peers, disabled students often find others who are non-disabled have little experience or hold stereotypes and stigmas about disabled people (Olney \& Kim, 2001). One of the many misconceptions held by students without a disability is that academic accommodations for disabled students are perceived as an "unfair advantage" (Olney \& Kim, 2001).

Learning disabled college athletes may face even further stereotyping threats within academic environments. The term college athlete is tainted with negative stereotypes often perpetuated by individuals who do not comprehend the relationship or experience of college athletes academically and athletically (Satterfield, Croft, \& 
Godfrey, 2010). Some inaccurate preconceived notions about college athletes consists of privileged, lazy, coddled, preferential treatment, and lack of intellectual ability or motivation to succeed academically (Ferrante, Etzel, \& Lantz, 1991; Watson, 2006). These stereotypes can be perpetuated by faculty and students who interact with college athletes in academic settings. Stigmatization and stereotyping are issues that hinders campus climate and environment in which learning disabled college athletes are exploring and navigating throughout their collegiate experience.

The distance and separation of athletic physical spaces and buildings on campus can contribute to the feeling of isolation for college athletes from the general study body population (Huml, Hancock, Bergman, 2014, Simons, Van Rheenen, \& Covington, 1999). Crosnoe, Cavanagh and Elder (2003), found that peer interaction with noncollege-athletes is beneficial from both perspectives. College athlete benefit from interactions outside of athletic spaces that foster social engagement and academics, and non-college-athletes are challenged to reconsider their perceptions of college athletes by understanding their demands and differentiating experiences. Despite research emphasizing the importance of athlete and non-athlete social connections to help with academic motivation, the isolation college athletes create an environment that hinders the potential for any relationships to foster over the collegiate experience (Bell, 2009).

The NCAA published research in 2014 and 2017 on social environments of college athletes. This research examines interactions and perceptions of college athletes within their campus community across all three athletic divisions. The number of college athletes who feel their peers perceive them as unsuccessful academically is alarming and differs based on sex. Although research and the literature focus heavily on faculty 
perceptions, these numbers appear lower than peer perceptions of academic ability. For example, $23 \%$ of NCAA D1 male athletes perceive their professors to assume they are not a good student because of their athletic identity or participation, compared to $11 \%$ for NCAA D1 females (NCAA, 2017b). With reference to perceptions of their peers, NCAA D1 male athletes reported $44 \%$ compared to $29 \%$ of NCAA D1 females (NCAA, 2017b).

The perceptions college athletes believe their peers hold about their athletic identity on their college campus can be examined by asking non-athletes their held beliefs. Lawrence, Harrison and Stone (2009) found that $41 \%$ of college students held negative stereotypes and perceived male college athletes as dumb, lazy and assumed students frequently engaged in partying behaviors and neglected academic studying. The general student body also believes college athletes are granted special privileges towards their academics (Lawrence, Harrison, \& Stone, 2009).

\section{Advocacy Skills}

Self-advocacy is a critical skill necessary for disabled students to utilize when speaking about their impairment and seeking accommodations. One definition of selfadvocacy pertaining to disability is provided by Hartman (1993).

Self-advocacy means that the student understands his or her disability, is aware of the strengths of the weaknesses resulting from the functional limitations imposed by the disability, and is able to articulate reasonable need for academic or physical accommodations (p. 40).

Another definition of self-advocacy is provided by Clark and Parette (2002) which is adapted from VanReusen, Bos, Schumaker, and Deschler (1994).

Self-advocacy is defined as an individual's ability to effectively communicate, convey, negotiate, or assert his or her own interests, desires, needs, and rights. It involves making informed decisions and taking responsibility for these decisions (p. 54). 
In essence, self-advocacy requires a student to have a working knowledge of their own impairment, make informed decisions about their abilities based on their rights, and communicate their needs with others in order to be successful in a variety of contexts and settings (Test, Fowler, Wood, Brewer, \& Eddy, 2005; Daly-Cano, Vaccaro, \& Newman, 2015). Self-advocacy allows for individuals to make informed decisions grounded in an individual's knowledge of their strengths and challenges (Dybwad \& Bersani, 1996).

Students with learning disabilities or nonvisible disabilities may be unable to communicate the extent to which their impairment affects their daily life or academic success (Barnard-Brak, Sulak, Tate, \& Lechtenberger, 2010; Smart, 2001). In order to actively self-advocate students' needs to process and comprehend their learning impairment and find strategies or techniques that work best for their unique needs (Hadley, 2011). The lack of education going towards teaching students how to advocate and communicate their needs and guiding students through transitions into postsecondary education are important concepts that are adding to the obstacles and barriers faced by learning disabled students in higher education (Cawthon \& Cole, 2010).

There is a lack of literature on how self-advocacy skills are formed, but what is known is the influence in which families, peers, and educators have on the development (Daly-Cano, Vaccaro, \& Newman, 2015). Family support can have both positive and consequently negative outcomes. Families can encourage students with disabilities to advocate by modeling the behavior and having conversations with their children about their disability. However, families can also become overprotective and share doubt or disbelief in their child's ability to succeed (Dowrick, Anderson, Heyer, \& Acosta, 2005; Janiga \& Costenbader, 2002). Educators can help in the development by teaching 
students in high school the importance of practicing self-advocacy (Janiga \& Costenbader, 2002; Trainor, 2005). Although little is known about the way in which peers help develop self-advocacy skills, disabled peers can help support by providing information on university disability services and role modeling advocacy development (Dowrick, Anderson, Heyer, \& Acosta, 2005)

A study conducted by Foley, Minick, and Kee (2002) examined how nurses learned to advocate for their patients' needs. The study found that individuals identified three key factors that helped them develop advocacy skills. Some participants stated its "who I am", another group of participants believed advocacy skills developed through observing other nurses' interactions with patients, and the final consideration was confidence building. In this study, confidence was gained by working with mentors who provided an environment for learning, growth, and support (Foley, Minick, \& Kee, 2002). This research helped provide literature on advocacy development and the importance of the advocacy skills being modeled and providing opportunities for individuals to put their skills into practice. It is important to note that some individuals did believe advocacy was just a part of "who I am", meaning they already had developed these skills. However, it is argued that specific skills in the nursing field such as caregiving practices do not come naturally, but are acquired through childhood from families and communities and are later reinforced in schools and environments of work (Benner, 1984).

Self-advocacy skills are directly correlated to the transition and retention of college students with disabilities and academic success (Adams \& Proctor, 2010; Getzel \& Thoma, 2008, Hadley, 2006; Murray, Lombardi, \& Kosty, 2014; Thoma \& Wehmeyer, 2005). Studies show that there are three major skills that promote success within higher 
education. This includes utilization of disability and tutoring services, finding a social support system on campus, and building connections with instructors (Adams \& Proctor, 2010; Getzel \& Thoma, 2008; Daly-Cano, Vaccaro, \& Newman, 2015). Administrators and professionals in the field of higher education can help students with disabilities by fostering further development in the areas of independence, self-determination, and selfadvocacy (Brinckerhoff, Shaw, \& McGuire, 1992; Hadley 2011).

It is important to note that some disabled students may have knowledge and language to communicate their academic needs in an academic environment but may struggle on experiences outside of the academic such as work (Madaus, 2008). The purpose of higher education is to help students develop and grow, to utilize learned skills and behaviors within society and environments outside of educational contexts. It is critical for all practitioners and administrators to begin learning how to support students with disabilities on college campuses and foster developmental skills necessary for success in the workplace, such as advocacy skills. This starts with identity development and self-awareness. It has been argued that the most common barrier disabled students encounter on college campuses are the lack of knowledge and collaboration amongst faculty and personnel (Greenbaum, Graham, \& Scales, 1995; Lehman, Davies, \& Laurin, 2000; Wilson, Getzel, \& Brown, 2000). Therefore, there is a need for faculty and staff to be better trained and provided resources on how to support students within their classrooms and the overall campus community (Rao, 2004).

Another way to explore self-advocacy behaviors or human agency is through resistance theory which "demonstrates how individuals negotiate and struggle with structures and create meanings of their own from these interactions" (Solorzzano \& 
Delgado Bernal, 2001, p. 315). Solorzano and Delgado Bernal (2001) suggest four different resistant behaviors which include reactionary, self-defeating, conformist, and transformation. Reactionary behaviors are viewed as lacking a critique of social oppression, and a lack of motivation by social justice (Solorzano \& Delgado Bernal, 2001). Self-defeating resistance is when a student has some oppressive social conditions but lacks the social justice motives. Conformist resistance is the desire to engage in social justice but relies on "Band-Aids" to fix symptoms to problems rather than recognizing the societal and structural systems of oppression related to the problem (Solorzano \& Delgado Bernal, 2001). The final behavior is known as transformational resistance. The can also be seen through the needs to "prove others wrong" which can be done through “(a) confront the negative portrayals and ideas about... (oppressed identity group) (b) are motivated by these negative images and ideas, and (c) are driven to navigate through the educational system for themselves and others" (Yosso, 2000, p. 109). By examining a students' response to the way in which they behave in situations that arise due to the education system and their disabled identity, transformational resistance can be an unique way and different perspective to consider when analyzing participant responses and the overall data.

Although there is no literature on college athletes and self-advocacy skill development, there is limited research on the college athlete experience regarding help seeking behaviors. College athletes are typically hesitant to seek help due to the stigmas or stereotypes that may be perpetuated by coaches, peers, and fans (Brewer, Van Raalte, Petipas, Bachman, \& Weinhold, 1998; Wrisberg \& Martin, 1994). Help-seeking behavior is defined as "an adaptive mode of coping with personal concerns or problems (Gulas, 
1974)" (Watson, 2005, p. 442). There are also large gender differences among helpseeking behaviors as men are less likely to seek help due to stigmatization (Addis \& Mahalik, 2003; Mahalik, Good, \& Englar-Carlson, 2003; Steinfeldt, Steinfeldt, England, \& Speight, 2009). Lund (2019) concluded that college athletes with ADHD were less likely to seek mental health support or help for a mental health concern, in comparison to their ADHD non-athlete peers. Reardon and Factor (2010) found similar results stating that college athletes experience barriers and stigma related to addressing mental health concerns. Teaching self-advocacy skills begins with changing the narrative and perception held by both society, collegiate communities and even those with disabilities.

Ridpath (2014) explains that athletic departments play an active role in encouraging college athletes to seek support and services related to their disability on their college campus. It is believed that college athletes with education impacting disabilities need education and guided opportunities to develop the knowledge and skills to explain their disability and navigate the process to implemented academic accommodations (Ridpath, 2014). Athletic trainers, coaches, and academic support staff all play active roles in help students learn about their intersecting identities and learn how to advocate for their needs.

\section{Academic Support Services}

Academic support programs provide services that help enhance learning and development outside of the classroom (Triano, Liefeld, \& Trachtenberg, 2010). These services are often targeted at undergraduate students (Kuo, Hagie, \& Miller, 2004). The number of programs and services provided to undergraduate students vary institution to institution due to organizational structures, resources, financial revenue, and mission and 
goals. For the purposes of this research, the two specific student support services being analyzed are athletic academic support services, and disability support services.

\section{Athletic Academic Support Services}

Participation in college athletics creates complex barriers to academic success, which require different support services compared to the rest of the student body. College athletes are often held to strict schedules and are expected to perform on and off the field or court (Simons, Van Rheenen, \& Covington, 1999; Rishe, 2003). Athletic academic support services are intended to assist college athletes through specific academic, socialemotional, and career services which promote academic success towards graduation (Thompson, Petronio, \& Braithwaite, 2012). There are two main purposes of college athlete support services which include engaging students in opportunities to further their development, and helping college athletes overcome barriers that are caused by their participation in athletics (Hollis, 2001; Mithaug, 1996). These barriers include legislation put in place by the NCAA that higher education athletic programs, personnel, and college athletes by which they must abide.

Part of the NCAA's mission is to ensure college athletes are obtaining wellrounded educational experiences and are working towards degree completion while engaging in athletic competitions, which in some athletic programs generates revenue (Satterfield, Croft, \& Godfrey, 2010). The NCAA began crafting academic regulations and measures in 1965 (Grandy, Lough, \& Miller, 2016). The first major academic initiative is known as Proposition 48, applied in 1983. Proposition 48 was introduced into the world of collegiate athletics due to low graduation rates amongst revenue producing sports such as football and men's basketball (Satterfield, Croft, \& Godfrey, 2010). The 
NCAA enforced eligibility requirements and placed emphasis on college athlete retention and graduation rates (Davis, 2006). The next major milestone for the NCAA relating to academic reform was introduced in 2004. The NCAA initiated academic progress reports known as APR which continued to aid in improving retention towards graduation (Satterfield, Croft, \& Godfrey, 2010). College athletes on athletic scholarship can earn a total of four points each academic year. The points are earned each semester by maintaining academic eligibility related to GPA and degree completion percentages (40/60/80 rule), as well as remaining enrolled at the institution or graduating (Scatterfield, Croft, \& Godfrey, 2010). APR is ultimately tied to an institutions athletic program, and each athletic coach, so if a student opts into the transfer portal throughout their academic career, they must meet a specific GPA requirement for an institution to maintain APR points. Failure to meet the required team score of 925, can lead to repercussions in decreased scholarship awards.

NCAA D1 institutions have enhanced their academic outreach and support services for college athletes to ensure that institutions and individual athletes are abiding by eligibility standards set forth by the NCAA (Ridpath, 2010). Many well-known athletic programs and institutions were criticized in the early 1980s for their lack of academic support, preparation, and graduate retention amongst college athletes (Benson, 1994). Furthermore, several athletic academic scandals were investigated and brought to the public's attention in the early 1980's which called for a pivotal shift in designing academic support services on college campuses (Hollis, 2001). These athletic support services were intended to improve the college athlete experience, helping college athletes persist towards graduation, and ethically maintain academic NCAA eligibility. 
The NCAA established bylaw 16.3.1.1 in 1991, which was revised in 2002, 2006, 2013, and 2014. This regulation states that institutions who are members of the NCAA must provide "general academic counseling and tutoring services to all student-athletes" (NCAA, 2019c, p. 237). The bylaw continues by stating that services can be provided by either the athletic department or an institutions nonathletic support service. In addition, this bylaw endorses other support services relating to academics, career counseling, and personal development. Providing services to help support college athletes has allowed for increases in the number of students who graduate with a degree. Today eight out of 10 college athletes will complete a bachelor's degree program earning a degree, and $35 \%$ of those students will further their education earning a postgraduate degree (NCAA, 2019a).

Trained professionals are essential to ensure college athletes' academic schedules and career planning process, eliminate athletic conflicts and abide by NCAA bylaws related to academic eligibility (Hollis, 2001). Additionally, graduation rates have been a hot topic in the literature in the past two decades. Gunn and Eddy (1989) stated that universities need to implement effective academic support services in order to help increase college athlete persistence and graduation rates due to the "role conflict" between athletic and academic demands (Hollis, 2001). In 1991, the NCAA mandated academic advising services to be implemented into collegiate institutions which included tutoring and life skills services (Abell, 2000; Carodin, Almond, \& Ratto, 2001; Meyer, 2005).

In 1975, the National Association of Academic and Student-Athlete Development Professionals (N4A), formally known as the National Association of Academic Advisors was formed. The purpose of this organization was to address the unique needs of college 
athletes' academic demands, but also personal concerns that had not been addressed in support services prior to 1975 (Harris, Altekruse, \& Engels, 2003). NCAA D1 academic support services have gone from tutoring, class scheduling and time management, to offering life-skills development, academic counseling and career assistance, which aids in helping college athletes plan for life beyond professional athletics (Shriberg \& Brodzinski, 1984; Harris, Altekruse, \& Engels, 2003). Today, college athletic support services consist of programs related to orientation, leadership and life skills development, career planning, academic advising, and academic support services (Scatterfield, Croft, \& Godfrey, 2010).

The NCAA requires athletic programs to review and teach college athletes specific rules and regulations which typically occurs during orientation. Other institutions have developed academic courses for credit to review required NCAA bylaws and specific issues concerning the college athlete experience (Scatterfield, Croft, \& Godfrey, 2010). Topics in these seminar courses include, "Title IX, gender equity, alcohol abuse, drug testing, tobacco use, role models, scholarship information, and other similar topics" (Satterfield, Croft, \& Godfrey, 2010, “Student Athlete Services”, para 4).

Academic support staff assist students through academic, social, and personal concerns by offering advice in a plethora of ways (Kuhn, 2008). Athletic academic advisors also offer a unique perspective as personnel often have trained expertise in NCAA regulations and an understanding of the demands and challenges faced by college athletes (Broughton \& Neyer, 2001; Huml, Hancock, \& Bergman, 2014). Athletic academic counselors help ensure college athletes are meeting NCAA eligibility which includes ensuring college athletes maintain full-time status, which is considered 12 credit 
hours per semester (Scatterfield, Croft, \& Godfrey, 2010). According to NCAA regulations, students who participate in collegiate athletics must be enrolled as a full-time student and if a course is dropped, placing the student under full-time status, the student loses their eligibility to participate in athletics (Meyer, 2005; Jolly, 2008). Therefore, students must meet with their college advisor and athletic counselor each semester before registering for courses to ensure college athletes are meeting the NCAA requirements (Carodine, Almond, \& Gratto, 2001).

College athletic academic support services are unique to each institution. Athletic academic support services can vary in organizational structure, funding, programs, or services offered, and personnel (Hollis, 2001). Athletic academic support personnel originally began utilizing unoccupied space wherever availability allowed on college campuses (Rubin \& Moses, 2017). However, a shift has occurred in which athletic academic centers are being built as standalone facilities to provide support to aid in college athletes' eligibility and compete with other rival institutions on amenities (Wolverton, 2008). It is important to note that some athletic academic support centers have been built into football stadiums, are located within the campus library, or exist within other campus structures (N4A, 2013). Support centers are defined as "any location where the college athletes are assigned to complete study hall/tutorial assignments" (N4A, 2013, p. 2)

A growing number of findings also indicate criticism of athletic academic support services. It is suggested that personnel are under too much pressure to maintain college athlete eligibility rather than having an educational attainment focus like the rest of the student body (Ridpath, 2010). One study concluded that college athletes perceive athletic 
advisors to be more concerned with eligibility requirements than with their overall academic success (Ridpath, 2010). In addition, the results of Huml, Hancock, and Bergman's (2014) survey further emphasized that college athletes perceived faculty and academic advisors to care more about their academic success compared to their athletic academic counselors. Criticism surrounding athletic academic support services includes isolation of college athletes from the general student body, low academic performance, and grouped major or career pathways, implying students are not truly provided the opportunity to academically succeed or explore their professional passions outside of athletics (Bowen \& Levin, 2003; Gayles, 2009; Schulman \& Bowen, 2001). Athletic academic support services bring about positive support to aid in persistence for a unique subpopulation on college campuses, yet some research indicates that the system is flawed.

\section{Learning Specialists}

In revenue-producing sports, many college athletes arrive in college underperforming academically and an increase in diagnosed learning disabilities has been reported (Eckes \& Ochoa, 2005; Ferris, Finster, \& McDonald, 2004; Levine, Etchison, \& Oppenheimer, 2014; Nwadike, Baker, Brackebusch, \& Hawkins, 2015). Students who are admitted to post-secondary institutions mainly for their athletic abilities are academically underprepared for collegiate academic expectations and will most likely struggle through the balancing act of athletics and academic demands (Harris, Altekruse, \& Engels, 2003). To support college athletes with diverse learning needs, athletic academic support services began implementing learning specialist positions to serve at-risk student populations within college athletics (Steinberg, Walther, Herbst, West, Zamagias, \& 
Smith, 2018). The term "at-risk" is used frequently in athletics to identify individuals who are on academic probation or in jeopardy of failing to meet NCAA requirements or academic expectations set forth by the university (Satterfield, Croft, \& Godfrey, 2010).

A newer term has recently surfaced within the literature which promotes a less stigmatized identity as the term "at risk", which is associated with a negative connotation or framework to viewing the potential of student failure. At-risk is a commonly used phrase within higher education and is associated with race, socioeconomic status, underperforming academic achievement, and triumphantly overcoming barriers, instead of considering student potential. The newer terminology being placed into practice is "atpromise" which is a paradigm shift that is more inclusive and has undertones of empowerment. Swadener (2010) explains the paradigm shift further.

In calling for an "at promise" view of all children and families... we would encourage everyone working with children and families to look for and build upon the promise in all children and to concentrate valuable energies and resources on building on these strengths while addressing the many structural and environmental factors that have been argued to place many children "at-risk" (p. 10). This terminology shift allows for personnel to have a shared philosophy in student promise, changing the discourse "from a discussion of 'them' or 'the other' to a discussion of 'us'" (Swadener \& Lubeck, 1995; Swadener \& Niles, 1991; Polakow, 1993). Professionals should adopt more inclusive language when discussing ways to support "at-promise" inclusive language.

Tutoring services can help students grasp academic content material. Building critical thinking and independent decision-making is crucial to help students learn and grow (Steinberg, et al., 2018). Although tutoring is helpful for all students, for those who 
are academically behind considered at-promise, conditionally admitted, or have a disability, further support is needed beyond content specific material (Gaston-Gayles, 2004; Steinberg, et al., 2018). Study skills and learning strategies can help strengthen a student's academic disadvantages in the classroom. The goal is to create an environment where students learn skills to feel self-confident to achieve their academic potential and decrease the potential risk of academic dishonesty or plagiarism (Steinberg, et al., 2018).

The increased need for learning specialists has substantially increased over the past two decades, as the enrollment of students with academic challenges continues to grow. For example, the number of learning specialists involved in the N4A grew approximately 70\% between 2012 and 2015 (Wolverton, 2016). Power 5 conferences employee the greatest number of learning specialists on staff, while other institutions outside of the Power 5 conferences lean towards dual-role positions, implying professionals act as academic counselors or career development specialists on top of the learning specialist's role, for budgetary purposes (Steinberg, et al., 2018).

The learning specialist position did not derive from athletic academic support services, although the origins of the position are untraceable (Bethel, Biffle, \& Scragg, 2012). College campuses have been implementing learning specialists in a variety of departments in higher education to support underprepared students before the profession bloomed in athletic support services (Bethel, Biffle, \& Scragg, 2012). However, with the rise of college athletes entering post-secondary education with educational gaps and learning challenges, the profession has rapidly grown since the late 2000's. It is important to note that learning specialists do not have a specific job description across the profession, yet the position is driven by a common goal of helping students achieve 
independence (Steinberg, Walther, Herbst, West, Zamagias, \& Smith, 2018; Weiss, 2011; Wolverton, 2016). A nationwide survey collected 53 responses from athletic academic learning specialists in 2012. Results concluded that more than half the participants were uncertain on the evaluation criteria of their professional position, and 60\% responded that some part of their job performance was directly linked to their student's grades (Bethel, Biffle, \& Scragg, 2012). Furthermore, Bethel, Biffle, and Scragg (2012), proposed nine professional standards that could be used directly in the evaluation of learning specialists in athletic academic support services. These standards include assessment, intervention, student evaluation, service coordination, organization, communication, student engagement, program evaluation, and professional development.

Weiss (2011) describes learning specialists as professionals who utilize techniques or strategies and understand how to best support college athletes with learning disabilities towards their academic success. Learning specialists also provide guidance for additional transition support and act as a liaison between the athletic department and disability services. Learning specialist personnel come from a variety of educational backgrounds. The positions main focus contributes to teaching and learning strategies, time management, and organization skills (Steinberg, Walther, Herbst, West, Zamagias, \& Smith, 2018; Weiss, 2011). Weiss (2011) recommends that learning specialists also provide individualized plans to help students with learning disabilities through transition from secondary to post-secondary education.

The NCAA published the Inter-Association Consensus Document: Mental Health Best Practices in January 2016 and was revised in May 2017. This document outlines recommendations for supporting mental health concerns and issues within intercollegiate 
athletics. In this document, the task force recommended collaboration amongst the athletic department and disability services (NCAA, 2016). Other considerations include utilizing disability support personnel to determine reasonable accommodations for students and consistent consultation to increase practices that are inclusive to all college athletes. These recommendations are guidelines in which learning specialist and academic support personnel should be incorporating into daily practice. Many learning specialists have the responsibility of creating partnerships with the department of disability services on their college campus, however it is the responsible of all athletic personnel to be informed and implement inclusive practices.

\section{Coaching and Athletic Staff}

Participating in sports can be both positive and negative (DeSensi, 2014).

Coaches play a vital role in the development of college athletes, athletically, academically, and holistically. Higher education institutions pay coaching staff six figure salaries, and place large amounts of funding into athletic programs which help develop college athletes' athletic abilities and instill values of competitiveness (Naylor, 2007). As students age, coaches' expectations surrounding competitiveness moves from development to the exception to win (Naylor, 2007).

Goulda (2016) suggest that there are five main attributes that make for a wellrounded coach. These effective qualities include coaching philosophies, openly share the process of decision-making process, build strong relationships with athletes, are effective, knowledgeable educators and foster development. Coaches should strive to build relationships that are grounded in support and care for athlete's emotional well-being (Fry, 2010). Supportive relationships between coach and athlete include taking the time 
to learn about an athlete as an individual, creating an environment where athletes feel welcomed and acknowledged, and creating a safe place and notion that bullying, or other negative actions that put down others are unacceptable and will not be tolerated (Fry, 2010).

Coaches have a commitment to more than just winning games, effective coaches should also care about the physical, mental, and social development of their athletes. Coaches have a large influence on the way they not only help develop their athletes on and off the field or court, but also the way they choose to engage in athletes lives outside of athletics, surrounding academics and personal well-being and overall moral and emotional development. Collegiate coaches at NCAA D1 institutions get paid large sums of money but are offered bonuses for athletic wins, and academic standards (i.e., meeting APR, GPA, or other academic goals) (Wilson, 2017). Coaches play an active role in the message's students receive on the importance of academics (Bell, 2009). With such a critical responsibility to help develop college athletes, it is essential for coaches to understand the responsibility they have and how their interactions are perceived by their athletes.

Division 1 athletes spend more than 20 hours a week engaging in athletic related activities, which includes spending a significant amount of time with athletic staff and coaches (Benford, 2007). Coaching staff and athletic personnel may be the first and only interactions a student has with a university throughout the recruitment and admissions process (Kamusoko \& Pemberton, 2013). The relationship between coach and athlete should be built on trust, respect, communication, understanding, cooperation, commitment, and a sense of care (Lafreniere, Vallerand, \& Carbonneau, 2011). The 
perception of a relationship between an athlete and their coach can lead to both positive and negative experiences (Barnhill, Czekanski, \& Turner, 2013; Pate, Stokowski, \& Hardin, 2011). A relationship a coach builds with their athletes can lead to either the construction or demolish in trust, respect, and perceptions of care when applied to an individual's holistic well-being. This same relationship is extended to other members of the athletic department personnel such as trainers and team physicians.

\section{Disability Services}

As previously mentioned, there are several differences between secondary and higher education for all enrolled students. One example is the amount of time spent receiving instruction. College instruction is typically 12 to 15 hours per week, whereas high school instruction is provided within 25 to 30 hours a week (McGuire, 1988). This requires students in transition to learn new skills, adjusting to a student-centered learning approach through reading and study time spent outside the classroom (Brinckerhoff, Shaw, \& McGuire, 1992). Higher education is geared towards students employing autonomous learning and effective study strategies, which are often not taught in the transition from high school to college (Brinckerhoff, Shaw, \& McGuire, 1992).

Students with disabilities experience further transitional concerns. If not addressed appropriately, some aspects can have lasting implications for the student. In K12 education, school districts are mandated to seek and support disabled students, however, this action of identifying students at the postsecondary level is not mandated and does not occur at most institutions (Barner-Brak, Lectenberger, \& Lan, 2010). Additionally, in secondary education responsibility of self-advocacy is the school districts and guardians, whereas almost all responsibility in higher education for issues 
surrounding disability accommodations and advocacy are placed onto the student in higher education (Brinckerhoff, Shaw, \& McGuire, 1992). There are also differences in laws as previously mentioned, the transition from IDEA utilized in K-12 to ADA implemented in higher education.

For students with disabilities, there is a lack of communication between secondary and post-secondary institutions throughout the transition even though there are vast differences between the environments and structural supports. For example, disability service support personnel conveyed a disappointment in the way in which high schools provided resources and information about the college experience and expectations (Janiga \& Costenbader, 2002).

During the high school years, as students with disabilities begin their transition plans, the IDEA federal law requires that students be an active participant in Individual Education Plan (IEP) meetings. However, approximately half of all students receiving special education services under IDEA attend their own IEP meetings (Mason, Field, \& Sawilowsky, 2004). When students are invited to attend their own IEP meetings, students only contribute vocally about $3 \%$ of the meeting (Martin, Van Dycke, Greene, Gardner, Christensen, \& Woods, 2006). Furthermore, students rarely have the ability to help create their IEPs (Reusen \& Bos, 1994; Cawthon, \& Cole, 2010).

Institutional administrators and disability service practitioners may underestimate the depth of a student's understanding throughout the high school to college transition (Cawthon \& Cole, 2010). To list just a few areas in which faculty and administrators feel disabled students are lacking within their educational transition include self-advocacy, knowledge of institutional differences such as class sizes, and examination methods, a 
student's strengths and weaknesses, independence, and lack of documentation (Cawthon \& Cole, 2010; Janiga \& Costenbader, 2002). Students with disabilities do not take full advantage of the services they should be receiving because they are unaware or choose not to seek out services or they seek services when it is too late (Barner-Brak, Lectenberger, \& Lan, 2010). There are several differences between the two educational experiences within K-12 and higher education, however, there is a lack of communication and adjustment support from both aspects of the transition.

Surprisingly, $40 \%$ of students who receive special education services in secondary education choose to self-identify in college (Newman, 2005). Students who struggle with their identity as an individual with a disability are found to be less likely to seek out disability support services compared to those who have accepted their identity (DaDeppo, 2009). Learning disabled students are ill prepared for life beyond high school, as copious amounts of students with disabilities are unable to self-advocate, and lack a basic understanding and ability to communicate their strengths and challenges (Cummings, Maddux, \& Casey, 2000). Having a working knowledge about an individual's disability and understanding of their academic needs is critical to ensure a successful transition (Cathone \& Cole, 2010). Being educated on the differences between accommodations and self-advocacy are critical conversations that are not occurring in many cases where disabled students choose to pursue a higher education degree (Milson \& Hartley, 2005).

The two federal laws that influence students with disabilities in higher education are ADA and the Rehabilitation Act of 1973 (Denbo, 2003). The ADA defines disability as "a physical or mental impairment that substantially limits one or more of the major life activities of such individual" who are disabled (ADA, 1990). Both laws mandate 
disability services provide "students with an equal opportunity to learn, it does not require that schools provide accommodations that would provide equal results with nondisabled peers (Brinckerhoff, Shaw, \& McGuire, 1992)" (Cawthon \& Cole, 2010, p. 115). Under these federal laws, institutions are required to provide appropriate accommodations to assist students with learning disabilities and ADHD towards their academic pursuits (Denbo, 2003).

Disability support services are intended to ensure institutions are following federal laws. First, is the protection from discrimination and the second is ensuring "reasonable accommodations" are being offered (Cory, 2011). Beyond determining student's eligibility for accommodations, another expectation of disability support services is to ensure faculty and staff are committed to providing these required accommodations within the campus community (Salzberg et al., 2002; Shaw \& Dukes, 2001). In addition, accommodations must be made unless it changes the program of study or is not financially feasible, causing financial hardship (Cawthon \& Cole, 2010). If an accommodation is deemed unreasonable, the institution is only required to provide the most basic accommodation to meet the student's needs (Brickhoff, Shaw, \& McGuire, 1992; Cawthon \& Cole, 2010).

Similar to athletic academic support services, support services and programs aimed at aiding disabled students vary from one institution to another (Mull, Sitlington, \& Alper, 2001; Getzel, McManus, \& Briel, 2005). The application process can vary, as there is no streamline process (Vickers, 2010). Some institutions choose to have one or multiple individuals in the disability service office who approves and denies documentation, whereas other higher education institutions choose to utilize multiple 
personnel through committees (Vickers, 2010). Disability service practitioners should work towards ensuring the accommodation process is not overwhelming or challenging to navigate for the student. It is suggested, "It is the role of the disability services personnel to seek, nurture, and preserve institutional commitment and support for ensuring that students with disabilities have equal access to educational opportunities available to all other students (Duffy \& Gugerty, 2005, pp. 89-90)

A study conducted at one university surveyed a group of students with learning disabilities. Out of 110 collected responses, $42 \%$ of students disclosed their learning impairment to the disability office, and $32 \%$ of students interacted with faculty members about their disability (Cawthorn \& Cole, 2010). These interactions are typically formal, where a student is providing their faculty member the accommodation request form, provided by the disability office. When it came to interacting with peers about their learning disability, similarly $32 \%$ choose to disclose. In addition, $21 \%$ of students indicated that they experienced some form of a barrier, challenge, or obstacle to obtaining their accommodations or services related to their learning impairment (Cawthorn \& Cole, 2010). A little less than half the participants in the survey also reported receiving no formalized assistance or information on who to contact in the office of disability services or how to apply for accommodations (Cawthorn \& Cole, 2010).

To receive accommodations, students must disclose their disability to an institutions disability service office by supplying appropriate documentation required by the institution (Shaw, Keenan, Madaus, \& Banerjee, 2010; Hadley, 2011). This process takes self-initiative to self-identify and self-advocate for individual success. This transition causes, "more passive dependent behavior to a more active and responsible 
role" (Hadley, 2011, p. 78) in connection with self-advocacy at the higher education level. Some students may resist the self-identifying process due to their prior experiences in primary and secondary education (Getzel, 2008). Research shows that some students may feel as though requiring accommodations may be considered as cheating (Denhart, 2008) or students dread the stigmatization associated with specific disabilities (Smart, 2001). The literature has outlined four major themes or potential barriers for requesting accommodations, which encompass the concepts of academic integrity, disability disclosure, disability acceptance, and the accommodations process (Barnard \& Lan, 2007; Barnard-Brak, Lectenberger, \& Lan, 2010).

Unfortunately, with an inability to communicate one's own strengths and weaknesses, many colleges have provided accommodations that are based on a specific impairment rather than an individualized plan that would be more effective and appropriate (Kurth \& Mellard, 2006). Disability support services have been criticized as they are more concerned with providing accommodations and meeting the immediate needs of the student rather than investing in long-term development (Mellard, Hall, \& Parker, 1999). Disability support services should spend more time empowering students with disabilities and educating others about disabilities (Kurth \& Mellard, 2006). Disability centers are offering "a menu of options based on their disability" (Cawthorn \& Cole, 2010, p. 122) rather than providing individualized accommodations similar to those required under IDEA (Brinckerhoff, Shaw, \& McGuire, 1992). The problem with accommodations is that they cater to specific disability rather than a students' "contextual and functional needs" (Kurth \& Mellard, 2006, p. 81). Accommodations should be 
adapted and formed around the individual student's unique educational, personal, and employment goals (Kurth \& Mellard, 2006).

Even if the most appropriate accommodations are crafted to meet students' individual needs, if implemented into a classroom inappropriately, students can find the execution to have negative impact (Kurth \& Mellard, 2006). For example, students shared that some accommodations, such as leaving the classroom to take their tests or exams in a separate location caused feelings of isolation (Kurth \& Mellard, 2006). Additionally, faculty members on college campuses also struggle with inadequate knowledge of disability law, comprehension of specific learning disabilities which hinders the ability to appropriately accommodate the students' academic needs, and have not established a collaborative partnership with the disability services at their institution (Murray, Flannery, \& Wren, 2008). It is important to note that faculty can provide accommodations for disabled students without an official academic accommodation letter from disability services, however it is not required by law (Barner-Brak, Lectenberger, \& Lan 2010).

It is argued that supporting students with disabilities is the responsibility of all staff, administrators, and faculty, rather than just one department on campus (Jones, 1996). Creating inclusive and accessible campus environments is the responsibility of all personnel employed by institutions (Huger, 2011). Students must work with several cross-campus resources and departments throughout their collegiate experience; therefore, all professionals should work towards creating a campus climate that is inclusive and collaborative. 


\section{Universal Design}

As higher education has focused on providing accommodations to students with disabilities since the formation of the ADA, the topic of disability has been ignored or briefly glimpsed over within the curriculum (Davis 2011). It is suggested that disability becomes a part of the academic curriculum in all disciplines when appropriate (Evans, Broido, Brown, \& Wilke, 2017). In addition, student affairs and higher education programs should focus more on preparing their graduate students on disability by offering courses to support this population and explore best practices (Evans, Broido, Brown, \& Wilke, 2017). Some graduate programs only spend one class discussing disability if they learn about the topic at all (Evans, Broido, Brown, \& Wilke, 2017). More research needs to be generated focusing on best practices and understanding the disabled student experience on college campuses (Evans, Broido, Brown, \& Wilke, 2017).

When it comes to knowledge about disability, research indicates that faculty believe they understand the concept of disability but stated they did not have a great wealth of knowledge on regulations and best practices (Baker, Boland \& Nowik, 2012). Pertaining to learning disabilities, faculty also believe that they have a basic understanding of the impairment but report having limited knowledge on how to provide support through accommodations related to exams and teaching (Murray, Wren, \& Keys, 2008) In order to support faculty members, workshops and courses prove to be effective strategies as well as interpedently or group reading books and articles which yield positive result (Murray, Wren, \& Keys, 2008). Another recommendation is to implement small group training programs, where individuals learn information and return to their department to facilitate trainings for all professionals (Murray, Wren, \& Keys, 2008). 
It is also important to challenge both faculty, staff, administrators and nondisabled peers' attitudes, beliefs, and assumptions surrounding disability (Evans, Broido, Brown, \& Wilke, 2017). Many schools have incorporated disability simulations to bring awareness and change student or peers' attitudes about disability. However, students who participate in simulations typically report feeling powerlessness, fear, and panic that most students with disabilities are resilient too (Evans, Broido, Brown, \& Wilke, 2017). Some better ways to address shifting non-disabled students' attitudes and beliefs would be student panels or watching a video about the lives of disabled people (Ostiguy, Peters, \& Shlasko, 2016).

Student affairs departments can collaborate with disability services on their campus to provide programs and services that are accessible, ensure professionals are educated and aware of the needs of the disabled student population, and feel comfortable using appropriate terminology (Evans, Broido, Brown, \& Wilke, 2017). It is recommended that departments utilize visual representations of people with disabilities in advertising and on published material, as well as practice inclusive hiring (Hugher, 2011). Disability centers also need to be staffed with well trained and equipped professionals and provided larger budgets (Evans, Broido, Brown, \& Wilke, 2017).

Faculty play a large role in the implementation of accessibility on college campuses within the classroom and learning environment. Universal design, "helps to ensure the provision of inclusive, flexible, and supportive learning environments for students with disabilities, as well as students from other diverse populations (Thompson, 2012)" (Evans, Broido, Brown, \& Wilke, 2017, p. 275). Universal design requires the environment to shift rather than placing the burden on an individual (Evans, Broido, 
Brown, \& Wilke, 2017). The positive aspect about universal design is that the modifications do not only benefit those with disabilities but all students on campus can benefit from the experience (Burgstahler, 2008).

Universal design can also apply to other areas outside of the curriculum design such as tutoring and learning centers, museum exhibits, and computer labs (Burgstahler, 2007). Universal design should be applied in four settings which include "services, information technology, physical spaces, and instruction" (Evans, Broido, Brown \& Wilke, 2017, p. 282; Burgstahler, 2007). For example, the athletic tutoring program can train tutors on how to create more inclusive "universal design" strategies when tutoring individuals or small groups. Learning specialists can also create more universal design strategies in their techniques when working with learning disabled students. This can be anything from providing accessible instructions to the physical set-up of the room.

In the classroom the Center for Applied Special Technology (2012a; 2012b), suggest using three main learning guideless which include providing multiple means engagement, representation, and action/expression. Universal design allows students to have autonomy within their own learning and provides unique experiences for all learners (Evans, Broido, Brown, \& Wilke, 2017). One example of universal design would be offering videotaped recordings of class lectures for students to review after class at their own leisure, as well as posting class notes and having peers share their notes or promote small groups for collaborative learning experiences (Shaw, 2011). These small adjustments to the curriculum not only support students with disabilities but can add benefits to the overall learning environment for all students. It is important to note that universal design helps elevate some of the most common accommodation requests, 
however it does not fix or support all potential modifications or accommodations that may be required for some students, depending on their specific impairment (Evans, Broido, Brown, \& Wilke, 2017).

Forming self-advocacy skills allows for student-athletes with learning disabilities to be change agents and speak up within their community (Council III \& Gardner III, 2018). In addition, it is suggested that disabled students be encouraged to take active leadership roles on their college campus (Evans, Broido, Brown, \& Wilke, 2017). Institutional leaders can also invite students with varying impairments into conversations and committee work surrounding construction projects effecting physical buildings, policies and procedures, as well as other organizational issues that may create disabling environment (Evans, Broido, Brown, \& Wilke, 2017).

\section{Conceptual Framework of Self-Advocacy}

The Conceptual Framework of Self-Advocacy was created by David Test, Catherine Fowler, Wendy Wood, Densie Brewer and Steven Eddy in 2005. All researchers worked at the University of North Carolina at Charlotte, and ranged from doctoral students, to faculty members in the Special Education department. The conceptual model was formed by conducting a thorough review of the literature from 1972 to 2003 on advocacy and input from 30 individuals invested in the topic ranging from teachers, parents, adults with disabilities, and researchers. The terms used during the literature review consisted of "advocacy, assertiveness, self-awareness, empowerment, disabilities, interventions, and teaching" (Test, et al., 2005, p. 44). The criteria for reviewing literature consisted of the publishing year (between 1972 and 2003), participants had a disability, and the data was intended to promote self-advocacy. The 
purpose of the literature review was to find research on self-advocacy through interventions.

The conceptual framework has four major categories which include knowledge of self, knowledge of rights, communication, and leadership (Test, et al., 2005). The foundation of the model begins with knowledge of self and knowledge of rights. Before an individual can communicate their needs with others, they must have an understanding and working knowledge of their own needs, strengths, challenges, and disability. The next layer of this model is considered the communication aspect. Individuals needs to have the skills and ability to talk with others through "negotiation, assertiveness, and problem solving" (Test, et al., 2005, p. 45). The fourth aspect to the conceptual model is leadership. This is where an individual can advocate beyond on their own personal needs and communicate for a collective group (Williams \& Shoultz, 1982). This form of advocacy can be done through organizations, gatherings, and political arenas (Test et al., 2005).

Knowledge of self requires an individual to learn about oneself and their "interests, preferences, strengths, needs, learning styles, and attributes of one's disability" (Test, et al., 2005, p. 50). Having self-awareness or allowing for self-exploration is an essential step towards developing self-advocacy skills. Beyond students with disabilities, college athletes with learning disabilities are navigating multiple identities which can be difficult to conceptualize. College athletes who have been participating in athletics since an early age have been praised for their physical abilities (Council III \& Gardner III, 2018). However, their cognitive and intellectual abilities are often ignored. From this conditioning, college athletes typically have a well-rounded perspective and working 
knowledge of their physical abilities related to their sport and athletic achievements but lack self-knowledge in other areas (Council III \& Gardner III, 2018).

Self-advocacy begins with being critically aware, which is tied to the second component which is knowledge of rights. This knowledge entails rights "as a citizen, as an individual with a disability, and as a student receiving services under federal law" (Test, et al., 2005, p. 50). For individuals with disabilities, legal knowledge may be associated with, but not limited to the ADA, IDEA, or Section 504 of the Rehabilitation Act. Learning about an individual's legal rights is critical in ensuring conscious decisionmaking. College athletes with learning disabilities may choose not to self-disclose their disability due to fear of losing their scholarship or negative impacts to their athletic commitment, such as loss of playing time (Council III \& Gardner III, 2018).

Furthermore, college athletes may also perceive their athletic academic support staff to be their advocates which creates a passive attitude (Council III \& Gardner III, 2018).

Communication is applying the foundational components of knowledge of self, and knowledge of rights, into communication which allows for an individual to promote self-advocacy by placing their learned knowledge into action (Test, et al., 2005).

Communication is defined as "effective and appropriate communication of feelings, needs, desires, and an ability to say no" (Test, et al., 2005, p. 50). Subcomponents include negotiation, persuasion, and compromise (Wehmeyer \& Lawrence, 1995) as well as assertiveness, body language and listening skills (Nezu, Nezu \& Arean, 1991; Van Reusen, Bos, Schumaker, \& Deshler, 1994). Beyond needing to communicate to faculty and the disability service office on campus, student- athletes are connected or involved with several other individual such as their coach, teammates, tutors, and academic 
support staff in which they navigate consistently (Council III \& Gardner III, 2018). For example, college athletes need to be able to communicate their academic needs to their coaches in order to receive an accommodation related to their athletic schedule, but many college athletes are unable to articulate or express their needs to others (Council III \& Gardner III, 2018).

Once an individual with a disability can communicate for themselves, they are able to not only model the behavior for others but take on leadership roles. Leadership in the self-advocacy framework is defined as "learning the roles and dynamics of a group and the skill to function in a group" (Test, et al., 2005, p.50). Forming self-advocacy skills allows for college athletes with learning disabilities to be change agents and speak up within their community (Council III \& Gardner III, 2018). One example may be college athletes with learning disabilities becoming accessible and mentoring other college athletes with similar needs (Council III \& Gardner III, 2018). Leadership roles within the self-advocacy framework and peer to peer interactions can allow for continuous cycles of self-advocacy among college athletes with disabilities (Council III \& Gardner III, 2018), which helps build a community and space in which speaking about advocacy and disability is acceptable.

Applying the conceptual framework for self-advocacy allows multiple ways in which the data can be conceptualized. Additionally, recommendations for practitioners are grounded through this model. Although the model is intended for individuals with disabilities, it can be used for the general college athlete population and college students as a collective. Learning how to self-advocate is a critical, often underdeveloped skill many college athletes with learning disabilities are unable to execute properly. With 
better education and focus on the development of self-advocacy students will learn to become more independent and can manage their own disability.

\section{Interactionist Model of Disability}

Disability is historically rooted in negative and stigmatized perspectives (Smart, 2009). In the 1960's and 1970's people in society began advocating and created the Disability Rights Movement, where individuals with disabilities became empowered and positive definitions of disability originated (Darling, 2013). Prior to this movement people with disabilities were isolated in different aspects, because of physical barriers and access to buildings, or lack of inclusion within schools (Darlings, 2013). Disability research lags far behind other minoritized groups in terms of other identity development theories (Mpofu \& Harley, 2006).

A disability can be deemed congenital, meaning an onset since birth, or acquired over an individual's lifespan. When examining research on identity development, some researchers have taken a grieving approach to disability which may not speak to the same experiences as someone whose disability was congenital instead of acquired (Lux, 2016). Individuals who were born with their disability also have no other experience to compare their circumstances. There is little research or literature focusing on identity development theories and disability (Evans, Broido, Brown, \& Wilke, 2017). However, there are several models in which are used as a lens to view disability within society. Each model also speaks to society and cultural norms and agenda surrounding disability when they were conceived (Evans, Broido, Brown, \& Wilke, 2017).

There are several well-known models of disability. Some of these models include the moral, medical, functional limitations, social, minority group, and the social justice 
model (Evans, Broido, Brown, \& Wilke, 2017). Furthermore, there are two critical theories which include circuital disability and critical realism (Evans, Broido, Brown, \& Wilke, 2017). One emerging model within disability studies, based in the field of higher education is known as the interactionist model of disability. This model was developed by Evans and Broido in 2011, grounded in two phenomenological studies conducted in higher education. The model is rooted in Lewin's (1936) interactionist model and concludes that, “...students' ability to function in an environment is an interaction of the environment, the person, and the person's impairment (Evans, Broido, Brown, \& Wilke, 2017, p. 77). The three elements (environment, person, and impairment) can affect the overall experience for a student or individual. The idea is that students can alter their experience by changing one of the three elements.

For student affairs professionals it is suggested that when taking an interactionist model approach, individuals must think through “...examine(ing) the degree to which specific aspects of the campus environment (are) disabling, the effectiveness of the individual student's choices, and the type of severity of the student's impairment, as well as, how these factors all intersect and contribute to the specific situation the student (is) experiencing" (Evans, Broido, Brown, \& Wilke, 2017, p. 78). The interactionist approach subscribes to the idea that disability is multifaceted. Where the medical model is rooted in the idea that the an individual has a disability, and the social justice model is developed on the belief that only the environment can be disabling, the interactionist model views disability as a combination of factors influencing an individual's overall experience within the world (Evans, Broido, Brown, \& Wilke, 2017). 
This model examines the interaction or the "student's ability to function in an environment" which is contingent upon the environment, impairment, and person (Evans, Broido, Brown, \& Wilke, 2017). The environment can range on a spectrum from "disabling to enabling" (p. 78), person ranges from an individual's "ineffective to effective" choices, and impairment ranges from "significant to minimal" (Evans, Broido, Brown, \& Wilke, 2017, p. 78). Each of these factors can vary based on the situation and experience at any given moment in time. What is unique about this approach to viewing disability is the understanding that disability is more than just a person, environment, or impairment, but encompasses all three factors into problem solving approaches. This indicates when trying to solve a disabling or problematic concern, practitioners can help address the issues and concerns from three different approaches and can role model this same perspective in problem-solving strategies for the students they work with.

\section{Literature Review Conclusion}

For a student to receive academic or physical accommodations in higher education a student must self-disclose and self-advocate for their needs. This process begins with developing self-knowledge and knowledge of an individual's rights. Figure 1 and Figure 2 below demonstrate how self-exploration, self-disclosure, self-advocacy, and academic support services are closely tied together as evident through the literature and conceptual model presented throughout this chapter. 

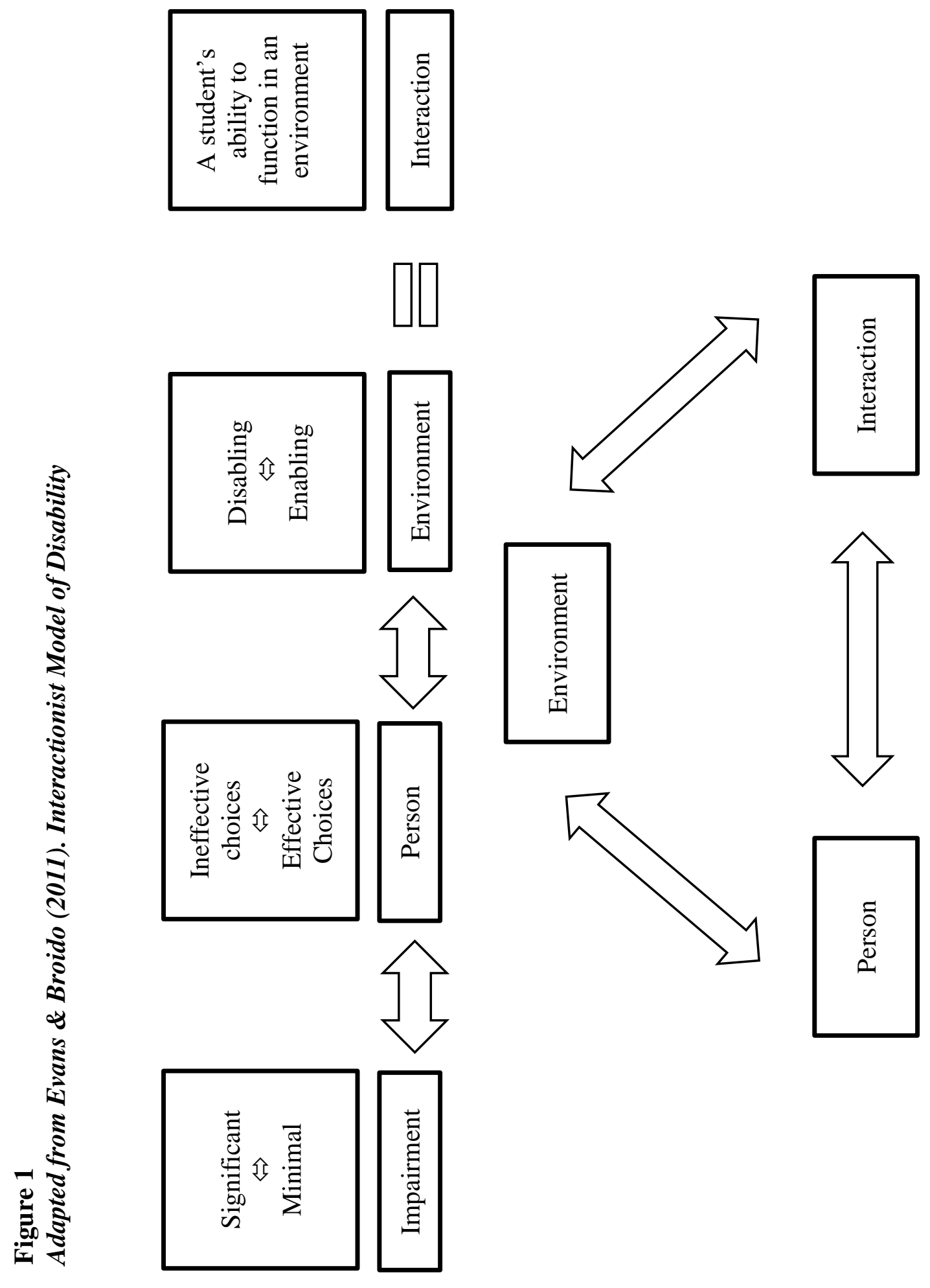


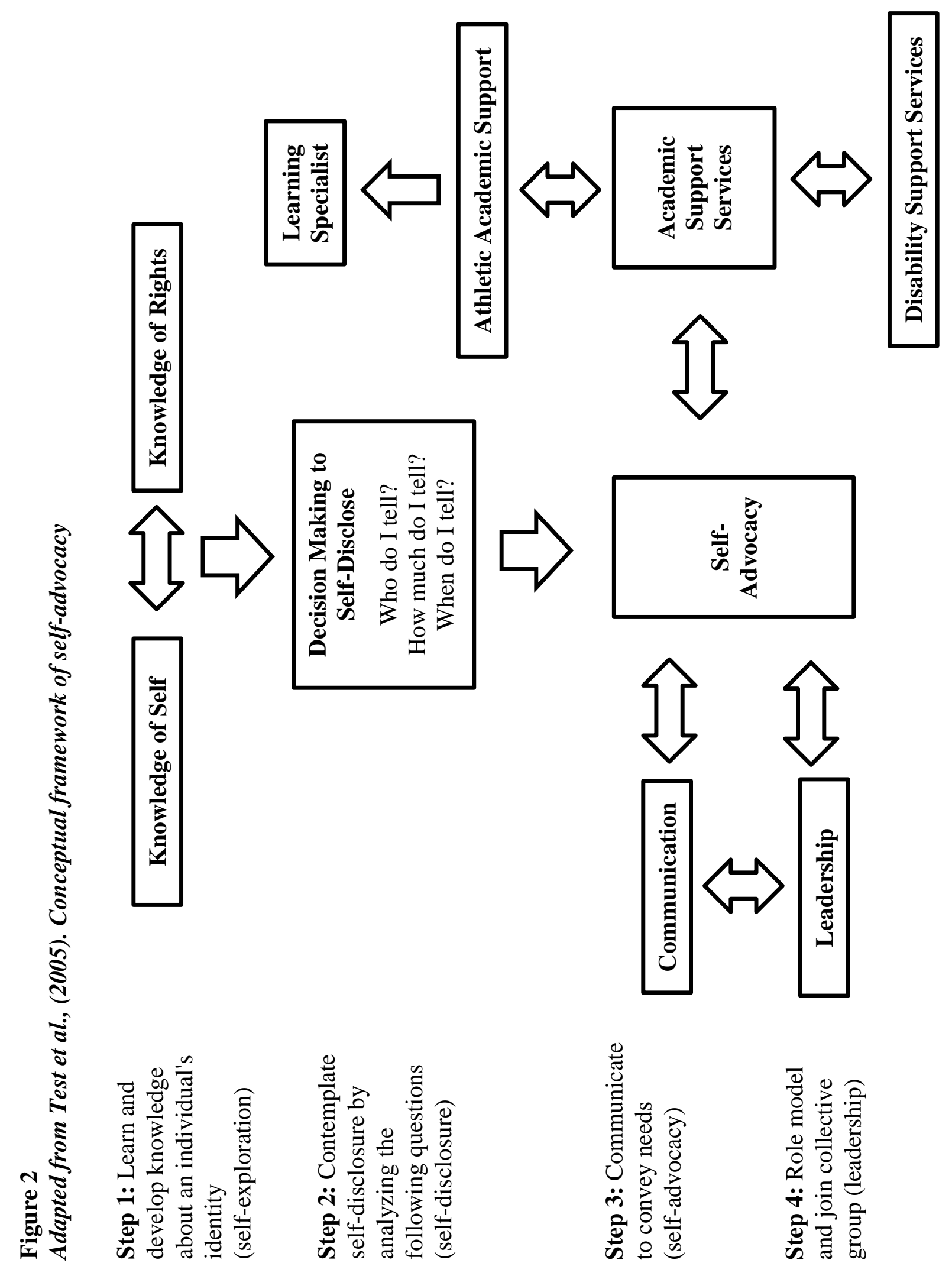




\section{CHAPTER 3}

\section{METHODOLOGY}

When looking at the term advocacy, one might find similar words such as approval, recommendation, supporting, promoting, and acceptance. Growing up I observed my mother take every action to ensure I was accepted in a sighted world, ensuring; I had the ability to succeed, working with advocacy organizations, educators, and health care providers. As I grew up as a disabled individual in this environment, the value of advocating was instilled quickly into my core, and was swiftly transitioned from parental, to student-focused action, when my mother would repeatedly state, "You need to speak up and say something, if you don't ask for it, people will assume you don't need it”. This message is still prominent today, as an adult I have learned to navigate selfadvocacy skills because I observed my mother flawlessly advocate as a fully sighted person, for a perspective she would never fully understand.

As an educator, I have experience in elementary education, school counseling and higher education settings. My professional statement visibly details my core values, which includes advocacy and inclusion for all students. As a professional I aim to live out my passion for helping others every day, and that includes helping students learn how to advocate. This is a necessary skill that I was fortunate enough to learn how to develop throughout my childhood, but not everyone is so fortunate. In some cultures, advocating is viewed as a weakness, or brings fear and shame. In high school I was privileged 
enough to work with a teacher of the vision impaired who guided me through research on my disability so I not only understood my diagnosed condition but could convey to other my needs. We also spent a semester learning about the difference between high school and college disability services. This educational experience, as well as TRIO support services offered to me throughout my undergraduate education equipped me to succeed within higher education as a first-generation student with a disability.

In between my undergraduate and graduate educational experience, I engaged in a year of service with City Year Boston. During this time, I worked with a group of 10th grade students receiving various special education services. I had the opportunity to work with students on improving their attendance, behavior, and coursework guiding this small cohort of students to advocate for their needs to get to the goal of graduating high school. As a society, we do not teach effective advocacy skills, or educate students on their own disability, and this is a crisis. Additionally, advocacy stems beyond those with disabilities, as a generation and society at large, we need to learn to advocate and speak up not only for what we need to succeed, but on behalf of others, in places where we are fortunate to have privilege. As an educated, white, woman, in her late 20's, I acknowledge I stand in privilege and I aim to dedicate my research towards creating perspective grounded in supporting minoritized groups.

As the literature explained, college athletes with learning disabilities may feel unsuccessful in academic environments. As someone who is blind, there have been times in my life that I felt inadequate or failed athletically. In middle school I vividly remember being removed from physical education to spend time volunteering in a self-contained K2 classroom. In high school when I tried out for our national state-champion cheerleading 
team, I was rejected because I could not perform as well as other students. However, I never gave up. The following season I went back to try-outs. This time I was asked to serve as a manager on the team. With my foot in the door, I still had a lot to prove. By the end of the season I was handed a uniform and was asked to fully participate.

When I got to college, I participated on the cheerleading team for all four years and made the 2012-2013 All-Academic Team. Although I have not directly participated in cheerleading, from a professional lens, I have incorporated my excitement for cheerleading with my passion for education. As I pursue a career in athletic academic support services, I hope to assist college athletes with learning disabilities and/or ADHD teaching advocacy development and persistence. I hope the research I conduct will inform my own practices as a practitioner and potentially others within higher education.

During my athletic leadership certification graduate program at Clemson University, I took a course called Psychology of Sports and Athletics. This course not only allowed me to apply my educational knowledge of students in different context but provided me opportunities to engage in the learning process through a diverse perspective, athletics. One of the first assignments was to choose a mental health disorder defined in the DSM-V and find articles related to an athletic perspective. As I began looking for scholarly articles on the topic, I realized there was a shortage of published knowledge on college athletes with learning disabilities and/or ADHD and their educational experiences and identity formation. This sparked my drive to learn know more and research more about the topic.

As I started the research process and found Stokowski's (2017) published article on college athletes with learning disabilities, I noticed something that sparked my passion 
even further. As previously mentioned, in Stokowski's (2017) study, she found that five out of nine participants on the football team did not have words to describe their disability. My immediate thought was that this is a crisis and wanted to understand the reasoning behind it. In addition, out of the nine participants seven who self-identify as African American, Black American, or Black either did not know their disability or had vague terms such as "learning disability" to define their disability (Stokowski, 2017).

I am left wondering how any person can self-advocate for their needs without having a basic understanding of their disability and how it impacts their life. No one seems to want to take responsibility for this crucial component to a student's development, and educational experience, yet it is an essential skill to form and critical for students to understand their own disability to navigate the world and communicate their needs with others. Therefore, I am not only interested in this topic but want to bring awareness to this silenced issue.

\section{Qualitative Research \& Approach}

Qualitative research is historically grounded in the social science discipline (Marshall, \& Rossman, 2006; Creswell \& Poth, 2017). Qualitative research allows for a problem to be explored from a group or individual perspective, which provides an indepth exploration of a complex question (Creswell \& Poth, 2017). Research conducted through qualitative measures requires dedication to collecting data, writing extensive detailed explanations, and time commitment to the process (Creswell \& Poth, 2017). There are three specific genres within qualitative methods which include individual lived experiences, society or cultural phenomenon, and language or communication (Marshall, 
\& Rossmann, 2006). This study will emphasize a focus towards individual lived experiences.

The purpose of qualitative inquiry is to provide an explanation and understanding of a specific experience (Stake, 1995). In addition, qualitative research encompasses a personal perspective and focuses on "knowledge construction" (p. 37, Stake, 1995). Qualitative research can be used to target specific populations in which statistical measures do not depict an accurate understanding or provide in-depth perspective of minoritized groups on college campuses (Friedensen, McCrae, \& Kimball, 2017). Furthermore, Taleb (2007) emphasizes that the quantitative normal curve neglects uncertainties and minoritized groups. Taking a qualitative approach to this research allows for a silenced student perspective to be incorporated into enhancing best practices grounded in research.

\section{Research Questions and Purpose}

The purpose of this phenomenological study is to understand the lived experiences of college athletes who identify as having a learning disability or ADHD at NCAA D1 institutions within the ACC, SEC, BIG 10, BIG 12, and PAC-12. This phenomenological inquiry will examine academic support, disability disclosure, and selfadvocacy within the college environment. In-depth interviewing will be used to collect data to answer the following research questions. The central question and three research questions are outlined below.

Central Question: What are the lived experiences of college athletes with learning disabilities and/or ADHD surrounding academic support, disability disclosure, and advocacy at NCAA D1 institutions? 
RQ1: What does the process of disability disclosure look like for college athletes with learning disabilities and/or ADHD?

RQ2: How do college athletes with learning disabilities and/or ADHD advocate for their academic success?

RQ3: In what ways do college athletes with learning disabilities and/or ADHD describe academic support within their campus community?

This chapter outlines the research procedure and holistic design. This chapter seeks to connect scholarly literature on qualitative research and phenomenological inquiry with the purpose of this study. This chapter outlines philosophical assumptions and the interpretive frameworks, followed by an in-depth explanation of the research design. Research about semi-structured interviews is provided with the research procedure, participant eligibility and sample recruitment strategies. Data analysis will explore the coding cycle, specifically InVivo and emotions and values coding mechanisms. The final section explains literature and connection to evaluation and validation of qualitative research and concludes with a statement about generalizability.

\section{Qualitative Approaches and Designs}

There are five well known qualitative approaches or designs within the socialbehavioral sciences. These inquiries include narrative, phenomenology, ethnographic, grounded theory, and case study (Creswell \& Poth, 2017). This emergent research is designed to examine the central phenomenon of college athletes with learning disabilities and/or ADHD within public doctoral granting NCAA D1 institutions. Phenomenology stems from philosophy, psychology, and educational disciplines. Creswell and Poth 
(2017) explain a "Phenomenological study describes the common meaning for several individuals of their lived experiences of a concept for a phenomenon" (p. 75). The purpose of phenomenology is to look for commonalities between the participants experiences. Since there is limited literature on this specific population, it is essential to examine the lived experiences relating back to the integration of academic support, disability disclosure, and self-advocacy skills on college campuses.

It is suggested that phenomenology be used to understand common experiences as it lends itself to aiding in the creation of best practices and policies which is the intention of this research. (Creswell \& Poth, 2017). Many phenomenological designs utilize interviews to gather information and firsthand accounts of the central phenomenon from participants who have experienced the phenomenon (Creswell \& Poth, 2017). Once interviews are complete, themes are generated and displayed through data analysis. Analysis includes descriptive and interpretive information (Creswell \& Poth, 2017). A written statement known as the "essential invariant structure" or "essence" is composed (Creswell \& Poth, 2017, p. 80). This is a description of common experiences shared amongst the participants which is followed by an interpretation of the description. An important criterion of qualitative inquiry is examining the researcher's beliefs and potential bias.

\section{Interpretive Framework \& Philosophical Assumptions}

An essential aspect to qualitative research is examining a researcher's philosophical assumptions and interpretive framework. Philosophical assumptions are the beliefs a researcher brings into their research study (Creswell \& Poth, 2017). A researcher's philosophical assumptions guide the interpretive framework, or theories that 
a researcher chooses to focus on throughout the study. Setting philosophical assumptions can help provide direction for the purpose or outcomes and provides a deeper understanding of the researcher's decision-making process (Huff, 2009). The four philosophical assumptions are known as ontological, epistemological, axiological, and methodological (Creswell \& Poth, 2017). These philosophical assumptions are addressed through interpretive frameworks.

There are two specific interpretive frameworks used throughout this research, social constructivism, and critical theory paradigms, more specifically critical disability, and critical race theory. Social constructivism focuses on seeking understanding of interactions from the contexts of an individual's life or work (Creswell \& Poth, 2017). When focusing on social constructivism, the nature of reality implies that multiple realities are constructed through experiences and interactions (Creswell \& Poth, 2017). I personally believe our opinions and world views vary based on our experiences which differ from one person to another as we have not lived through life with the same lens or perspective. My epistemological belief is that research is created and shaped by the participant's experiences. Axiological beliefs stem from individual values which should be honored throughout the research process (Creswell \& Poth, 2017). Finally, the best way to process and present the research when examining data through a social constructivism interpretive framework includes analyzing interviews and text analysis.

It is important to also acknowledge an intertwining worldview of critical disability and race theory. Critical theories focus on providing individuals the support to surpass the limits placed on them by specific oppressed identities such as race and/or disability (Creswell \& Poth, 2017). Critical theory is defined as "an attempt to understand 
the oppressive aspects of society in order to generate societal and individual transformation" (Tierney, 1993, p. 4). Disability theory attempts to bring attention to the issues around inclusion (Creswell \& Poth, 2017). Critical race theory is based on "studying and transforming the relationship between race, racism, and power" (Delgado $\&$ Stefancic, 2012, p.3). Critical race and disability theories offer philosophical assumptions that must be considered.

Disability studies began growing attention in the 1970's (Meekosha \& Shuttleworth, 2009). The focus of disability studies in academia are examining "meaning, knowledge, and consequence of disabilities as a social construction" (Pena, Stapleton, \& Schaffer, 2016, p. 88). Disability critical theory strives to eliminate oppression and works towards emancipating and empowering individuals with disables (Pena, Stapleton, \& Schaffer, 2016). However, a critique of critical disability theory is the one-sided perspective and ignores intersectionality or intersection of social identities. Disability is often neglected compared to other identities within research (Henry, Fuerth, \& Figliozzi, 2010; Thompson, 2013). As Pena, Stapleton, and Schaffer (2016) suggest, "when it comes to disability, there is a tendency to isolate the identity and oppression, and not fully problematize or understand the complexities of an intersectional lived experience" (p. 90).

Professionals and researchers who are grounded in social justice must adopt a culturally sensitive perspective to communicate with students, connect them with resources, or advocate on their behalf (Pena, Stapleton, \& Schaffer, 2016). It is argued that students are entering collegiate environments with "factors influencing overrepresentation of culturally and linguistically diverse students (in special education 
classes) are socially constructed at the complex intersection of race/ethnicity, gender, and socioeconomic status" (Banks \& Hughs, 2013, p. 369).Yet little research has taken a stance to incorporate an approach to understand intersectionality. However, disability is unique as there are several dynamic variables.

The single most demanding aspect of disability as a variable (when looking at intersectionality) is that disability is qualitatively more complex than race, class, gender, and sexual orientation... the intracategorical variations of disability offers even more difficulty in accounting for the interaction effects with other variables within the matrix of oppression (Sommo \& Chaskes, pp. 52-53).

The complexity of disability adds an additional layer understand the impact of intersectionality. It is recommended that practitioners reflect and consider their own identity before attempting to understand the complexity of another individuals (HowardHamilton, Cuyjet, \& Cooper, 2011). All forms of oppression work to reinforce each other (Pearson, 2010). In order to move towards intersectionality, we must adopt a social justice perspective and place it into practice, act on inequity, and work towards ensuring students with disabilities are understood and respected (Pena, Stapleton, \& Schaffer, 2016).

Therefore, ignoring race and other socially constructed identities would do a disservice to the participants and social justice perspective. This is where critical race theory is introduced. As previously mentioned, the majority of NCAA D1 football and men's basketball rosters are Black men (Harper, 2016). As Wolverton (2016) estimated that 1 in 5 or even $40 \%$ of the football team on scholarship at some NCAA D1 institutions have diagnosed learning disabilities, to ignore critical race theory would continue to perpetuate critical disability theory as separate ignoring the effects of intersectionality. 
There are five main tenants of critical race theory, but for the purposes of this research there are two specific tenants that will be explored further. The first tenant is the challenge to dominant ideology. This tenant challenges deficit frameworks used to perpetuate educational inequalities. Deficit language are used to "camouflage for the selfinterest, power, and privilege of dominant groups in U.S. society (Calmore, 1992)" (Solorzano \& Delgado Bernal, 2001, p. 313). The second tenant is the commitment to social justice. This research can empower individuals and will advocate for institutional change. Higher education institutions "operate in contradictory ways with their potential to oppress and marginalize coexisting with their potential to emancipate and empower (Solorzano \& Delgado Bernal, 2001, p. 313). When appropriate, both tenants will be applied through the analysis and reflected in the findings.

From a critical theories' perspective, ontology is based on social, political, and culture realities. This is grounded in the understanding some identities have power and privilege based in their identities, whereas others are oppressed based on their race, ethnicity, class, or ability (Creswell \& Poth, 2017). Epistemological beliefs are known through the study and understanding of social, political, and cultural structures. Axiological beliefs are rooted in diversity of values within various identity communities (Creswell \& Poth, 2017). Methodological approach finds assumptions through documenting power and identity struggles while calling action for change (Creswell \& Poth, 2017). In order to change policies and procedures that benefit minoritized groups, it is critical that research challenges current structures set in place that benefit the majority. In addition, research should help provide a deeper understanding on how to better support individuals or groups who do not hold privileged identities. 
Throughout this research both social constructivism and critical race and disability theories will be used to help make connections. Social constructivism is used as a framework to interpret the world in which the participants live with an understanding that our realities and perspectives are based on our lived experiences. Each person has a different perspective on their own experiences and reality. Critical race addresses inequalities while critical disability theories focus on addressing inclusion (Creswell \& Poth, 2017). Disability will play a large role in this research study as the central population is college athletes with learning disabilities and/or ADHD. Although race is not a criterion within the recruitment sample, I expect it to have a significant impact in the way the data are analyzed by interpreting data with a social justice and challenge of dominate ideology. Based on previous research, although race was not mentioned, the demographic data presented revealed the majority of racially minorized football college athletes with learning disabilities and/or ADHD at an NCAA D1 institution did not know their diagnosed disability (Stokowski, 2017). If similar findings are to be analyzed within this study, it is imperative that it be acknowledged and examined through a critical race interpretive framework.

\section{Research Design}

This research design can best be described as advocational phenomenology. This can be explained further as the traditional phenomenological approach was underlined and driven with a passion for advocacy throughout the research process. This approach is evident in the way in which the philosophical framework and interpretive assumptions on disability helped inform adjustments made throughout the research process. An example of this would be centering participants' voices when designing the research study. Each 
individual's personal voice must be highlighted and honored to create a deeper understanding and provide personal perspective of the importance of advocacy within disability studies and research. Therefore, this study continuously used a qualitative phenomenological approach with additional components introduced to emphasize and consider an advocational perspective.

Since phenomenological studies examine a shared phenomenon, typically interviews are used as a central aspect for data collection, however other forms of data can be gathered (Creswell \& Poth, 2017). This study analyzed data through 90-minute one-on-one semi-structured interviews. In addition, a demographic data sheet asking students questions surrounding their personal identities and beliefs surrounding advocacy skills. This demographic sheet along with the preamble was emailed prior to the 90minute interview to allow participants time to review the materials without feeling pressure constraints. The researcher conducted interviews through video calls using FaceTime, but other accommodations were offered based on the participant's access to technology. With the participants' consent, interviews were audio recorded and transcribed using otter.ai and a second examination of the transcripts was conducted by the researcher.

Interviews are viewed as one of the most powerful data collection strategies to provide a greater understanding to the lived experiences of individuals (Fontana \& Frey, 2000). Interviews can vary in length and formality. For example, some interviews are structured, and controlled others are considered unstructured and fluid (Russell, Gregory, Ploeg, DiCenso, \& Guyatt, 2005). Interviews lend themselves to allowing participants to share more intimate and detailed accounts and discuss sensitive topics with researchers, 
compared to the use of focus groups (DeJong \& Schellens, 1998; Kaplowitz, 2000; Kaplowitz, 2001).

Semi-structured interviews are defined as, "a dynamic exchange of ideas based on researchers' open ended-questions or areas of interest with probes that are designed to elicit details and explanations" (Trainor \& Graumann, 2012, p. 126; Roulston, 2010). In addition, questions may be rearranged or may change based on the response each participant provides, varying each interview (Kvale, 1996). When deciding an instrument for data collection it is important to think about the purpose of the study and if the data collection design can be justified (Trainor \& Graumann, 2012). In addition, to protect the integrity of qualitative research it is important to choose participants to engage in interviews who have a connection to the experienced phenomenon (Richards, \& Morse, 2013b).

Semi-structured interviews are beneficial as they provide the opportunity to probe for further information and follow-up individuals' responses (Adams, 2015). Guiding questions are referred to as an interview guide or interview protocol like an agenda outline. Questions should be tiered from most important to least important. Keeping track of time is essential when implementing a semi-structured interview approach to ensure all important questions are answered within the timeframe provided (Adams, 2015).

Active listening is an imperative skill to activate when performing semi-structured interviews. One specific technique that can be demonstrated to emphasize active listening is repeating back to the participant a one or two sentence summary using their own words. This tactic has two outcomes. First it helps builds rapport and a comfortable exchange by showing the participant that the researcher is truly interested in hearing 
about the participants' experience. The second benefit of this tactic ensures the researcher is interpreting the information provided by the participant accurately (Adams, 2015).

Creation of a semi-structured interview protocol is established in five phases (Kallio, Pietila, Johnson, \& Kangasniemi, 2016. The first phase is identifying the reasoning behind implementing the instrument. The second is reflecting on previous knowledge. The third phase is constructing the interview protocol. The fourth phase includes a pilot interview, which tests the interview protocol for flow and ease. The final phase is finalizing the interview protocol. The interview protocol that was used for this research study can be found in Appendix A.

It is important to address that "deficit paradigms prohibit us from seeing students with disabilities as fully equal" (Vaccaro, Kimball, \& Wells, 2015, p. 27). It is recommended that researchers examine relevant questions that focus on the entirety of campus operations (Vaccaro, Kimball, \& Wells, 2015). When crafting the individual questions listed on the interview protocol, I wanted to ensure that questions were not leading, and offered students the ability to direct the conversation in whichever direction they saw fit.

In this study, the 90-minute interviews were spent in the following manner. First, the preamble was reviewed verbally via video chat, questions were answered, if any arose during this time, before the participants provided verbal consent. Before delving into the interview protocol, I provided each participant a brief history on why I am interested in this topic and share some of my own experiences of having a disability and participating in intercollegiate athletics. This method helped build rapport and comfort throughout the interview. Rapport continued to be established by asking relevant but non-sensitive 
questions relating back to the demographic sheet (Adams, 2015). Recommendations suggest asking questions about the positive before approaching the negative aspects when collecting data in semi-structured interviews (Adams, 2015). To end the interview, I asked if the participant had any final thoughts or would like to share anything related to the topics discussed throughout the interview that they may have not had the opportunity to share. Interviews appeared natural and professional.

\section{Procedure}

Since March 2019 contact had been made with several learning specialists within NCAA D1 institutions to gather further information on recruitment strategies and networking opportunities to conduct this study. To determine which learning specialists were contacted, a list of all NCAA D1 Power 5 conference schools was collected. All private school institutions were originally removed, as I wanted to focus on four-year, public, doctoral granting institutions. From that list, two or three institutions were chosen based on location of the institution and emails were sent directly to learning specialists at each of the selected institutions asking questions about recruitment strategies. Throughout this process I documented which schools were willing to assist with recruitment efforts and which were non-responsive. In addition, I attended the National Association of Academic and Student-Athlete Development Professionals (N4A) convention June 6 through June 8, 2019 in Orlando, Florida where I had the opportunity to network with professionals invested in enhancing research in the field and working with college athletes who have specific learning concerns. From these several engagements in person and electronically a list of 12 learning specialists from 12 
different NCAA D1 institutions were selected to receive initial contact for recruitment purposes.

Therefore, purposeful sampling was utilized through initial contact of learning specialists at 12 identified NCAA D1 institutions to obtain and recruit participants within Power 5 institutions (ACC, SEC, BIG 10, BIG 12 and PAC-12). Purposeful sampling is used to recruit participants with specific criteria from characteristics or experience with the central phenomenon (Etikan, Musa, \& Alkassim, 2016). The researcher has a lot of control over this process, “...the researcher decides what needs to be known and sets out to find people who can and are willing to provide the information by virtue of knowledge and experience" (Etikan, Musa, \& Alkassim, 2016, p. 2; Bernard, 2002). Since the specific population in this study is difficult to recruit, as many athletic departments are protective of their college athletes, purposeful sampling is the best strategic recruitment method.

In November 2019, with the approval of the Institutional Review Board (IRB) at the University of Louisville, recruitment emails and flyers were sent to the 12 identified learning specialists to disseminate to college athletes with learning disabilities and/or ADHD. Since it is against The Family Educational Rights and Privacy Act of 1974 (FERPA) to disclose which specific college athletes have a disability, the learning specialist aids as a buffer or gatekeeper of this information having direct access to specific college athletes who meet the qualifications of the study, but not disclosing this information specifically to the researcher. Once emails and flyers were sent to the learning specialist, it is on the learning specialist to post the information and the college athlete to opt into the study voluntarily, by emailing the researcher expressing their 
interest in the study. Students who volunteered to participate were provided the option to receive a one-time $\$ 20.00$ incentive for their time, which falls in compliance with the NCAA D1 Bylaw 16.11.1.6.2.

\section{Recruitment Timeline}

The recruitment process was a strenuous aspect to this research study. After the first wave of emails were sent to the 12 originally identified support personnel, some of the professional athletic academic support staff did not respond to the recruitment email, and others stated they needed further approval from their institutions IRB, compliance, or director, but never provided additional information on the request. A select few professionals stated they would be willing to post the recruitment flier in their office space, but no participants came forward from those specific institutions. One institution in the ACC was willing to assist by placing the flier around their department and within their office space. Learning specialists took the time to encourage and recommend the study to specific students who showed more interest in discussing their disability while in college. Two students came forward, but one withdrew their interest. The other interview took place during the first week of January 2020.

In the middle of January, a follow up email was forwarded to the 12 professionals originally contacted asking for their assistance now that a new semester was underway. Some personnel stated they would be willing to assist and others were still unresponsive, but no participants came forward from this method. Throughout February, individual learning specialists from the SEC, BIG 10, BIG 12 and PAC 12 were contacted via email with recruitment materials and information about the research with little to no engagement. With a lack of response, the decision was made to widen the scope of the 
research to include all NCAA Division 1 Football Bowl Subdivision (FBS) conferences (SEC, Big Ten, Big 12, Pac-12, ACC, AAC, MW, C-USA, Sun Belt, and MAC). In the middle of March 2020, a recruitment email was sent through the N4A professional organization listserv where two students were informed of the research study and reached out for further information. One student opted into participate, and another student never responded to three follow up emails. In addition, two students showed interest and were recruited through the researchers' professional relationship and connections within the college athlete population. One interview took place in December 2019 and another in May 2020.

In May of 2020 about 20 different disability support centers on college campuses were contacted asking for recruitment assistance. Again, very few departments responded. One director stated the study needed to be approved through their institutions IRB. One institution in the SEC was willing to send emails to 31 of their registered athletes with disability services, but no participants came forward or showed interest. In June 2020, all disability support centers whose institution were registered as an NCAA DI FBS school received a recruitment email. Two schools responded and were eager to assist by sending emails to students through their department's listserv. One department sent 13 emails to registered college athletes with disabilities and one student opted into participating, the interview took place at the beginning of June 2020. In addition, all five participants were contacted to ask for their assistance through snowballing recruitment, however this approach did not create any new interest. At the end of July, one student had emailed the researcher with interest in participating, but never responded for follow-up 
after two emails and a text message were sent. At that point in time, it was decided to end the recruitment at five students and continue onto the process of data analysis.

\section{Participants Process}

To determine eligibility for this study, the student had to be a current collegiate athlete. To be considered a current college athlete, the student must be listed on the current academic year team roster or be receiving services from their institutions athletic academic support center. As far as inclusivity relating to disability, the medical model of disability would require students to submit documentation proving they have a documented impairment. Since this research is invested in taking a social justice perspective, students will need to self-identify themselves as an individual with a disability. Within our society, if someone walked into a room with a visible impairment which could be seen by an assistive device or physical appearance, the legitimacy of the disability would not be questioned. However, invisible disabilities are often questioned and forced to be proven by documentation the student must provide to administration at the collegiate level. Subscribing to the social justice approach, I believe students who opt-in to participate in this study should not have to justify their identity through physical proof or documentation, therefore no documentation was collected.

When determining how many participants should be included in a phenomenological study, there are mixed perspectives. One scholar suggests phenomenological studies can range widely from 3 to 4 participants, to 10 to 15 (Creswell \& Poth, 2017). However, Polkinghorne (1989) suggests between 5 and 25 participants. This study originally aimed to recruit six to eight participants, but ultimately ended at five. The objective was to recruit at least one student from each of the NCAA 
D1 Power 5 conferences, this approach was also limiting, and to allow more student voices to be heard, the researcher decided to reconsider the restrictive measures. Providing college athlete perspectives from different institutions and different athletic programs helps provide a broader representation of the phenomenon. It also helps in identification of student information, as I can classify the college athlete by athletic conference rather than institution affiliation.

\section{Data Analysis}

After all audio-recorded interview were complete, the audio files were immediately sent to a transcription service (otter.ai) to be transcribed. I double checked all transcripts to the original audio file to ensure accuracy and no computer or human errors were made on behalf of the transcription service. Since the interview process is spread over four to five months of data collection, I waiting to code each interview transcript and placed the data into a matrix to help make sense of the data analysis.

The word code is used often in qualitative research; however, the word can have diverse meaning depending on the researcher and context (Richards, \& Morse, 2013a). For this purpose of this research, a code is defined as "getting from unstructured and messy data to ideas about what is going on in the data" (Richards \& Morse, 2013a, p. 149). When deciding what gets coded, Richards and Morse (2013a) suggest, "If it moves, code it" (p. 162). To determine what coding techniques to use in application, will depend on the qualitative approach, design, and methods of data collection (Saldaña, 2015).

To analyze qualitative research, it is essential that the data is processed through a coding cycle. A coding cycle is made of several different stages but for the purposes of this study, analysis will be examined through multiple first cycle methods which is 
considered "direct" (p. 69) and second cycle method is considered "challenging" (p. 69) as it entails more complex conceptualization (Saldaña, 2015). To ensure a central phenomenon is being depicted accurately it is suggested that two or more first cycle codes be applied to the data to capture the essence (Saldaña, 2015). First cycle coding utilized in vivo coding along with emotions or values coding. As suggested by Saldaña (2015), the research question(s) and epistemology help guide the researcher to determine which codes are more appropriate. Coding cycle one will apply in vivo coding, values and emotions coding which will then be placed into a matrix display. After round one cycling, cycle two used pattern coding which is described further in the text below.

In vivo coding was the first type of coding method used as soon as the interview transcripts were ready for analysis. In vivo coding falls under the category of elemental methods, which is focused on laying the foundation for future code cycling (Saldaña, 2015). In vivo coding uses the direct "terms used by \{participants\} themselves" (Strauss, 1987, p. 33). It is critical to allow my participants voices to lead the research and language used since my participants as explained previous, are considered an institutional minoritized group (Friedensen, McCrae, \& Kimball, 2017; Saldaña, 2015). In addition, in vivo coding provides a guarded approach for beginner researchers, but restriction can be harmful as it may prevent further analysis through conceptualization (Saldaña, 2015).

After in vivo coding was completed, emotions and values coding were applied to each individual interview transcript. The use of affective coding methods allows for the researcher to examine specific experiences (Saldaña, 2015). Since this study is examining human interactions, beliefs, and perspective, employing an effective coding method allowed for deeper depth and breadth of the experience. Emotions coding allowed the 
researcher to code using the emotions or feelings charred throughout the interview (Saldaña, 2015). Whereas values coding examines the data for an individual, "integrated value, attitude, and belief system" (Saldaña, 2015, p. 124).

It is argued that emotions coding is most appropriate when examining "explore(d) intrapersonal and interpersonal participant's experiences and actions, especially in matters of social relationships, reasoning, decision-making, judgement, and risk-taking" (Saldaña, 2015, p. 125). Since this study is examining the participants experiences surrounding decision-making of disability disclosure and self-advocacy which implies risk-taking, emotions coding was considered an additional benefit to the coding process. Values coding also provides a deeper understanding of each participant's worldview, beliefs, and values as it relates to their experience (Saldaña, 2015).

Upon completion of first cycling coding of each transcript, the data was entered into a matrix. A matrix can be used after first cycle coding, and before the second coding cycle begins (Saldaña, 2015; Miles, Huberman, \& Saldaña, 2013). This is where I took all three coding strategies and applied it into one large document where a matrix was utilized to organize the data. Once the data had been inputted into the matrix and codes had been determined second cycle coding methods were applied.

To meet the needs of the research question and data being collected, pattern coding was used as a second level coding method. Pattern coding allows for codes from the first cycle of coding to be combined into more meaningful units of analysis (Saldaña, 2015). Upon completion of patterns coding, themes began to emerge creating meaning of the central phenomenon of the participants. Themes are larger than a "topic or category" (Saldaña, 2015, p. 160). Themes are considered to "run right through data and is not 
necessarily confided to specific segments of text" (Saldaña, 2015, p. 160). Throughout the data analysis process, categories and themes emerged, allowing for analysis of the central shared experience of participants and recommendations to be provided. Figure 3 below depicts the coding cycle process.

Figure 3

Coding Cycle Process

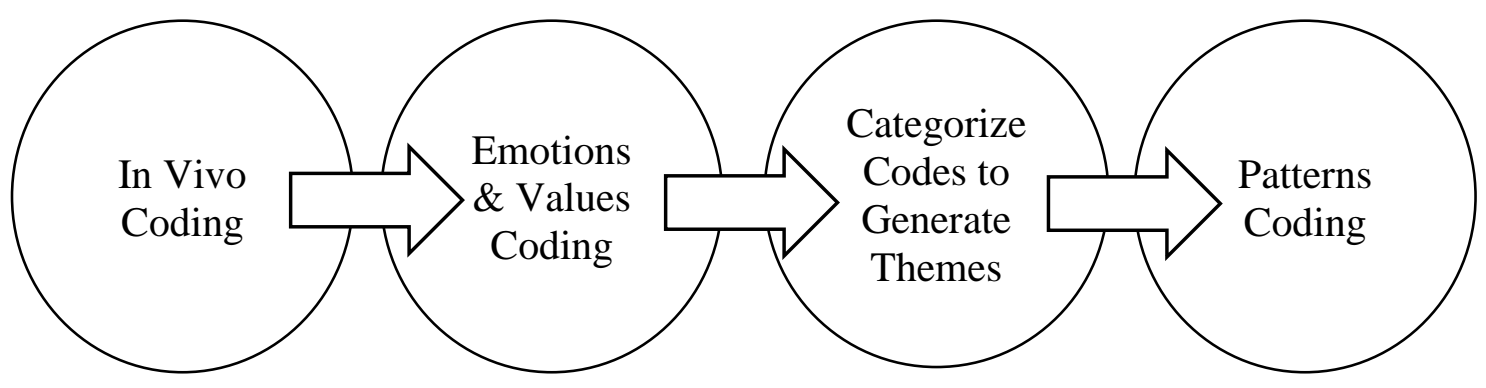

Data saturation is defined as, "an indication that a concept has been thoroughly examined such that no new themes or point in need of further exploration emerge from the recursive process of data collection and analysis" (Trainor \& Graumann, 2012, p. 127; Corbin \& Stauss, 2008). It is argued that data saturation should not focus on sample size but rather on how rich and thick or rather the quality and quantity of the data or in this case interviews (Burmeister \& Aitken, 2012; Fusch \& Ness, 2015). Meanwhile some researchers believe that data saturation is inapplicable to phenomenology (Cohen, 2000; van Manen, 2014). This is important to note as stopping before saturation has occurred is typically discouraged in other qualitative research designs (Gentles, Charles, Ploeg, \& McKibbon, 2015).

\section{Research Quality \& Rigor}

When assessing the quality and rigor of qualitative research it is important to examine the transferability, credibility, and dependability within qualitative research. 
This can also be viewed in three various perspectives which include the researcher's, participant's, and reviewer's lens (Creswell \& Miller, 2000). Creswell and Poth (2017) recommend that at least two validation strategies be used in qualitative studies. One of these strategies is known as confronting potential bias or resistance. Through this approach, the researcher discloses their experiences, values and biases that are present throughout the research (Hammersley \& Atkinson, 1995; Merriam, \& Tisdell, 2015). Since qualitative research heavily relies on the researcher's lens or perspective throughout the study, the potential for human bias is present. This explains why confronting and examining one's own perspective is likely to shape the research design (Creswell \& Poth, 2017). This approach also allows for trustworthiness to be present throughout the study by allowing the research to consistently engage in personal and reflexivity in practice.

Trustworthiness and rigor have been studied since the 1980s by Lincoln and Guba (Cypress, 2017). Trustworthiness is known as "quality, authenticity, and truthfulness of findings" (Cypress, 2017, p. 254). Furthermore, trustworthiness addresses the trust or belief a reader has in the results of a study (Cypress, 2017). By addressing the interpretive frameworks and personal positionality statement, I can provide the reader or reviewer a deeper understanding of the data analysis and findings. It is also my intention to be ethical throughout this research from formation to conclusion and analyze the data in an ethical and truthful manner.

Triangulation is the use of specific strategies to help create a well-rounded understanding or testing the credibility, dependability and confirmability for the phenomenon being studied (Patton, 1999). There are four different types of triangulation 
which include method, investigator, theory, and data source (Carter, Bryant-Lukosius, DiCenso, Blythe, \& Nevill, 2014). It is suggested that researchers have a handful of ways to ensure "data dependability, and credibility such as debriefing, member checking, triangulation, or use of a reflexive journal" (Carter et al., 2014, p. 546). For this study, data triangulation will be defined for a context of including more than one participant in the data collection process. Furthermore, each participant was from a different higher education institution and occurred at different times throughout the semester (Denzin, 1978). Examining the data from a variety of different conditions can help understand the central phenomenon better (Mathison, 1988).

From a credibility standpoint, the idea of member checking or seeking participant perspective and feedback is important to ensure their voices are heard and are being reflected accurately within the analysis and findings. This technique involves participant's feedback to ensure credibility in the analysis or interpretation of the data (Lincoln \& Guba, 1985; Creswell \& Poth, 2017). Member checking for the purpose of this study included sending all written data analysis back to the participant to ensure the written section of the data analysis depicts their story and phenomenon accurately. Students will have two weeks to respond with any concerns or clarifying information. Another strategy to ensure credibility and good qualitative practice is the concept of a pilot study or opportunities for participants to collaborate in the data instrument creation (Creswell \& Poth, 2017). Specifically, when researching students with disabilities on college campuses, best practice is to allow for assistance from the student population when developing questions and seeking pilot studies (Vaccaro, Kimball, Wells, \& Ostiguy, 2015). Therefore, the interview protocol had been piloted once with a 
student who has a learning disability to ensure the questions flow appropriately and the participant or researcher feels specific information is not left unanswered. This process allowed for further analysis and reflection to occur by adding additional questions into the protocol and reflecting on the flow of questions and responses.

The final perspective to credibility is known as peer debriefing which focuses on the lens of the reader or reviewer. Since this is a dissertation, there are multiple reviewers and committee members ensuring accuracy, and truthfulness (Creswell \& Poth, 2017). In addition, throughout the data analysis, crafting rich and thick descriptors throughout the findings is needed to allow the reader the ability to determine in which contexts the findings may be transferred which is known as transferability (Erlandson, Hartis, Skipper, \& Allen, 1993). This can be done by writing in-depth descriptions of the data being analyzed (Creswell \& Poth, 2017). The guidance of my dissertation committee can also ensure the analysis and findings that are generated are rick and thick when assessing the quality and rigor of the research.

In summary, credibility will be assessed using member checking, and triangulation. Transferability will assess the quality and rigor or the research through both purposeful sampling techniques, and by providing thick descriptions of the data throughout the analysis. Dependability will be placed into practice through code and recoding cycle strategies, and peer examination. Finally, confirmability will be presented through triangulation and displays of personal reflections and consistent practice reflexivity. 


\section{Research with Special Populations}

When starting to craft a research design dealing with disability as a topic, there are three main questions that should be consider. It is essential to reflect and answer who the research and work is intended for, what rights do we have to conduct the research and undertake answering the question, and what responsibilities come with that specific research. French and Swain (1997) argue that other questions should be addressed during the research design recommending analysis of the following questions (p. 31). First, does the research promote disabled people's control over the decisions-making processes which shape their lives? Second, does the research address the concerns of disabled people themselves? Finally, does the research support disabled people in their struggle against oppression and the removal of barriers to equal opportunity and a full participatory democracy for all? As researchers we must focus our efforts on empowerment.

Once argument surrounding disability research is the lack of preparation in which is provided to researchers within higher education. Berger and Lorenz (2015) explain that little to no information or methodological courses provide guidance or information on how to best conduct qualitative research with disability-methods. The IRB professional staff may also lack knowledge about varying disabilities as some impairments are considered a protective population under federal law. Therefore, the IRB application was written with extremely specific language surrounding the term "learning disability". Professional staff members who work in IRB are only trying to ensure the research protocol follows federal guidelines however, some education surrounding disability within research may be beneficial. 
There are also several complexities that can cause challenges to conducting research with individuals who have disabilities such as the variability amongst each participant (Odom, Brantlinger, Gersten, Horner, Thompson, \& Harris, 2005).

Educational contexts or varying environments within special education can cause further complexities within the research design. It is emphasized that, "researchers cannot just address a simple question about whether a practice in special education is effective; they must specify clearly for whom the practice is effective and in what context" (Odom, Brantlinger, Gersten, Horner, Thompson, \& Harris, 2005, p. 139; Guralnick, 1999). According to Odom and colleagues (2005), there are currently no guidelines for specific types and levels of evidence that are provided within the special education discipline that offer how to determine and identify effective practices.

Pertaining to including disabled people, specifically those with learning challenges into research, there is much debate surrounding ethical concerns specifically around sensitive topics which include methods of gathering information, consent, and potential harm (Tuffrey-Wijne, Bernal, \& Hollin, 2008). These ethical concerns should be addressed if the content of the research is related to sensitive matters. Seeking informed consent from participants must occur ethically, ensuring an individual is fully aware to what they are agreeing to without feeling pressured or coerced to participate (Ninds, 2009). Protecting confidentiality is essential and explaining the purpose of the informed consent in lay terminology is critical to ensuring the participant understands how the information they share will be used throughout the process (Ninds, 2009).

Participatory research has picked up some rapid momentum in the past few decades related to conducting research with disabled people (French \& Swain, 1997). 
This type of research suggests that disabled people should be involved in the entire research process from design to evaluation (French \& Swain, 1997). Another large debate is the idea of conducting research "with" or "on" disabled people (Ninds, 2009). The participatory research approach would suggest that research should be "with" people (French \& Swain, 1997). Additionally, participatory research allows for disabled individuals to participate in the creation of knowledge about themselves (French \& Swain, 1997).

Gaining access to participants can be a difficult journey to navigate as many individuals with disabilities have gatekeepers or individuals who want to protect them at all cost (Lewis \& Porter, 2004; Ninds, 2009). To conduct research, seeking access to participants may create communication through several layers of management or in this specific research design, administration. In addition, all information about the study may have to be filtered from the facilitator or gatekeeper to the participants to seek for volunteers (Ninds, 2009). This is a potential barrier to the recruiting process, which can make research with this specific population difficult to conduct. To get gatekeepers to assist, it is critical to explain the benefit of the research and how it will directly influence the participants (Ninds, 2009). It is also vital for researchers to consider how they conduct their research to ensure all aspects are in an accessible format (Ninds, 2009). It is suggested that questionnaires be provided in a visual or tangible format when working with individuals who have a learning or communication disability (Ninds, 2009). Universal design should be considered when crafting a research design and instrument, specifically for special populations. There may be times where sending research questions in advance could be beneficial for example, those with auditory processing 
impairments may prefer to see the questions, to follow along visually while conducting the interview.

This is not an exhaustive list but rather a surface level consideration of things that should be considered when conducting research and thinking through ethical concerns and issues related to the specific population. However, there are several ways to preplan for pitfalls or issues within the research design prior to conducting the research and there are also things that will be learned along the process. This is where the action of memoing or journaling the research process and consulting with other experts, and individuals within the disability community is encouraged. 


\section{CHAPTER 4}

\section{FINDINGS}

The purpose of this research was to examine the lived experience of college athletes participating in NCAA Division 1 athletics who have a learning disability and/or ADHD. Five students from different educational institutions within the NCAA D1 Football Bowl Subdivision (FBS) conferences opted into participating by expressing interest in the study, returning a demographic form, and taking part in a 90-minute interview. Recruitment took place between November 2019 through July 2020, through various methods. The researcher was able to recruit two members through personal direct contact, two students were informed of the research directly by an athletic academic staff member (academic counselor/advisor or learning specialist) and one student was informed of the research directly through their disability support services on their college campus. The interviews were held in various months throughout the recruitment timeline, one occurring in person in a secluded space on campus and four were conducted via video, where both the participant and researcher were in the comfort of their own homes. Before each interview, students were sent an email pertaining the preamble and demographic form. Upon return of the demographic form, interviews were scheduled and at the beginning of each interview, the preamble was reviewed and acknowledged. Each participant provided verbal consent for audio recording of the interview. 
Although phenomenology focuses on the central themes and reoccurrences throughout the data and overall shared experiences amongst the participants, one of the main goals of this study is to provide voice to a population that is often ignored within society and within literature. Therefore, this chapter aims to serve two purposes. First, this chapter will provide individual demographic information and brief a personal synopsis of each individual's narrative provided throughout their interview. The second section focuses heavily on the themes and phenomenon that was shared amongst each participant throughout the data analysis.

It is imperative to continuously be reminded that this research is exploratory in nature, and is not a comprehensive analysis, as there is little research conducted on disabled college students since 1990 (Pina, 2014), and insignificant amounts of literature on college athletes with learning challenges. As evident throughout the findings, students have unique experiences that apply to their institution, impairment, and personal academic journey. There are multiple variables and perspectives to consider, and each student's voice is just as important as the collective voice. The following findings seek to honor both perspectives.

\section{Demographics}

In order to protect the identities of each student, participants were asked to provide a pseudonym, or one would be assigned by the researcher. In addition, institutional information is not provided to protect each student's identity, however the conference in which the student's institution athletically competes and the sport in which each student participants in is provided. Two students are enrolled at institutions within the ACC, one student from the BIG 10, one from the AAC, and one from the MAC. 
Three of the participants were first year students. One interview took place in the final month of the student's first semester in college, while the other two were completed at the competition of their first year in college. The remaining two participants classified themselves as fifth year seniors. Students were asked to provide their gender and race/ethnicity. Two participants were male, and three were female, while four selfidentified as White and one as Black. The ages of participants ranged between 18 and 22 . A wide variety of sports are included in this study, including baseball, rowing, swimming and diving, football, and volleyball (see Table 1).

When it comes to accommodation two students received special education services in high school and three did not. While in college, three students were registered with the disability support services on their college campus and actively use accommodations while two were not registered with their disability support center at the time of their interview. Three students in this study self-identified as having ADHD, one student self-reported dyslexia and one student has a combination of ADHD and a learning disability. Three students have been diagnosed with their disability by a professional while in grade school, one student was diagnosed a few months prior to entering higher education and one has never been professionally diagnosed. 
Table 1

Participants Demographic Information

(*) indicates pseudonym for individuals' name

\begin{tabular}{|c|c|c|c|c|c|c|c|}
\hline Name* & Conference & $\begin{array}{l}\text { College } \\
\text { Year }\end{array}$ & Gender & $\begin{array}{l}\text { Race/ } \\
\text { Ethnicity }\end{array}$ & Age & Sport & Disability \\
\hline Don & $\mathrm{ACC}$ & $\begin{array}{l}\text { First } \\
\text { Semester } \\
\text { Freshman }\end{array}$ & Male & White & 19 & Baseball & ADHD \\
\hline Alex & $\mathrm{ACC}$ & $\begin{array}{l}5^{\text {th }} \text { Year } \\
\text { Senior }\end{array}$ & Female & White & 22 & Rowing & $\begin{array}{l}\text { ADHD \& } \\
\text { LD }\end{array}$ \\
\hline Emily & BIG 10 & $\begin{array}{l}\text { Entering } \\
\text { Sophomore }\end{array}$ & Female & White & 18 & $\begin{array}{l}\text { Swimming } \\
\text { \& Diving }\end{array}$ & Dyslexia \\
\hline Earl & $\mathrm{AAC}$ & $\begin{array}{l}5^{\text {th }} \text { Year } \\
\text { Senior }\end{array}$ & Male & Black & 22 & Football & ADHD \\
\hline Jamie & MAC & $\begin{array}{l}\text { Entering } \\
\text { Sophomore }\end{array}$ & Female & White & 19 & Volleyball & ADHD \\
\hline
\end{tabular}

Don

Don is a 19-year-old, White male. He participates in baseball at an institution which is associated with the Atlantic Coast Conference (ACC). Don had just completed his first full-time semester as a first-year student at his institution when the interview was conducted. Don was diagnosed with ADHD in the summer between his high school and college experience, just eight months prior at the time of his interview. Don stated he never used accommodations in high school and qualified for two academic accommodations which included extended time and reduced distraction on tests once he completed a psychoeducational evaluation and submitted the results to his institution.

Although Don does not elect to utilize his approved accommodations through his institution's disability support services, he does take ADHD medication. Don disclosed that he tries to only take his medication on a need to use basis rather than a scheduled time each day. He finds that the medication helps him focus and tries to only take it when he needs to sit still or concentrate academically. Pertaining to his diagnosis, Don stated 
that his physical therapist, and athletic academic counselor are aware of his ADHD. His personal relationship with his head coach was described as distant.

Don said he is very comfortable disclosing his disability to anyone willing to listen. Don stated several times throughout his interview that he feels "grouped" or viewed as "a number" rather than being treated as "an individual" by most people within his collegiate experience. He stated that “...it's a lot more listening not hearing”. He feels frustrated that he will speak up and advocate for what he personally needs to succeed but expressed that people do not genuinely care which is evident through their lack of action.

One of Don's largest complaints is that he does not have full control over his academic choices and overall success. Don stated he has no control over when he takes his classes, as his athletic academic counselor dictates many of these decisions. Don began working with a learning specialist and continued to explain his frustrations. He stated that he felt as though the learning specialist did not take the time to get to know him personally. Furthermore, he felt as though the learning specialist was only teaching strategic academic techniques that applied to the label of ADHD rather than taking an individualized approach to assist Don in his academic struggles.

As far as interacting with peers and teammates, he mentioned that people view him as "weird" because he speaks freely and says whatever is on his mind. Other people's perceptions do not bother Don, and he said he is unapologetic for who he is and stands firmly in sticking with his beliefs. Don said he felt extremely comfortable advocating and speaking up for his needs which stems from his upbringing and parental figures, such as athletic coaches that were influential in his childhood. 


\begin{abstract}
Alex
At the time of the interview, Alex was 22 years old and a fifth-year senior. She identifies as a White female. Alex is on the women's rowing team at an institution which competes within the ACC. Alex was diagnosed with a traumatic brain injury due to an accident that occurred at the age of 10 . The onset of her hearing loss, ADHD, and learning disability were caused due to the traumatic accident she experienced in her preadolescent years. Alex currently takes ADHD medication for her disability. Alex did utilize multiple accommodations in high school and continues to utilize them throughout her collegiate experience. She stated she had to complete another psychoeducational evaluation when she entered college because the assessment results were only valid for so many years. In addition, Alex stated that the process to retest, and receive accommodations through her school took three months. Disability support services required a lot of paperwork and the evaluation to diagnosis is expensive.

The process to receive accommodations was simple, she sat down with a specialist in disability support services and was told what could be offered to her based on her disability. Alex utilizes several accommodations due to her various impairments, but the ones that were brought up with additional context during the interview were testing with extended time and reduced distraction. She stated that the space the disability support center provides is not always the most accessible, as the lighting is poor quality, or the environment can be too loud at times, which defeats the purposes of her accommodation.
\end{abstract}

Alex expressed that sometimes she does not understand why she does not qualify for specific accommodations that can help her in the classroom. ".. the service can help 
me, but I don't qualify, but I don't understand why... like taking my laptop to class". Alex found herself advocating to the ADA coordinator who questioned her on why she needed the accommodation, and she did not feel the response from the ADA coordinator was reassuring. Alex stated she ended up discussing it with her professor who was more than willing to accommodate her request. Furthermore, she was offered an accommodation to use a scribe pen but was not provided any workshops or education on how the technology operates. Her accessibility coordinator provided instructions on how to download the software but did not offer a tutorial on how to navigate the assistive technology.

To ensure her needs are met, Alex stated she will speak up and disclose her disability when necessary. She stated that she felt "it's not valid if I don't disclose it" she explained that sometimes she feels pressure to tell faculty members, specifically in her declared major. She learned how to advocate from struggling on an academic exam and feeling overwhelmed. Her struggle helped her gain the confidence to realize she needed academic accommodations to perform her academic work on the same level as her peers.

Alex stated that her college life feels like a "balancing act" between her athletic obligations, academic demands, and potential social engagements she may be missing out on with other peers. Academically she felt support from her athletic academic counselor, especially her first year in college. She openly discloses her impairment to tutors and she has created a close relationship with her universities learning specialist, even though she does not utilize the services on a consistent basis. She stated the learning specialist offer a quiet space and assist with organization skills when needed. Regarding her athletic involvement, Alex feels comfortable speaking up for her needs with her coaching staff 
and has asked for accommodations to help improve her athletic participation. There are times when her team is on the road and mandatory study hall is implemented in spaces that are not conducive to environments of reduced distractions. She stated that her coaches are supportive and have offered other alternatives, willing to accommodate, if she speaks up and explain her needs first.

\section{Emily}

Emily is on the swimming and diving team at an institution who participants in athletic competitions within the BIG 10 conference. Emily identifies as White and was 18 years old, and a rising sophomore at the time of her interview. When Emily was in the fourth grade, she attended a school that specialized in reading techniques and strategies for individuals with dyslexia. After two years in the program, Emily was enrolled in a mainstream middle school without accommodations as her parents and teachers felt as though she had developed the skills to be viewed equivalent to her peers academically.

During her first semester in college, Emily found herself struggling and went to her athletic academic counselor for assistance. She was set up with accommodations through her institution's disability support services. She mentioned using a few accommodations such as spelling forgiveness and extended time on exams or assignments. Screen readers are considered a new area of exploration for Emily which helps with reading large texts and passages that are assigned in her coursework.

When disclosing her disability to faculty, Emily stated she has not had to experience this interaction as her accommodations were approved weeks prior to COVID-19 and her institution decided to move to remote learning in March of 2020. Due to the pandemic all accommodation letters were provided to faculty via email. Although 
Emily has not had the opportunity to experience a face-to-face conversation with faculty, she stated she would not feel comfortable disclosing too much in-depth information. Additionally, Emily thinks through the level of the course before she opts into accommodations for a course stating, "if I was going to take like a level 100 class... I don't think I would do it". Emily spends time thinking through each of her courses and if she can handle the course load without accommodations before opting into disclosing her disability through accommodations letters.

Throughout the interview Emily expressed several times her lack of selfconfidence and wanting to be viewed as smart by her peers, faculty, and others she interacts with, in her college experience. Despite others telling Emily "I've been told I'm very vocal about things" on a scale from one to ten, Emily rated herself at a 6 for both her confidence and comfort in reaching out to self-advocate. She explained that asking for help related to her disability feels "counterintuitive to being smart". She struggles with her confidence because "how can you balance being smart... with having a reading disability".

In relation to disclosing her disability to her peers, she stated that the process has been an opportunity for self-growth for both her and others involved. She mentioned how she attended high school in an environment where people were accepting and exposed to diversity and individuals with different identities. Emily stated that many of her peers at her current institution have not been exposed to as many diverse individuals, so sharing her disability with her teammates lead to shock and surprise, but left Emily feeling a sense of discomfort. At this point in time, Emily has not disclosed her disability to her coach or athletic staff as it is not pertinent for them to know. 


\section{Earl}

Earl self-identified as a Black, 22-year-old male. He is enrolled as a fifth-year senior and plays football at an institution who competes within the American Atlantic Conference (AAC). Earl has never been evaluated or diagnosed with ADHD, but teachers and other professionals throughout his upbringing have alluded to his behaviors aligning with symptoms of ADHD. Earl stated he did not want to get diagnosed for two specific reasons. First, he expressed that he was against medication because he does not want to alter his personality and "dull" who he is stating, "I'm perfectly fine in my skin". Additionally, Earl mentioned that the way his family views disability may impact his choices on not seeking further medical documentation or evaluation.

Earl views his disability as a challenge to be overcome. From the way Earl struggles to concentrate during tests and exams, to his athletic academic counselor excusing him from tutoring sessions if he completes his work early in the week.

Additionally, Earl said he performs better academically when in season and when he procrastinates and waits until last minute to complete assignments because there is no time to get distracted. Being an athlete provides Earl with a sense of "privilege" as he stated, all the academic support he needs to access is located in one building, and the support is flexible on his time, meaning he does not have to make appointments with these resources.

When examining how Earl views his disability, he stated that it makes him "fun and witty", and it's a part of his personality. In high school, Earl was reminded of times when his peer would call him "weird", but he embraced those comments and views himself as unique. Earl also stated that he views every conversation when he discloses as 
an opportunity to change an individual's perspective on how they view people with ADHD, as more "creative and outgoing". He often feels the need to disclose to tutors when he is distracted or getting off topic, because he does not want their perceptions to change, or think Earl is doing it on purpose or as disrespect.

Since Earl attends an institution that is outside of the Power 5 conferences, he stated that there are financial restraints that influence his college experience. He mentioned that his teammates have friends and family members who attend colleges in the Power 5, and they talk. Earl said he was aware that his institutions athletic facilities are not the greatest, nutrition is sub-par at times, tutor or athletic academic counselor to student ratio is higher than an institution with more income and the additional resources are not provided like they would be at an institution that had a higher athletic revenue. That being said, Earl stated he often feels that his team has to try 10 times harder athletically and academically to compete with other football teams that derive from Power 5 conferences, even if his team has better skills on and off the field.

Earl said he learned to advocate and speak up for his needs by being stubborn and finding his voice when his peers were looking at him different. He has experienced peers in his academic courses assuming specific beliefs and capabilities relating to his identities as a Black, collegiate athlete, with ADHD. Athletically Earl has not disclosed to his coaching staff but he believes his coaches would bring it up as a joke in conversation, but that is only because of the relationship he has with his coaching staff, and Earl alluded to the normalcy of this behavior. 


\section{Jamie}

Jamie is a 19-year-old, White female with ADHD. She participants in volleyball at an institution who athletically competes in the Mid-American Conference (MAC). At the time of the interview Jamie was a rising sophomore. Jamie was diagnosed with ADHD in the eighth grade. She is currently not taking medication for her ADHD, as it altered her personality and made her "a different person" when in social environments and she wanted to avoid the complication of the NCAA and prescribed medication.

In high school Jamie received accommodations but she described the teachers being lenient, whereas in college she had to go through the process of requesting accommodations which involved disclosing her disability to a lot of people and completing or providing an overwhelming amount of paperwork. Her athletic academic counselor recommended her to the disability support services on their campus to see what accommodations she could get with her ADHD diagnosis. She was offered time and half and reduced distraction on tests and exams. In addition, some of the current processes the disability support services subscribed too are inaccessible or place more burden onto the student.

One struggle Jamie had with her institutions disability support services is the process to sign up for accommodation letter for faculty, and/or request academic accommodations for an exam. Jamie shared her frustration that everything is done on paper and in person, instead of online. Due to COVID-19 and her universities administrator's decision to move all courses remote in March of 2020, forced a shift to occur in the process that was more accessible. In addition, Jamie explained her frustrations with the location of the nearest parking lot to the disability support services 
location, and the amount of time and advance planning it takes to utilize her approved accommodations when test taking, but she said "it's hard to complain because it is worth it".

When choosing to disclose to professors, Jamie thinks through which courses she may need her approved accommodation in, before opting into providing paperwork to faculty. She stated that from her experience faculty interact with so many students that her conversations are typically kept brief and it feels like "oh thank you for that, like move along". Additionally, Jamie mentioned a time where her Teacher Assistant (TA) for a course struggled to understand English, as it was not their first language. Jamie tried explaining the process to get accommodations for her upcoming test, but the TA did not understand. In the moment, Jamie made the decision to take the test in the class as she weighed her options and did not want to continue to overwhelm and stress the TA in the moment.

When discussing academic support, Jamie explained that she feels she "can get down" on herself sometimes. She has no problem vocalizing her needs in terms of understanding content material, but she struggles in other areas related to personal growth and reaching out for help. Jamie stated, "I feel like I can figure it out mentally on my own". On a scale from one to ten, Jamie ranked herself at six on her comfort in reaching out for help when in need. Jamie did mention her coaches are aware of her disability and are super understanding. She felt supported by most of the people she has interacted with from a professional lens throughout her collegiate experience thus far in regard to disclosing her disability and getting the academic support she needs to succeed. 


\section{Themes}

The first major theme is reactions and perceptions of others regarding selfdisclosure of a disability. In addition, interactions with peers and interactions with athletic staff were two sub-themes that were presented throughout the data. The second major theme that emerged throughout the analysis was being vocal and persistent when it comes to self-advocacy. The two subthemes in this category include knowledge and education as well as the influence of personality and upbringing on confidence. The final overarching theme that appeared from the data consists of, building rapport and relationships influence perceptions of support. The first subtheme in this category includes academic support staff such as athletic academic advisors/counselors and tutors. The second subtheme in this category include targeted support services or programs (see

Table 2).

Table 2

The Research Questions \& Emerging Themes

Central Question: What are the lived experiences of college athletes with learning disabilities and/or ADHD surrounding disability disclosure, advocacy, and academic support at NCAA FBS D1 institutions?

\begin{tabular}{|c|c|c|c|c|}
\hline$\#$ & Research Question & Theme & Subtheme A & Subtheme B \\
\hline $\mathbf{1}$ & $\begin{array}{c}\text { What does this process of self- } \\
\text { disclosure look like for college } \\
\text { athletes with learning } \\
\text { disabilities and/or ADHD? }\end{array}$ & $\begin{array}{c}\text { Reactions and } \\
\text { perceptions of } \\
\text { others }\end{array}$ & $\begin{array}{c}\text { Interaction } \\
\text { with peers }\end{array}$ & $\begin{array}{c}\text { Interactions } \\
\text { with athletic } \\
\text { staff }\end{array}$ \\
\hline $\mathbf{2}$ & $\begin{array}{c}\text { How do college athletes with } \\
\text { learning disabilities and/or } \\
\text { ADHD advocate for their } \\
\text { academic success? }\end{array}$ & $\begin{array}{c}\text { Being vocal and } \\
\text { persistent }\end{array}$ & $\begin{array}{c}\text { Knowledge } \\
\text { and education }\end{array}$ & $\begin{array}{c}\text { Influence of } \\
\text { personality and } \\
\text { upbringing on } \\
\text { confidence }\end{array}$ \\
\hline $\mathbf{3}$ & $\begin{array}{c}\text { In what ways do college athletes } \\
\text { with learning disabilities and/or } \\
\text { ADHD describe academic } \\
\text { support within their campus } \\
\text { community? }\end{array}$ & $\begin{array}{c}\text { Building rapport } \\
\text { and relationships } \\
\text { influence } \\
\text { perceptions of } \\
\text { support }\end{array}$ & $\begin{array}{c}\text { Athletic } \\
\text { academic } \\
\text { support staff }\end{array}$ & $\begin{array}{c}\text { Targeted } \\
\text { support services } \\
\text { and programs }\end{array}$ \\
& \multicolumn{2}{|c}{} & \\
\hline
\end{tabular}




\section{Theme 1: Reactions and Perceptions of Others}

Pertaining to how students feel about making their own decisions within their college life, all participants stated they felt comfortable. Don mentioned that it was "the goal of college" and Earl stated he could reach out to someone if he needed assistance. However, Alex mentioned that sometimes being an athlete adds pressure to not only do things right but get everyone's opinion about the decision.

They encourage us to use so many different resources, it's almost as if you make a decision on your own, then you didn't do it right... let's make sure you know everything, know all information, and get everyone's opinion before you do this

Students feel comfortable enough to make their own decisions but can also feel overpowered by professional opinions which may stem from the need to do everything right in collegiate athletics to avoid or interfere with NCAA eligibility and policies.

Even though students feel comfortable making their own decision, they do not always feel comfortable disclosing their disability to professionals, peers, and athletic staff. Participants explained that before they make the decision to self-disclose, they think through how the individual will react to the information. In addition to their reaction, participants think about how the individual will perceive the student with a disability after the information has been disclosed. Students stated they did not want to be seen as less than or incapable.

Jamie mentioned that the most important thing she considers is how the other individual is going to treat her after she discloses the information about her disability. She shared that she does not want to be treated differently and does not want others to "dumb things down" or feel as though she is not self-sufficient now that they know she has ADHD. Emily provided similar thoughts. 
...when I feel like it will make me like less than everyone else, I don't usually disclose it. I want to prove to everyone that I deserve to be there just as much as everyone else instead of being someone who got their based on a disability.

Emily also shared that she often thinks through how self-disclosing her disability will be received, if it is "poignant for others to know", and if others will have a negative perception of her ability.

Alex considers how an individual has reacted to other information in the past, or comments people have made regarding personal information. She stated if an individual found the information to be overwhelming, or, made insensitive comments, she would be less inclined to disclose information about her ADHD or other impairments. She also considers if the information will be kept confidential or shared with someone else.

Earl mentioned how the perceptions of others is important in his decision-making process. He states that sometimes he is not able to focus during tutoring sessions and that he does not want the tutor to think he is being disrespectful or rude. He wants the individual to know he is not trying to be rude or disrespectful, or wasting their time but rather he cannot help getting off topic or distracted due to his ADHD. Don mentioned that he considers the situation and genuinely analyzes the person that he his speaking to before he decides to self-disclose information about his ADHD. He said when he shares his disability

...if it doesn't pertain to them, it doesn't matter ... So, it's very frustrating when I tell someone (and their reactions is) okay yeah, I understand that, and they immediately turn away. It's like to you, it could be a big deal, to them it's not and you hear that a lot, but that's just the truth, that's really the way it is

Don also stated numerous times throughout the interview that he felt more like a number or often grouped into a category rather than being viewed as an individual. 
Ultimately student athletes with learning disabilities or ADHD want to ensure they are disclosing to someone who will be understanding and non-judgmental. When considering the process of self-disclosure students base their choices off the individual's potential reaction and perception. There were two specific groups of individuals that appeared frequently discussed throughout the data on disclosing information which include interactions with peers and coaching or athletic staff interactions.

\section{Subtheme 1A: Interactions with Peers}

When discussing the reactions and perceptions of others, students appeared to have either negative interactions or hesitated to discuss their disability with peers. Students shared experiences of feeling stereotypes as "dumb" or incapable. Students speak about peer interactions in terms of other students in their classes and other peers on their athletic team.

Jamie speaks about how her peers perceive her to only have accomplished admissions into college because of her association with sports rather than academic accomplishments even though she has received scholarships for her academic performance. Jamie stated these reactions are evident through rude comments. Jamie said her teammates, especially the upperclassman on the team are academically smart and have more years of experience in college, so she feels comfortable to ask them for assistance in her own work.

Like Jamie, Alex also chooses to withhold information about her disability while participating in group assignments, especially if the topic is about disabilities, as she does not want the project to be solely focused on her experiences. Alex also has experienced similar comments from her peers about attending the best parties, not getting good 
grades, and the misconception of getting admitted into college based solely on athletic ability. There are also times where Alex thinks about her environment and explained how athletic academic workshops can be helpful, but they can also lead to fear and pressure of exposing one's disability identity without thinking.

Sometimes we have speakers come in every semester for student athletes and sometimes they'll ask, does anyone have trouble concentrating? And I just think it's kind of tricking us into making us feel more comfortable that were all going through the same thing. I remember thinking if we would raise our hands right now, we would give ourselves away, but not in a mean or oblivion way but it's just trying to get other athletes to realize people have similarities

The fear of being singled out by her peers caused slight discomfort in a large group setting.

Emily shared her experience of disclosing her disability to her teammates stating there was a lot of shock, surprise, and sympathy. She began feeling as though her teammates only liked her because she was viewed as "not a tokenism, but sort of like a step under". Similar to Jamie, Emily struggles with wanting to feel equal to her peers. She states she will not disclose her disability if it will make her feel less than her peers. "I want to prove to everyone that I deserve to be there just as much as everyone else instead of being someone who got their based on a disability". Emily stated throughout her interview that self-confidence regarding her academic abilities is a skill she is working on daily.

Don stated that most people view his ADHD as a weakness, but he sees it as a part of who he is, which makes him unique. When it comes to his teammates, Don spoke about a time he was asked to participate in specific team activities in which he was left feeling uncomfortable and opted out of participation. Over time, he stood his ground and 
stated he felt more respect from his teammates, as his teammates started asking him to hang out one-on-one.

Earl recited a powerful memory where he was assigned to work on a group project with his peers. He first struggled to find group members because everyone in the class knew he was a football player and had assumptions about his academic performance and abilities. By taking ownership and leading the delegation of tasks for his peer, he felt the need to prove his peer's assumptions wrong.

I was actually the only Black person in the group, so I could just tell the vibe like they were trying to be friendly, but I knew we started talking about all the work and stuff, like they were just trying to give me something so simple and I just felt so belittled like I can do more than that. It was like writing my name. I was like no, you're not gonna do that, this is how we're gonna break it down and I delegated the portions. Obviously, I was asking them too, if there were willing to do it... it was kind of an even split, but I made sure that I had one of the portions that people would think twice about getting because it was a little extra work and we got the second highest score out of all the six groups in that lab

Earl also shares that his teammates do not really discuss academics or support each other.

Being on a football team the only time academics are really discussed, is typically in conversation about an athlete passing his courses. The only other time teammates discuss academics is during season, and if a teammate asks, they're not asking how did you perform, they are just purely asking if you completed the assignment or tasks so that everyone can go and perform on the field.

Each participant shared a sense of wanting to feel equal to their peers and validated for their academic achievements. The intersectionality of identities influences the perceptions and reactions college athletes with learning disabilities or ADHD encounter when interacting with their peers. Furthermore, college athletes with learning 
challenges want to be seen as equal to their peers and hesitate to disclose their disability in various environments.

\section{Subtheme 1B: Interaction with Athletic Staff}

Athletic staff, coaches and athletic trainers or physical therapists were mentioned overlapping in several interviews. All three female participants have athletic coaches who are male, and each individual said they have a close enough relationship with their coach that they feel comfortable disclosing their disability. Jamie and Alex have similar experiences in disclosing their disability to their head coach. Jamie stated she needed to share the information with her head coach, to be excused from practice to meet with their disability support coordinator on campus for an initial intake appointment. She stated her coach was supportive and had an individual and private conversation with her expressing his support.

Alex had to disclose to her coach as she needed accommodations to perform at her peak athletically. With a slight hearing loss, she needed her coach to make accommodations on which side of the lake he voices his instructions from, and Alex explained he may need to repeat instructions multiple times. Alex also mentioned that her coach was willing to incorporate the changes for a few practices but then fell into his old habits, so she had to remain consistent and remind him of her needs and accommodations. When her coach followed through with Alex's requested accommodation and started to see improvement, he was willing to engage in these changed behaviors consistently.

Emily stated she has not needed to self-disclose to her coach, but if she ever felt there was a need to, she would feel comfortable because of their relationship. Earl 
expressed similar beliefs that his coach would not treat him differently, but his ADHD might be used as a joke within conversations. He reiterated that disclosure comes down to the persons situation, and coach's relationship with the athlete. Don expressed that the relationship he has with his head coach is distant. He stated his coach could care less from his own interactions, or lack thereof, and things he has heard from other teammates, so he chooses not to have a conversation about his ADHD. However, it is important to note that Don's disability does not influence his athletic ability to focus the same way his ADHD influences his ability to succeed academically in the classroom. Earl and Jamie also shared similar comments about how they can hyper focus in while participating in their sport because it something they are passionate about, and they are continuously moving their bodies.

In addition to the relationships and reactions of coaching staff, another commonality amongst the participants is the topic of medication and athletic participation. For athletes who are diagnosed with ADHD, two students opted out of taking medication as they did not want to deal with the side effects or want their personality to be altered. Two participants actively take medication for their ADHD. Both students who actively take prescribed medication disclosed times where their medication was openly discussed around teammates and other individuals without their permission. For example, Alex recalled a time where her coach addressed her medication in front of other teammates, because he was frustrated. She stated that the athletic trainer had a personal conversation and explained she planned on reiterating in the next coaches meeting that his actions violated HIPPA. Alex stated she was thankful for her athletic 
trainer's support and educating her that her coaches' actions were inappropriate. Don

speaks about similar experiences but with his physical therapists.

So the prescription I take is called methylphenidate, well the root word is meth and so someone saw my prescription when they handed it to me and then the whole team thinks I'm taking meth, and everyone knows I'm not so they start giving me a hard time... there is a moment where I was annoyed by it, but that was very brief... its very thrown around, you'll have a physical therapist say, oh I have your ADHD medicine or a couple days ago did you get the medicine yelling it across the entire room, I'm like yeah I got all of it and its, I mean cuz I'm very like that, but someone else that doesn't really want it shared its very non confidential

When it comes to a student's self-disclosure process their relationship with their coach helps guide their comfort and decision-making process to disclose their disability. Athletic support staff also play vital roles in terms of managing college athlete's medication and privacy information about their ADHD. Disclosure of a disability, such a personal and private matter comes down to the interactions, perceptions and reactions of others, especially athletic staff, and variations peer interaction. The theme of reactions and perceptions of others is continuously streamed throughout the remaining analysis as it overlaps several times with advocacy and beliefs on academic support.

\section{Theme 2: Being Vocal and Persistent}

The second major theme that appeared throughout the data is the participants shared response to being vocal and persistent about their needs. Jamie said she asks a lot of questions in the classroom or with tutors surrounding content knowledge, when she does not understand the material. Alex has had to ask to be relocated during an exam she was taking in the disability support center because the environment was inconducive to her success on the exam. Emily stated she asks as a last resort because of her confidence, but she has been told that she is vocal about her needs. Earl said he shares his needs with 
his athletic academic counselor and Don stated, "I can speak my needs, but I can't ensure my needs". Don has consistently remained vocal throughout his first semester in college about his needs, but he feels he has little control, but he continues to speak his mind.

Each student shared a story of a time they had to be both vocal and persistent to seek change. Don mentioned a time he asked to drop ECON from his schedule and he did not want to waste the next four weeks in additional tutoring or continue attending the class, when he knew he could place more time and effort into his other classes. Don ended up dropping the course on the last day to withdraw with a "W" on his transcript that semester.

I still say how I feel... but I actually stopped speaking up when I realized I had no one else to speak to, I knew nothing was going to change... At that point, I talked to everyone I could possibly talk to and so it kind of turned into, well he did everything he could

He felt agitated because he was vocal and persistent in asking to have some say and control in his academic demands but felt as though his athletic academic counselor was not listening to his needs and individual perspective.

Alex was struggling in an anatomy course at one point in her collegiate experience and asked her athletic academic counselor for more tutoring sessions. Her athletic academic counselor appeared apprehensive to the idea, but Alex continued to push and eventually got what she needed as she saw her grade starting to rise. She said, "if an athlete needs it, then give it them". Emily was hesitant to ask for help her second full semester in college when she knew she was struggling to keep up with the academic demands because of her disability. Reaching out to her athletic academic counselor was one of the most monumental moments in her collegiate career throughout her first year. She had to vocalize her needs with confidence something Emily struggles with as she 
said she is still growing her confidence but she is beginning to view her disability in her own way stating, "It's not like you're not trying hard enough, it's sort of just something in your way that keeps you from being as equal".

Earl talked about a frustrating moment where technology was not on his side. Reflecting on the experience, there was a course that had assignments each week, and one week there were no assignments on his calendar on their institutions online academic platform, and no weekly announcements in the course. When he noticed he had received all zeros the following week for missed assignments Earl reached out to his athletic academic counselor and faculty member about the concern. Earl mentioned that he felt as though everyone was pointing the blame on him, stating it was his fault. He felt frustrated in the moment and ended up dropping the course a few weeks later, but he continued to be vocal about the issue and reached out to the professor to ask for assistance, but the requests were not approved.

Jamie was reminded of a time in high school where she was continuously asking the teacher questions because she did not understand the material. The teacher got so frustrated that she threw her papers across the room. Jamie continued to stand her ground and ask questions. She felt it was important and although people may "get annoyed", it helps Jamie to vocalize her questions and seek understanding rather than giving up on the process of learning.

Students can be vocal and persistent but unfortunately, they are not always in control of ensuring their own needs. In some situations, being vocal and persistent helps ensure personal and individuals needs are met. Other times, individuals feel as though they exhausted all options, and they were vocal with persistence but sometimes their 
requests are not heard or fulfilled. In order to vocalize and remain persistent individuals must first have the knowledge and education. In addition, the person's childhood and upbringing can have implications on how students view their disability and advocacy skills.

\section{Subtheme 2a: Knowledge and Education}

Knowledge and education were themes that were found numerous times thought the interview transcripts which can be split into two different categories First the individual's knowledge and education, and faculty and professional staff's knowledge, or lack of education. For the purposes of this analysis section, personal knowledge and education will be addressed. When asked about their working knowledge of laws and services that pertain to their disability, Jamie and Alex stated they had more knowledge about 504 plans from their high school experience but lack any specific knowledge pertaining to federal laws that may affect them now that they are in college. Emily mentioned she has more knowledge about the process of how to apply for accommodations in college but knows very little about the laws. Earl said "zero", and Don said he "has a lot of knowledge from a strategy perspective". All participants lack knowledge about the laws that effect their rights as a disabled individual.

When asked about their personal knowledge regarding their disability Don and Jamie mentioned vaguely sitting down with a psychiatrist who conducted a psychoeducational evaluation and reviewed their test results with them. Jamie was reminded of when she first was diagnosed in the eighth grade.

That was a really hard time to try and figure out what was going on, but like once I knew it just brightened everything up and I was like, okay, like now I can figure out what I need to do to like be successful in school 
Whereas Alex and Emily rely heavily on their athletic academic support staff (learning specialist or athletic academic counselor) for assistance. Don, Earl, and Jamie all mentioned the influence the internet as had on their knowledge. Earl said he has looked "on google", Jamie said she used the internet to do research and she has recently started, "following more twitter pages and social media platforms about it". Don stated he took "time on my own to really look into it".

When speaking up and advocating for other individuals, everyone said they would feel comfortable, with one exception, language usage and education. Don said "knowledge" was important to have when it came to advocating and Emily said "spreading awareness" was important to consider. Jamie talked about a time she did not have enough knowledge to continue to push for accommodations on the ACT. She said, “I didn't try to fight anymore, I didn't really know what I was talking about at the time". Without the knowledge or education, Jamie was left feeling unconfident on how to address the situation and gave up on being vocal and persistent. Alex stated that as long she has access to the education, she feels comfortable, stating "First I had to learn what's appropriate language to use". Similarly, Earl explained that he does not feel comfortable unless he has some background knowledge one what he is speaking about.

I've always been a person who if I'm not educated enough don't speak for nobody because I can get trapped into a debate or argument so I try to like find certain times where I know enough to speak up because I don't want to speak up and be wrong, now I'm embarrassing that person even more

Having the language, knowledge, and education is crucial for students to stand up for their needs and advocate for others, but also is needed for their own personal advocacy skills. 
When students lack the knowledge or language to communicate their needs or lack education about the laws and processes to receive accommodations, they lack the ability to remain persistent and stop advocating for their needs. Students feel more confident when they know what they are talking about and can communicate those needs vocally with other. Persistence is critical in ensuring students get their needs met with proper accommodations.

\section{Subtheme 2b: Influence of Personality and Upbringing on Confidence}

Throughout the data analysis students attributed their personality and upbringing to their overall confidence in connection with advocating or communicating their needs. A participant's childhood and overall personality either improves or reduces their decision to communicate their need. For example, Jamie grew up watching her stay at home mom stand up for whatever she needed. Jamie described her mom as "persistent", and a "strong women figure". Jamie also contributes some of her vocalization to her outgoing personality. When looking at confidence, Jamie stated she is willing to speak up and ask for help when she is trying to understand content material in the classroom.

Similar to Jamie, Alex also shared that her parents attending college influenced the way she communicates her needs. She said her parents had open conversations telling her to "make sure you get this, this, this and this". Alex also remembers a learning moment in her educational journey where she "wasn't successful" and she remembers feeling "really overwhelmed". She stated that the moment she realized she was struggling allowed her to pause and reassess her decisions. Alex said her confidence has come with time practicing vocalizing what she needed to maintain academic success throughout college. 
Like the support Jamie and Alex described, Emily also finds comfort and support in her parents, as they have watched her struggle throughout her educational experience. It appeared that her parent's decision to place Emily in a specialized school for dyslexic children in elementary education altered the way she views and disability which continues to influence affect her self-confidence. Once she entered middle school, Emily and her parents felt she had developed the skills to continue her education without disruption. However, when Emily entered college she was met with unexpected struggles, like those she experienced when she was younger. Her childhood experiences affect her confidence and comfort levels in vocalizing her needs today. When she is feeling overwhelmed Emily will call her parents as they can relate to her experience as they have played an active role in her educational decisions throughout K-12.

Don spoke about the confidence he established in childhood from not only his parents instilling the importance of standing up for his beliefs but also the parental figures he was surrounded by when growing up, which influenced his learned behaviors to vocalize his needs. Don said when he got hurt playing sports throughout his childhood he was encouraged to speak up and say something instead of playing injured which could cause more damage to the body. Having strong, influential parental figures helped shape the way Don communicates his needs. In addition, Don capitalized on his personality and embraces his disability attributes.

And I'm more of like the person that says whatever's on my mind. And I say it with confidence because that's how I feel. And so then there's times where I think with ADHD a lot of people utilize it in different ways. Some people are a lot more hyper, some people are more talkative. I tend to be more talkative, so I say things that people think are weird, and that's perfectly fine with me. 
Don's confidence comes from his personality and upbringing. He grew up in an environment where he was encouraged to speak his mind and communicate his needs. Additionally, Don he also finds confidence through his personality when interacting with others.

Earl attributes his confidence to his "unique" and "different' personality because he is "fun and witty" and enjoys engaging in conversations with others. He learned different ways to bring up the topic of ADHD from his interaction with peers in high school. Earl also shared a different experience when it came to his family and overall perspective on vocalizing his disability:

I did have some people in my family who were diagnosed with disabilities. We still love them the same, but you can just tell every so often they will treat a little different so I'm like nah, I'm good, I'm fine... I can do this I don't need that, I don't need to live that life, disability makes me unique... it's not bad it's just me.

On top of his childhood experiences and family's perceptions of disability, Earl thinks that some of his confidence also stems from the stubborn side of his personality. He can strike up a conversation with anyone and utilizes his fun and witty personality to help gain leverage in conversations when he is advocating for his needs.

The development of confidence and speaking for one's needs appears to be attributed to an individual's childhood experiences while overall personality influenced their confidence and decision-making process to advocate for their needs. Some believe their personality is more influential where others believe their parental figures helped shaped their perspectives when communicating their needs with confidence. Either way, each participant demonstrated skills through examples and their own beliefs on how confidence, communication and advocacy skills were instilled or developed into their tools for success. 


\section{Theme 3: Building Rapport and Relationships Influence Perceptions of Support}

As previously mentioned, disclosing a disability to a coach begins with the relationship and connection an athlete has with athletic staff. When it comes to academics, building rapport is essential. There are two main areas students felt relationship building was critical to their overall academic success. The first category is academic support staff, which for the purses of this analysis refers to athletic academic counselors. The second category examines targeted support services pertaining to peer interactions, and professionals within the field of athletic academic support services.

Disclosing their disability with faculty members, can cause discomfort and several students discuss this concept of a missing meaningful relationship throughout the disclosure process. Looking at some of the students' experiences may provide a deeper insight to this overarching theme of rapport building and perceptions of support. Jamie mentioned that teachers do not usually engage in meaningful conversation with her about the matter.

...teachers that I just met and I tell them they're obviously not gonna be like, oh I didn't know this, but like they have so many students to deal with so they're like oh thank you for that like move along

Alex shared in her interview that faculty need "better contact... better communication". She said there needs to be more education or "emphasis" on what is appropriate and inappropriate to ask when you are approaching the discussion with a disabled student. Don also shared a similar perspective to Jamie on how professors handle the topic of disability.

In college, it really doesn't matter, the professors don't really care in terms of lecture halls, and there's a point to be said about how teachers even in smaller classrooms, it doesn't seem like they genuinely care. A lot of the times, you have so many teachers that have so many students, and you're just one of them. So, you 
try to build relationships as much as you can, but at the end of the day, you kind of leave and so some teachers take time, and I've had a couple that are (but) it's kind of rare, but most of the time you don't feel like you're close enough to bond or they don't really come forward to you personally to the point where you shouldn't even tell them because if you tell them they're like, Okay, well, thanks for telling me and it's kind of pointless, okay. So, it's one of those where it kind of seems like it doesn't matter. It's not as big of a deal.

Don expressed similarities that align with Jamie's perspective on disclosing and discussing an accommodation with faculty members. Emily also stated she would not feel comfortable going into an in-depth conversation with faculty about her disability.

One factor influencing academic success appears to be related to students seeking support through meaningful relationships, which begins with building rapport. The consensus with disclosing a disability to faculty members derives from a lack of rapport and meaningful relationship building. Many times, students are discussing something personal within their first interaction with a professor, which cause uncertainty. However, the underlining perspective is if students had a "bond" or connection with their faculty member prior to seeking accommodations, then students may feel more supported and forthcoming with information.

\section{Subtheme 3a: Athletic Academic Support Staff}

Athletic academic counselors and tutors were mentioned throughout each participant's comment regarding their academic success. Jamie mentioned that she disclosed her disability to her athletic academic counselor early on in her collegiate experience. She said she met with her athletic academic counselor once a week for about 30 minutes her entire freshman year and feels as though their office is a safe place to "vent". Although she feels as though her athletic academic advisor is understanding, she said their "not really like knowledgeable on like what I kind of go through" but she 
reassured me that they have never made her feel different, they just want to make sure Jamie is taken care of in regards to her academic and overall success.

Emily shared a similar experience where she felt comfortable enough with the relationship and rapport that had built with her athletic academic counselor to seek help. At the time she said she did not get into the details, but she felt comfortable and confident enough to express her need for further academic assistance. Emily meets with her academic advisor once a week, either weekly or biweekly depending on their schedule. Emily said her academic advisor is available if she ever needs support on anything and meets consistently to check in on her academic progress.

Earl stated that he engages in academic conversations about $90 \%$ of the time, when speaking with his academic counselor. He shared that he feels comfortable conversing with his athletic academic counselor, and they are consistently in communication about assignments. Earl said he views his athletic academic counselor and the tutoring support program as a privilege.

I low key get a slight bit more privilege than a non-athlete. Because I know I'm working for every single thing that I get.... like an advisor I can just go straight into a building and talk to them and they talk to me every single day. I understand. I'm working for all those things, but at the same time a regular student doesn't get that access as easy as I do.... I get to have access to my advisors. And my tutors like on command like one call. So, I don't have to go search for an advisor or set up an appointment as often you know what I'm saying, so yeah. So, just a bunch of positives to come with playing my sport.

Earl provides a unique perspective to the services athletes are provided in connection with helping maintain their NCAA eligibility and overall academic success. It is important to note, although Earl feels privileged to have these services, nothing is handed to him, he still must put in the work and effort to succeed academically and athletically. 
Alex describes her athletic academic counselor as being supportive and offers an open-door policy. Her athletic academic counselor was already informed of her disability when she entered college, and during her first year, she met with them on a weekly basis. After her first year in college, her athletic academic counselor would conduct meeting when it was time to schedule and enroll in courses for the proceeding semester. Alex also shared that her academic counselor "makes sure that I'm NCAA eligible, um, which is way harder than you think".

Every participant provided positive comments and insisted that their athletic academic advisor was supportive, built positive relationships, and cared about their overall success academically and individually. However, Don stated that he felt the least support from his athletic academic advisor when considering his academic success. He never feels as though they hear him, and he perceives them to take everything as a personal attack. He says, "anytime I ever have something to say, I would be spoken for...". Although he does not feel support from his athletic academic counselor, he did find a sense of rapport and genuine connection with his campus advisor, who Don stated he believed had his best interest in mind academically.

Two students mentioned learning specialist support, as Alex stated she feels her learning specialist's office is a welcoming environment, a quiet space to get work done, and they are encouraging, and understanding. She has used the learning specialist once her sophomore year when she was struggling with organizing her notebooks, papers, folders, and binder. Don stated he was placed with his learning specialist and he felt they was uneducated, viewed him as a number, grouping him prescribing techniques and 
strategies that are given to all students with ADHD, rather than being provided specific support for his own individualized needs.

I have to sit in this meeting for 20 minutes, then it turned into where we didn't know what to do, so (they) tried to help me with my homework, and we couldn't, it took us 22 minutes to get through one question, and then she's like, yeah, let's just not work on this today... Then she made me download an app to play a Lumosity game. I am like, I'm not three I don't need to connect trains to these tracks to make my brain work, this is a waste of time. And everything (they) told me specifically for me, we had a PowerPoint presentation, and that is what she told everybody else. So, the teaching learning specialist is not necessarily, it doesn't feel individualized, and it's probably for someone that doesn't care about school. Maybe other sports that just have terrible grades and someone that needs to be constantly told what to do the entire time.

Don not only provided a frustrating experience he had with his learning specialist, but he talks about her strategy of grouping, rather than viewing students as individuals.

Additionally, he seems to express some stigma related to going to a learning specialist, as he states they are better suited for people who get below average grades.

All students stated that tutors played an integral part to their overall academic success. Jamie and Alex shared experiences where they have had to advocate for additional tutoring appointments to keep their grades from declining. Don stated that some tutors are more helpful than others, explaining that he had a tutor who googled information the entire session, and felt he could google his own questions to seek the answers. His tutor ended up getting switched throughout the semester and he felt more confident with the knowledge his new tutor was presenting. Building rapport and meaningful relationships with athletic academic advisors and tutors is important for students to feel a sense of academic support on their college campus. 


\section{Subtheme 3b: Targeted Support Services and Programs}

When building rapport and meaningful relationships, the participants felt as though two main areas of targeted support services would improve their overall sense of academic success and connection to their campus community. The first area of improvement is peer interaction and finding a community of other college athletes who have disabilities or challenges like their experiences. The second area pertains to the transitional support from high school to college and the resources or outreach that are limited or non-existent at most institutions. Students offered several suggestions on how services could be improved. These ideas and suggestions are explored further below.

Acknowledging college athletes' multiple priorities and identities, is often forgotten, as Emily stated there is limited time or resources to address any other aspect of her identity because her time is consumed thinking about her athletic and academic demands.

I feel like college athletes experience some type of issue with learning or attention or even like depression or anxiety. So I feel like sometimes not at (my institution) per se but sometimes it's sort of hidden or not addressed because they're athletes and then their students and then there's all these other roles that they need to fit before its bubbled down to you have like anxiety or depression or a reading disability. So, I feel like for most college athletes, it's not one of their top concerns because they have so much more to focus on ... if you look at my time, it's sort of like, I swim for four hours a day, I go to school for six hours a day, I study for another like eight hours a day. And then like, you know, there's not a lot of time to address that part of me. And I feel like most athletes might feel the same way... So, it's sort of hard to find time to address those things that are abnormal or something that not everyone faces

As Emily stated there is no time to really think about other considerations outside of her athletic and academic demands. However, students also agreed that there are limited resources or opportunities to address their other identities, especially relating to disability. 
When examining what peer interaction may look like, students suggested different perspectives. Jamie stated she would like to see groups that have a "social aspect" to them, normalizing and finding a comfort in the idea that other college athletes also have ADHD or a learning disability. Having a group to talk about their experience is viewed as a positive, because Jamie only had adults telling her the process of seeking accommodations, which lead her to feeling alone, and isolated thinking she was the "only one having to do it". She said she was confused throughout the process, and she was the only one on her team that had to follow the process.

Student stated that group interactions can be intimidating and Alex pointed out that high profile students such as a head quarterback on the football team, if invited to a group for students with ADHD or learning disabilities may not be as comfortable showing up, as people would talk and gossip. She stated, “I don't know if people would be okay with self-identifying...like this is a meeting and everyone in here has a learning disability". She said she would feel comfortable with it, but not everyone is as comfortable with the idea of self-disclosure. Emily validated Alex's perspective by stating, “I don't think most people would go to a group... it's like you want to support the people but you don't want to like make them feel different, so there is that fine barrier". One thing Alex, Emily, Earl, and Don all mentioned was a peer mentor or a buddy system that incorporated a similar consideration of navigating the universities policies and procedures with a disability. Don said if he had an upperclassman who took the time to speak to him about their experiences, he would listen to them, and it would be more relatable than much older, unrelatable professionals guiding him through his collegiate experience.

Another issue is the transition from high school to college and the lack of outreach that occurs between the institution and the admitted disabled college athletes. The first step to changing campus culture is as Emily suggested, talking about it, and not feeling judged by everyone else, or as Alex summarized, normalizing disability in conversation. After including more conversations about disability into the overall campus culture, it is important to examine 
what type of support is missing for this population of students. Jamie and Alex both agreed that an email providing outreach would have been beneficial in their transition from high school to college.

Jamie wanted the information to be accessible so, 'you don't have to go like searching for it". She suggested a webpage that shows college athletes with disabilities how to navigate the accommodation process at their institution. She also suggested having coaches reach out over the summer to offer information about disability services for all students. Both Alex, Earl, and Don suggested having a professional advocate specifically for collegiate athletes which would be beneficial. Don and Earl agreed that colleges can be more proactive in their outreach by assigning a professional advocate once they are admitted making contact via phone and email, so students do not have to search for help. Don and Earl also wanted more educationally qualified individuals to help provide support towards academic success. Earl stated that he felt a program that focused on the first six weeks of college focusing on topics such as organization and transitional support would be helpful.

It wouldn't hurt having like an actual professional who knows about disability and knows like this person gets sidetrack, this might be too much of an assignment right here, let me break it down for them, and just like showing them the ropes for like six weeks so they can like learn it

Students want to learn, and feel included in their campus community, but they need more targeted support services from their institutions to make their experience smoother and more relatable.

Rapport building among college athletes and their athletic academic support staff is important as students are spending large amount of time with their academic counselors and tutors throughout the semester. More services need to be offered, allowing students to explore aspects of their identity. It is important for students to feel a sense of community with other disabled college athletes and be reminded they are not alone or isolated throughout the process. Additionally, university administrators should evaluate their outreach to college athletes with disabilities. 


\section{Mission \& Value Statements}

Every institution has a different mission, vision, and value statement that help guide institutional employees' actions. Without giving away specific institutional information to protect the identities of each student, a blind review was conducted of each participant's institutional mission and value statements. Each institution provided different language and words such as "inclusion", "diversity", "personal growth", "student development", "community", and "equity". Although words sound great on paper, when this language is not met with action, individuals can feel excluded, ignored, or forgotten.

Each participant shared different experiences on their college campus where they felt unheard, excluded, belittled, or appeared "different" than others through interactions with their peers, faculty, or athletic staff. If the mission and values of each institution are to strive to create environments of inclusion, or personal growth and development, then institutions pose a gap between words and actions, specifically within this population of collegiate athletes with ADHD or learning disabilities.

As expressed in the introduction, many individuals are uncomfortable with having conversations about disability or individual impairments. It is often a "forgotten" identity in diversity statements and educational opportunities. Creating change means becoming uncomfortable through cognitive dissonance and providing learning opportunities in and outside of the classroom. Colleges and universities across the country offer diversity, and inclusion centers focused on BIPOC (Black, Indigenous, and People of Color) communities, or LGBTQ+ support services. These departments not only provide resources and professionals who help towards identity development and community 
education but also allow for connections and a sense of community or safety within the campus culture. But where do students who are disabled go to build community?

The sole purpose of many disability support services is to ensure that the institution is meeting the legal obligations of the ADA and are in compliance with offering appropriate accommodations for registered students. Many disability support services are also expected to take on educating the entire campus community but are understaffed. However, I question which office and professional personnel are responsible for helping disabled students learn about their own identity development and support diverse training with others in the community. We have student development theories based on race, gender, sexual orientation, but why has it taken decades for any attention to be focused on disability identity formation and included within student affairs and higher education curricula and research? Higher education needs to improve and reflect on their actions to ensure their words meet their students' perceived experiences.

Below are two different word clouds (see Figure 4) that help examine the differences between university mission and value statements in comparison with words from participants transcripts and what students stated they wanted "more" from their institution. The images in Figure 4 show large gaps between the values college documents profess within their campus culture and overall local community. However, students shared experiences where they wanted "more" of these same or similar services, opportunities, and values. 


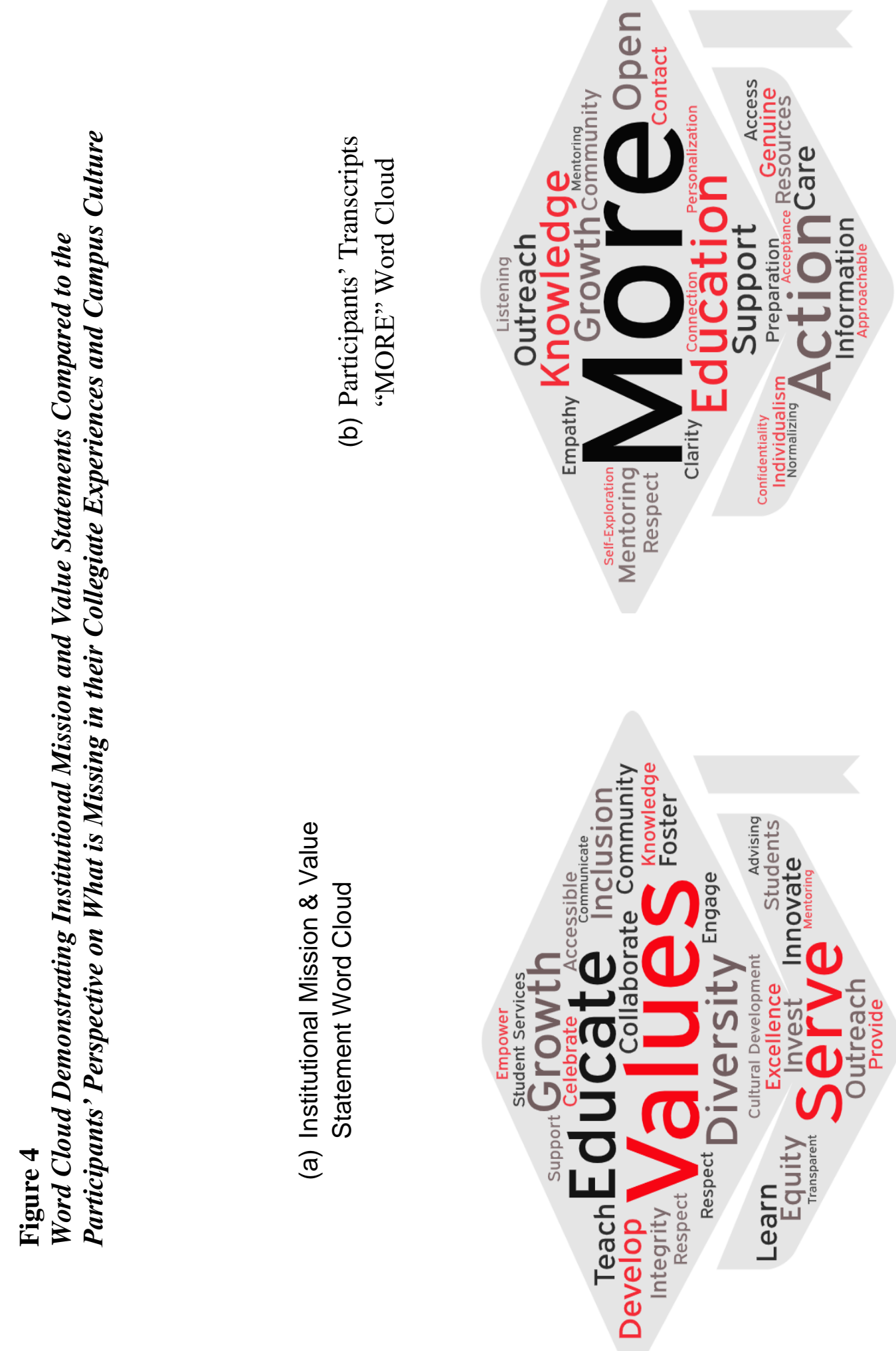




\section{Conclusion}

Each student provides a unique educational experience and journey which lead to their current perspective relating to their disability disclosure, self-advocacy, and academic support and success. The first section of this chapter was intended to provide an insight into each student's perspective and summarize the individual interviews, highlighting key information. The second section aimed to find the common themes that were streamed throughout the data. Students appear to consider the reactions and perceptions of others in their decision-making process when deciding to self-disclose their disability. There interactions with peers and athletic staff emphasized and provided examples of their thought process. Additionally, students are vocal and persistent, speaking up for their needs. Having a basic education and knowledge is essential to being vocal, and the influence of personality and upbringing on their confidence may influence the amount of communication an individual commits to a specific cause. Finally, building rapport and relationships influences the perceptions of support students feel towards their academic success. Many of the participants agreed their athletic academic counselors were supportive and understanding, as they had built a sense of good rapport and meaningful relationships with them throughout their collegiate experience. Furthermore, students provided various ways targeted support services and programs could be implemented into their campus culture, for disabled college athletes.

The next chapter will focus on connecting previous literature and research to the themes identified above, by addressing the original research questions. Recommendations will be provided from various viewpoints, sharing different ways in which improvements can be implemented and enhanced within the field of collegiate athletics, and academia. Finally, the various limitations and future research considerations will be addressed. 


\section{CHAPTER 5}

\section{DISCUSSION \& RECOMMENDATIONS}

The purpose of this research was to examine the lived experiences of college athletes with learning disabilities and/or ADHD surrounding disability disclosure, advocacy, and overall academic support at NCAA FBS D1 institutions. This chapter will examine the common themes and how they inform the research questions guiding this study. Similarities and potential discrepancies between the findings and previous published literature will be revealed. Recommendations, limitations, and future research suggestions will also be discussed.

\section{Discussion}

The purpose of this section is to outline the themes that emerged throughout the data, connecting the findings back to the central research question, and examining how they align with previous literature and research. This section will walk through each theme and subtheme providing connections between all three aspects from the research question, finding, and literature review. As previous stated, only $1 \%$ of all published scholarly work in top-tier higher education journals involved students with disabilities (Pena, 2014). It is difficult to link these findings to the literature, as limited publications have barely skimmed the surface of examining the experiences and lack voice for this specific student populations (disabled, college athlete). 


\section{Decision Making Process \& Choices}

College is a place to learn content knowledge, challenge beliefs, gain new perspectives, and develop skills and independence. Students are often transitioning from a dependent environment, living with parental or legal guardians, to an autonomous environment. Although all participants in the study stated they felt comfortable making their own choices and decisions in their collegiate experience, Alex stated she felt pressure to ensure she verifies her choices through several adults in athletics to ensure she makes the right choice, and Don explained that academically his opinions are not validated or considered.

The descriptions Alex and Don provide may be linked to the pressures academic support staff are under to maintain students NCAA academic eligibility (Meabon \& Schuh, 1994). Therefore, Alex feels the consistent need to ensure she has cleared any final decisions she makes by all potential stakeholders. There is also the underlying pressure to ensure any decisions made reflects proper representation of their team, and institution (Hill, 2001). In addition, Don's experience of feeling a lack of control or input into his academic schedule or course load in conversations with his athletic academic counselor could be linked to the balancing act athletic academic counselors consider to ensure their athletes are academically eligible to continue their athletic participation.

\section{Reactions \& Perceptions of Disclosure}

Students shared a commonality that the potential reactions and perceptions of other dictate their decisions to disclose their disability. Disclosing a disability to another individual can be a vulnerable experience, which comes with potential benefits and disadvantages (Gerber \& Price, 2003; Hughs \& Graham, 1994; Petronio, 2002; Barnard- 
Brak, Lechtenberger, \& Lan 2010). One benefit described by a Jamie, Alex, and Emily include the approval of academic accommodations. However, disclosing a disability can cause several potential uncomfortable questions to arise (Marshak, Van Wieren, Farrell, Swiss, \& Dugan, 2010) Don, Earl, Alex, and Jamie all expressed times they felt treated like a number rather than an individual when disclosing their disability with a faculty member. This same concept aligns with findings that disability support personnel are known to group students as a number when they offer accommodations based on a diagnosis or label rather than an individual's specific academic needs (Brinckerhoff, Shaw, \& McGuire, 1992; Cawthorn \& Cole, 2010).

Petronio and colleagues (1984) provided four factors that influence a student's decision to self-disclose. These included the relationship with the individual, the context of the situation, the individual's potential response and the individuals own beliefs about their disability. Students in this study stated that the reactions and perceptions of others were consistent thoughts that potentially hindered or persuaded their decision to disclose their disability to others within their collegiate experience. Similar to Megivern, Pellerito, and Mowbray (2003) study on psychiatric disabilities, students want to feel a sense of belonging on their college campus, and their research found that one third of participants struggled to feel a social connection which lead to feelings of isolation, stigma or discrimination. Sense of belonging plays into two major aspects of college athletes' lives, their peer interactions and athletic involvement.

\section{Interactions with Peers}

Peer interactions are critical for helping students get acclimated to campus and feel a sense of belonging. When peers uphold negative stereotypes of students who 
participate in intercollegiate athletics, it can be detrimental to the academic success and personal beliefs one may hold about their own capabilities. Stereotypes linked to an athletic identity are filled with words like "dumb", "lazy", or lack of motivation and intellectual ability (Ferrante, Etzel, \& Lantz, 1991; Watson, 2006). All participants in this study shared an experience of a time when their peers assumed a negative stereotype about their identity and abilities. Earl and Don, both stated they have been called "weird" or "strange" by their peers for their ADHD and how the symptoms manifest as "different" to what Western society deems normal. A research study conducted by Smith in 1999, on college athletes with ADHD found similar comparisons, where students explained negative messages they received from individuals which led to feeling abnormal due to their ADHD, which caused a sense of devalue and perpetuated this concept that individuals with ADHD were abnormal.

Emily shared a time where she disclosed her dyslexia to her teammates and peers and explained the interaction was "awkward" and made her feel uncomfortable. She is often balancing this identity of being smart with the assumptions that an athlete with a learning disability cannot be perceived as smart, because as she explained, having a learning disability is "counterintuitive" to the idea of intellectual intelligence. Similar research by Olney and Kim, (2001), aligns with these same findings which showed nondisabled students have little exposure to disabled individuals, which perpetuates misconceptions. These misconceptions are internalized by students with learning impairments.

The NCAA has published data on the perception's athletes have about interactions with their peers in academic settings. This study found that $44 \%$ of male 
NCAA D1 college athletes and 29\% of female NCAA D1 athletes report feeling that other students assume they are not good enough academically because they participate in college athletics (NCAA 2017b). These perceptions rang true throughout this phenomenological study, for all students. The findings could be even more evident because there are multiple layers to each participants identity which are linked back to negative stereotypes and assumptions. Students wanted to be viewed by their peers as equal pertaining to their academic success and the role they play in the classroom.

\section{Interactions with Athletic Staff}

Students spend a large amount of time with their coaches and athletic staff. The NCAA allows DI athletes to only engage in 20 hours of athletic practice a week, however coaches are known to expect more time (Benford, 2007; Huml, Hancock, \& Bergman, 2014). Don mentioned in his interview how athletic programs and coaches bypass the NCAA bylaw by creating "optional" athletic practices, but there is an underlying assumption that these are mandatory.

Optional turns into noptional, pretty much all the time because...if you don't follow the rules and you kind of do your optional thing, then you will be more in a situation where you and everyone knows that your coaches are going to look at you in a different... I think it's all about the ignorance you can act like it's optional, but I think even the coaches know it's not

As described above, coaches and athletes are spending more than 20 hours a week together, which demonstrates the amount of influence a coach has on their athlete's holistic development and success.

As seen throughout the data four of the five participants had created close relationships with their coach, stating that they have already disclosed their disability or would feel comfortable doing so, if needed. Whereas Don felt their coach never took the 
time to get to know him as an individual once he was recruited and signed to the team. One reasoning behind this lack of holistic development and individualism could be due to the lack of focus on development and the pressure and expectation to win athletic competitions (Naylor, 2007).

Fry (2010) suggests that coaches should take the time to get to know their athletes and create a team culture that is welcoming and acknowledges their athlete's presence. In addition to supporting their athlete's holistic development, many coaches at NCAA D1 institutions are provided large financial bonuses each year if their team meets specific academic eligibility requirements linked to GPA and APR (Wilson, 2017). Coaches play an active role in the message's students receive about the importance of their academics (Bell, 2009). There appears to be a higher standard and overall environment of academic success for female sports, compared to male sports. Emily, Alex, and Jamie each shared different experience that highlighted their coach's response towards their academic endeavors. Whereas Earl stated the coaching staff and players care more about the completion of work rather than grades, and Don stated he felt his coach only cared about their teams grades for the monetary bonus, rather than the individual success and development of the players.

The decision to disclose a learning disability or ADHD to a coach was based on the relationship between the coach and athlete, and if it was necessary crucial information for a coach to be made aware of the impairment. This stems back to the perceptions and reactions students have about their relationship with their coach which guides their decision on disability disclosure. If a student does not feel supported by their coach, they 
will not share information about themselves, such as a disability in fear of being labeled, stereotyped, or perceived as incapable within their athletic performance.

When a student opts into taking medication for their ADHD, the NCAA must be notified under the education-impacting disability process (NCAA, 2019b). Students must disclose their diagnosis to their team doctor, trainers, and compliance office, if they decide to continue medication throughout their athletic participation while in college. Alex and Don were the only two students who are prescribed medication for their ADHD and both provided times where their coach or other athletic staff member mentioned their medication in front of their teammates. Both agreed that sometimes their confidentiality and rights to privacy around their medication is not a top priority.

\section{Being Vocal and Persistent}

One major theme throughout this study was the need to be vocal and persistent to advocate for ones needs or the needs of others. In order to consistently vocalize their needs, participants felt a desire to be competent in their knowledge and education on the topic. In addition, having a sense of self-confidence within the context of the situation to self-advocate was critical. Confidence appeared to stem from either personality or a student's childhood and parental figures throughout their upbringing,

With a lack of literature on self-advocacy within intercollegiate athletics, the closest body of literature where connections can be drawn, derives from help seeking skills around mental health. Lund (2019) concluded that college athletes with ADHD were less likely to seek mental health support or help for a mental health concern, in comparison to non-athlete peers. Reardon and Factor (2010) found similar results stating 
that college athletes experience barriers and stigma related to addressing mental health concerns.

Gender differences also exist, as males are less likely to seek support than females due to societal stigmatization (Addis \& Mahalik, 2003; Mahalik, Good, \& EnglarCarlson, 2003; Steinfeldt, Steinfeldt, England, \& Speight, 2009). Asking for help could also be linked to masculinity threat to some capacity. Ultimately, Earl was less likely to speak up and ask for help unless it was going to cause others to perceive him in a negative light during tutoring sessions, and Don felt ignored and stopped advocating for his needs as he often felt unheard. All three female participants use accommodations regularly and some are still learning how to be vocal and persistent, whereas Alex is extremely confident and persistent which is evident in her examples and narrative experience. This could also be due the fact Jamie and Emily were finishing their first year at the time of their interview, and Alex was in her final semester of undergraduate studies. Additionally, Alex has more knowledge and education about her disability which allows her to have more confidence to practice using self-advocacy skills.

The concept of persistence can also be tied back to stereotypes and negative labels. Stowkowski (2013) found that college athletes with learning disabilities and/or ADHD were aware of labels and stereotypes but used the misconceptions as motivation to challenge other individuals' perspectives. Students in this study used the possible misconception of labels to remain persistent and vocal throughout their self-advocacy. Each participant demonstrated resilience which helps the momentum of persistence. 


\section{Knowledge and Education}

In order to be vocal and persistent, it was evident that knowledge and education are essential. Communication of needs is unattainable without having proper language and the comfort to speak about one's own impairment and how it affects their daily life, in and outside of the classroom (Test, Fowler, Wood, Brewer \& Eddy, 2005). All students agreed that knowledge and education is essential to advocate for others, and they would not feel comfortable speaking up if they did not have the proper language or were uneducated on the topic. The same applies to self-advocacy, in order to communicate one's personal needs and be persistent, one must process and comprehend their learning challenges or find the language, strategies, and techniques that will help them be vocal about their needs (Hadley, 2011; Test, Fowler, Wood, Brewer \& Eddy, 2005).

Similar to the claims in other bodies of literature, there is a lack of emphasis within education, on advocacy skill development and the transition from high school to college (Cawthon \& Cole, 2010; Brinckerhoff, Shaw, \& McGuire, 1992; Vaccara, Kimball, \& Wells, 2015). Jamie and Don stated they vaguely remember a psychiatrist or clinical psychologist sitting down and reviewing their psychoeducational report once testing was complete and a diagnosis was prescribed. However, Jamie, Alex, Don, and Earl stated they used the internet to research more about their disability to find language and learn about their impairments.

Without the basic knowledge or language to express how their impairment effects their environment, students are limited to their self-advocacy and persistence. Additionally, all five participants had no working knowledge or educational background on any laws that influence their rights as an individual with a disability. Test and 
colleagues (2005) state that knowledge of laws and services are critical to an individual's advocacy skill development. Council III and Gardner III (2018) explain that students who lack knowledge of their rights may be less likely to advocate for their needs in fear of losing their scholarship and other negatively impacting consequence related to athletic participation. Lack of knowledge or language about an impairment can lead to students who shy away from vocalizing their needs in academic environments (Barnard-Brak, Sulak, Tate, \& Lechtenberger, 2010; Smart, 2001).These alarming results emphasize the need for more education and advocacy skill development, taking an individualized approach, to guiding students towards finding their voice and confidence to stay persistent in their efforts.

\section{Influence of Personality and Upbringing on Confidence}

The second subtheme that emerged when analyzing the theme of being vocal and persistent which was student's confidence, rooted in experiences from their childhood and upbringing, their personality, or a combination. There is limited literature or research on how the formation of self-advocacy skills are learned, but the influence of family, peers and educators are known as important factors (Daly-Cano, Vaccaro, \& Newman, 2015). One study which can be strongly connected to the findings in this study derives from the professional field of nursing. Foley, Minick and Kee (2002) demonstrated the nurses learn to advocate for their patients by observing others and explained that some individuals felt like it was a part of "who I am". In addition, putting these skills into practice-built confidence which reiterated the learning process.

Jamie, Alex, and Emily spoke about their parental figures who they either observed modeling the action of advocacy on their behalf or played an integral role in 
their current experiences by supporting their advocacy and choices to advocate while in college. Don suggested his coaches growing up were viewed as parental role models and encouraged him to speak up for his needs.

Although parental figures played a major role in the development and confidence of advocacy skills, personality also seemed to be a factor for Earl and Don. This "who I am" concept that is grounded in research (Foley, Minick, \& Kee, 2002) is similar to the way personality was described by Earl and Don. Earl and Don both stated that their personality allows them to advocate as they can make others feel comfortable when conversating by using their humor. They are not afraid to be seen as different, which provides them the confidence to speak their mind and not shy away from advocating for their needs.

\section{Building Rapport and Relationships Influence Perception of Support}

As discussed earlier, the relationship between coaches and athletes is essential as trust, and respect allows for connections grounded in safe environments that inform students decision to feel comfortable enough to disclose their disability without judgement. Faculty appeared to be a common denominator which helped validate the importance of rapport building and the perceptions of academic support. Students who utilize and connect with their disability and tutoring services, find social groups within the campus community, and build relationships with faculty, which appears to align with more success in their educational endeavors (Adams \& Proctor, 2010; Getzel \& Thoma, 2008; Daly-Cano, Vaccaro, \& Newman, 2015).

Alex, Emily, and Jamie all described times they methodically contemplated the pros and cons of disclosing their disability to a faculty member due to potential 
stereotypes or risk of being asked in-depth personal questions. This discomfort was met with the competing thought that their request for accommodations could offset potential barriers within the curriculum such as timed test and exams which eases some anxiety and helps provide an equitable academic experience they need and deserve.

Don, Alex, and Jamie also spoke about times in which they felt faculty members were dismissive throughout the disability disclosure process. Research demonstrates that faculty members perceive their engagement with disabled students as approachable and accommodating (Cawthon \& Cole, 2010; Debrand \& Salzber, 2005; Murray, Flannery \& Wren, 2008). Despite this believed assumption, research demonstrates similar findings as Don, Alex and Jamie, where students felt dismissed or unwelcomed within the academic environment, lacking a sense of belonging within the classroom (Kurth \& Mellard, 2002; Hadley, 2011)

The relationship and rapport faculty build with their students, aids in creating a comfortable environment for students to disclose a disability. Faculty can either be dismissive or overly engaging, which can cause the student to feel uncomfortable. As Alex stated, more education is needed for faculty to properly engage in these conversations. Students want their faculty members to genuinely care, without asking too many in-depth questions as some faculty are unsure on the most appropriate way to approach the conversation.

\section{Athletic Academic Support Staff}

Athletic academic support services are implemented for college athletes to help support retention and guidance through academic, social-emotional, and career endeavors towards the goal of graduation (Thompson, Petronio, \& Braithwaite, 2012). All five 
participants mentioned their athletic academic counselor playing a role within their academic journey. Most participants viewed their athletic academic counselor as a positive role model, who they felt comfortable sharing information with, relating to their disability. Jamie, Alex, and Emily mentioned they attend frequent appointments with their athletic academic counselors their first year in college. These weekly meetings allowed for rapport, trust, and genuine care to be established. Earl explained he talks with his academic advisor multiple times a week, even in his fifth year of school. Don however expressed negative interactions with his athletic academic counselor which lead to his disbelief in their overall support for his academic success. Don's experience reiterates Huml, Hancock, and Bengers (2014) research which found college athletes felt a lack of support from their athletic academic counselors in connection with their academic and overall career endeavors.

As previously illustrated specific services such as the utilization of tutoring is beneficial for academic success (Adams \& Proctor, 2010; Daly-Cano, Vaccaro, \& Newman, 2015) and mandated by the NCAA (Abell, 2000; Carodin, Almond, \& Ratto, 2001; Meyer, 2005). All students mentioned tutoring in some capacity throughout their interviews. Jamie and Alex mentioned how tutoring services have assisted in their academic success. Earl talked about how he often tries to use tutoring as a challenge, motivating him to do his work independently, so he does not need to sit with someone at a scheduled time to complete his work. He feels comfortable enough to disclose his ADHD with tutors because he often struggles with attention during sessions. Don provided mixed perceptions on tutors, stating that it depends on how well the tutor can reteach the content material. 
Building rapport and having a genuine connection with athletic academic support staff such as tutors and athletic academic counselors helps cultivate a culture of acceptance and academic support. Ridpath (2014) reiterates that athletic academic support staff are vital in the process of encouraging students with disabilities to seek disability support services on campus. In addition, it is understood that athletic academic support staff are critical in help students develop the knowledge and skills to advocate (Ridpath, 2014). It is important to consider if athletic academic counselors are hindering or assisting in the development of their disabled students advocacy skills as Council III and Gardner III (2018) explain that athletes may perceive their academic support staff to be their advocates instead of taking ownership and practicing the required skills.

Finally, there is a limited amount of research on learning specialists and the role they play in disabled college athletes' lives (Steinberg, et al., 2018; Weiss, 2011). Learning specialist were mentioned by Alex and Don with different viewpoints. Alex mentioned that she finds the learning specialist offices to be welcoming and professionals have helped her once to organize her coursework and physical notes and paperwork her sophomore year. Don mentioned that he felt his learning specialist was helpful the first few minutes until they prescribed a "group" approach to working with Don's ADHD, instead of getting to know Don as an individual. Surprisingly, learning specialists did not appear as a major theme, as many students did not interact with learning specialists on a consistent basis. This could be related to each student's personal advocacy skills and their ability to succeed academically, however learning specialists should be helping students transition beyond academic needs, assisting students build their advocacy skill 
development and deepen their knowledge and education of their own strengths and challenges in academic settings.

\section{Targeted Support Services and Programs}

A few students stated that they felt as though their disability identity is ignored within their campus culture. Two main ideas emerged from the data which included peer support or mentoring and transitional services or college outreach. Support programs when implemented through consistent assessment and evaluation, help students gain knowledge, develop skills, and guide students towards retention and graduation.

Students mentioned wanting to feel connected to peers through either an upperclassman with similar experiences and identities, or a mentor program. This concept is suggested by Council III and Gardner III (2018) as an excellent way for student to build leadership roles and allow opportunities for students to be change agents within the campus culture. Mentoring peer to peer interactions allows for continuous self-advocacy and perpetuates a culture of acceptance (Council III \& Gardner III, 2018). Furthermore, this concept is reiterated by other research that demonstrates peer support can help incoming student navigate disability support services processes and role model selfadvocacy skills (Dowrick, Anderson, Heyer, \& Acosta, 2005). Don mentioned that he was told by older professionals how to navigate the process of testing and seeking accommodations and the information would have been more receptive if it came from a peer who was also an athlete. Jamie said she felt isolated as she thought she was the only one seeking support.

When transitioning from high school to college, students often struggle due to their athletic obligations (Lally \& Kerr, 2005), and new academic demands (Hodes, 
James, Martin \& Milliner, 2015). Students suggest support services for college athletes with disabilities that begin when the student is admitted into college. Jamie suggested this responsibility fall on the coach or an easily accessible website that outlines the process to request accommodations specific to college athletes. Alex, Don, and Earl all suggested a professional advocate who begins outreach during the admissions process and serves as a resource between athletics and academic campus services. Don suggested continuous outreach via phone or video chat throughout the summer would help build a relationship between student and the advocate. Earl suggested a professional that would provide support the first six weeks of college and is educated in learning challenges for those with learning impairments. Students felt colleges could do more to foster an environment of awareness, acceptance, and overall support for a hidden population of students on college campuses.

\section{Recommendations}

There are many different aspects that individual professionals and institutional systems can consider creating change from the findings provided in this research study, either from the collective voice, or individual experiences. The following recommendations address suggestions that disability support services, faculty and staff, higher education administration, and the NCAA and policy which should consider creating environments of inclusion. The final section will make recommendations for students. These recommendations are not an exhaustive list but provide some guidelines and insights into how improvement around inclusion can begin at various levels within higher education. 


\section{Disability Support Services}

When addressing disability support services, it is essential that departments are practicing what they preach. Out of the three students who opted into utilizing disability support services, one student at a non-Power 5 institution stated that the process to request accommodations and provide letters to their faculty were inconvenient, as everything was still being processed on paper rather than using technological advances. Technology can provide more opportunities and accessibility for students with varying impairments. It is recommended that disability support services evaluate their numerous documentation processes and determine if they can utilize technology to allow students a smoother and easier accessible format, to a process that already has several hurdles and barriers to access. Allowing processes to take multiple formats (i.e., paper base and via online) encourages an environment that is accessible for all disabled students. Disability support services should role model and practice what they preach, inclusivity and accessibility.

Another consideration which falls under disability support services but is a larger institutional concern, are the environments and physical spaces allotted for students to take tests when extra time, or reduced distraction accommodations are utilized. Two students in the study who currently use this accommodation described the reduced distraction aspect to benefit their overall test taking experience, however both students stated concerns about the location, or overall physical environment of the space. Jamie mentioned that her testing center is far away from any parking structure, which is inconvenient and causes her to need to preplan and factor in walking time and consider parking when she opts to take her exams at the testing center on campus. Additionally, 
Alex mentioned that her testing center has poor lighting, and at times can be louder than the classroom she would be taking the test in if she did not opt into the reduced distraction accommodation. Many times when we think of "building access" we think about physically accessing a building for those with physical disabilities, but administrators neglect to think about the location of the building, or interior of the buildings and how lighting, noise and other sensory items could affect the test taking environment. Testing centers and disability support services should be located in accessible locations and offer an environment that is conducive to academic success.

All students agreed that knowledge, language, and education is essential to feel comfortable taking a stand to advocate for their own needs, and others. Students can benefit from a college professional sitting down and talking through psychoeducational evaluation, strengths, and challenges to learn not only how their disability affects their learning but also find ways they feel comfortable communicating their needs with new language. In addition, it is important for students to understand what accommodations they can receive and why they are receiving those specific selected options. Two students mentioned that there were other accommodations that could be beneficial but were uncertain why they were not offered. Viewing the student as an individual is critical to their advocacy development, rather than prescribing accommodations based off what is typical for a group of students with ADHD or a specific learning disability to receive.

The final improvement this study focuses on when examining disability support services is the lack of additional support beyond providing accommodation letters and a quiet space to take tests or exams. Alex stated she was provided an accommodation to use a ScribePen, but she was left feeling overwhelmed and was unsure how the 
accommodation could assist her note taking process. Emily stated that she felt on her own when learning how to navigate technology pertaining to text-to-speech or audio readers on her computer. It is fantastic that individuals are provided such great accommodations, but if students do not have the knowledge or education on how to operate these specific technological advances, they are useless.

\section{Faculty and Staff}

When considering or thinking through ways faculty and staff can improve their support, there are two main concepts that arise. The first concept that will be discussed deals with education, training, and privacy. The second concept will focus on universal design, and how it can be implemented into the classroom and overall campus community.

The privacy issue surrounding HIPPA and the ignorance on behalf of the athletic coaching staff, and trainers or physical therapists is alarming. Two students who participated in this study take medication for their ADHD. If a student opts into taking any medication, the NCAA needs to be notified and approve the medication and dosage. Taking medication is a private matter that should be kept confidential amongst those who truly need to know. The privacy of athletes should be considered in all situations. The best way to address the issue of medication or any medical information would be privately, in a one-on-one setting. Coaching staff and athletic support staff should also go through yearly trainings on how to navigate conversations surrounding students personal and medical records.

Education is important for students with disabilities to have conversations with faculty and staff that feel safe and free from judgement. The findings indicated that there 
is room for all faculty and staff from all departments to improve their education and knowledge. Simply placing a paragraph in a course's syllabi and reviewing it on the first day of classes is not enough. Faculty and teaching assistants (TA) should attend more trainings and educate themselves on appropriate language and how to navigate the accommodations process at their institution. One suggestion is normalizing conversations surrounding disability and ensure these voices are being acknowledged in public spaces, where they matter most. In addition to open communication, a training that provides faculty and staff with a symbol that can be placed outside of their office space and department may begin to allow visibility and a sense of acknowledgement and comfort, so students know who they can speak to about their disability, and which faculty and staff have been through the training. One student did state that faculty have the best intentions, but they do not always know the most appropriate course of action or word choices to use in conversations. A workshop focusing on how faculty can hold conversations with students throughout the disability disclosure process would be beneficial.

One thing that was evident was the critical role athletic academic counselors play in the overall academic success of college athletes. Most students did feel extremely supported by their athletic academic counselor, however, athletic academic counselors are not usually trained on how to approach conversations around disability and typically resort to referring a college athlete to a learning specialist or to disability support services. Although these are important steps to take, it is also essential that athletic academic counselors are taking the time to educate themselves on different disabilities, and how these disabilities can affect a student's overall learning and academic experience. Another suggestion is implementing more hybrid roles to help college 
athletes with learning disabilities learn from professionals who are trained to support learning challenges as a learning specialist, and support NCAA athletic academic eligibility as an athletic academic counselor. Hybrid positions allow for students to connect with professionals who help towards development and creating spaces that consider a student's holistic academic success.

One subtheme that was evident throughout the research was the importance of knowledge and education on the ability to advocate. Although it is recommended that personnel from disability support services engage in these conversations, it is evident that many services that support the disabled community on college campuses are understaffed and underfunded. Many athletic academic support centers hire learning specialists who are not educated or equipped with the skills and knowledge to hold in-depth discussions with their college athletes interpreting what their personalized psychoeducational assessments indicate about their learning strengths and challenges. Hiring individuals with a background in reading psychoeducational evaluations, learning strategies, adaptive technology, and disability law will allow for professionals to begin holding conversations and helping students develop the language and education they need to not only be successful as a learner throughout their collegiate tenure, but also understand and build knowledge to express and communicate their needs in the workforce.

Beyond education and knowledge, it is important for action to be implemented to create change. Universal design is a tool that can be used throughout academic curriculum and considered when planning the use of materials, technology, and assessments. The purpose of universal design is to ensure inclusion, and flexible support. Faculty should consider some of the most common accommodation requests they receive 
and create new innovate ways to implement those requests into their curricular. For example, extended time on assessments such a quizzes, tests, and exams are accommodations frequently approved for a variety of impairments. Instead of forcing students to come forward to request this modification, professors can already remove timed assessments. Universal design benefits all students, and faculty should begin to consider how they can implement some of these practices into their teaching styles. This takes reflection and consideration on analyzing how barriers can be removed and how removal will allow a more inclusive educational experience for all students, not just students in the disabled community.

Another consideration is to begin incorporating more disabled theories and examples of disability into the curriculum. Disability is often ignored in the learning environment, and there are many opportunities to incorporate exceptional and disabled identity into the academic curriculum. Faculty and staff should also consider being more inclusive by ensuring their PowerPoint presentations are accessible, making their reading materials accessible for all students who may use a screen reader or assistive technology, and modeling some assistive technology in their classroom. Assistive technology may be created to assist a student with a disability, but it is not limited to just the disabled community.

\section{Administration \& Organization}

Administrators who have influence and power over the holistic operations and organizational structure of institutions within higher education and athletic departments should consider implementing several programs and services that support disabled college athletes. The first recommendation focuses on campus climate and marketing 
materials. Often, when someone envisions someone with a disability, they picture images of wheelchairs, canes, service animals, or physical attributes, but often time nonapparent and cognitive disabilities are neglected. When considering the way disability is presented, it is important to ensure that students with varying disabilities are visually represented through marketing materials and publications (Huger, 2011).

One theme throughout Don's interview was the concept of feeling more like number rather than an individual in almost all aspects of his collegiate experience from the classroom, to his athletic participation. It is important to consider if disability perspectives are being acknowledged in decisions that affect the entire campus such as building construction, policies and procedures, and organizational issues. Ensuring students play an active role in their institution's decision-making process can help minimize barriers that effect all individuals, but especially those with specific impairments. Inviting students to serve on committees can help ensure accurate representation is implemented and students are provided a voice.

One subtheme highlighted throughout the data was a need for more targeted support services aiming to provide specific assistance for college athletes with a learning disability or ADHD. Students expressed the importance of transitional support and outreach from the university. Students recommended that their athletic departments or academic support offices provide outreach to all students, spreading awareness about the disability support services via email, or having accessible information on the athletic academic support website. Letting all students know what is available is important, as not all students choose to come forward and disclose. Outreach also takes less pressure off the student and allows the institution to be more proactive rather than reactive. It may 
also be suggested that disability support services be renamed "accessibility" services as the name "disability" may hinder students from seeking help and support, and the term accessibility could be more student friendly language.

One specific idea voiced consistently by participants, consisted of the creation of a college athlete advocate position. Students had a wide range of ideas on what the purpose and role of this professional would include. One student suggested that the college athlete advocate focuses on working with students in crisis, helping them through various moments throughout their collegiate career which could include navigating the accommodation process, connecting students with resources on campus when a sexual assault, mental health concern, family emergency or other crisis arises.

The word cloud was one of the most powerful images of how universities are missing the mark on the disabled student experience. In order to create an inclusive environment, there must first be buy in from upper administration who have an understanding of the importance of placing words and values outlined in university mission and value statements into action. One way individuals can check to ensure their words are meeting their actions is by consistently observing and assessing through evaluating their campus climate. The actions of diversity, equity, and inclusion must be felt throughout the entire campus community for values and mission statements to be more than fancy words on paper. Assessments are a great way to gauge if words are meeting up with perceptions at large.

When it comes to budgeting and funding, there are many ways universities can invest more financially into the disabled community, rather than just providing the minimum requirements. The ADA provides guidelines, but the law does not always 
consider student perspectives. For example, the ADA may ensure a space is physically accessible by building a ramp for an individual who uses a wheelchair, but the question is to consider is whether or not that space is welcoming and inclusive beyond the building structure the ADA requires by law. Administration should consider investing in a disability expert or consultant to conduct "accessibility audits" which can be continued year round by an institutional ADA coordinator or maybe hiring a member of disability support services whose position solely focuses on creating inclusive and accessible spaces in and outside of the classroom.

When it comes to testing students who have ADHD or learning disabilities, a psychoeducational evaluation can range between $\$ 2,000$ to $\$ 5,000$ depending on the types of assessments needed, geographical location, and the professional conducting the assessment. In addition, the testing time to conduct a full evaluation can take between two weeks or up to several months. Administrators should consider policies and procedures that allow temporary accommodations for an academic semester, for students to be able to access while they go through the evaluation process. A pre-screening appointment with a member of the disability support staff could allow for further discussion on what these accommodations may entail. Funding and scholarships could also be provided for students who cannot afford this costly testing, which is another barrier to receiving the services a student may require for their overall academic success.

Another consideration administration should consider is the physical organization and where disability support services are housed. Every institution is different and there is no consensus on the best location, however it would be beneficial if administrators and other stakeholders began viewing disability support services beyond just required spaces 
to meet ADA laws and began viewing accessibility centers as a place to build community and connect with other likeminded individuals who hold similar identities. Faculty and staff may also feel excluded from disability support services as a place to connect within a community and only view the services as a place to seek assistance on accessibility and proper ADA documentation. Creating an accessibility cultural center similar to the one at Syracuse University would allow for an inclusive environment similar to the same objectives and goals multicultural, LGBTQ and international centers provide on campus.

When hiring and recruiting faculty, staff, administrators, or professionals who work in disability support services, it is important to be inclusive and ensure disability is represented at all levels throughout the organization. Disability support services should be staffed by qualified, educated, and well-informed individuals who have knowledge on ADA law, but also have the skills to help develop students through counseling and advocacy work. It is important for students on college campuses to see others with disabilities represented in all aspects of their college campus.

\section{NCAA \& Policy}

The NCAA has tremendous room to grow and an opportunity to set the precedence in best practices when it comes to supporting college athletes, and athletic departments. The NCAA D1ctates many rules and regulations, but the organization has rarely touched anything relating to disability and implementation of best practices. First the NCAA should consider investing more money into research that can provide evidence-based practices that can be implemented at any institution across all three divisions. The NCAA should acknowledge students with education-impacting disabilities 
and allow student perspective to be voiced in the creation of bylaws that affect academic progress and standards.

Students with ADHD had mentioned that they were nervous to consider the possibility of medication due to the strict NCAA guidelines. The NCAA should consider student perspectives asking for student who use medication for more information about their usage. Students should never have to feel as though they need to choose between medication or going without because the process is strenuous or there is no room for individualization. Every individual's impairment is unique and should be examined on a case by case basis rather than clumped into one bylaw or expectation on dosages. This is not an area where one policy pertains to all. Students should have the right to medicate their ADHD as they see fit, and there should be room for mistakes as we are all human, mistakes will happen.

Finally, the NCAA has a lot of control and power over what types of trainings and educational opportunities are mandated for coaches, compliance staff, and other athletic department personnel. The NCAA should consider implementing annual trainings and workshops that focus on learning challenges and students with learning impairments. These trainings should focus on HIPPA and FERPA but could also include knowledge and workshops on various learning styles and how this knowledge can be incorporated into their coaching style or interactions with students in various forms. There should also be a culture of acceptance rather than fear of retaliation if a student wants to pursue a formal complaint about a coach or athletic staff member in alleged violation within the compliance office. The NCAA can help support students with varying disabilities voices through their immense power over athletic programs. The NCAA has invested financially 
through money and time on mental health over the past decade but have neglected to invest the same resources into college athletes with EIDs.

\section{Students}

This section is split into two sections, the first aspect will address ways students who do not identified as disabled can promote inclusivity and advocacy on their campus. The second will be examining ways students with disabilities can create change and recommendations for inclusion. It is important to note that we all play a role in creating inclusive environments and solely placing this burden on the student with a disability will not change the system or current operation of society.

As evident in the self-disclosure process, reactions and interactions with peers were fueled with stereotypes and feelings of incapability within academic success. It is encouraged that student organization leaders engage in workshops focusing on inclusive event management and workshop that teach students to consider varying perspectives when it comes to universal design. When planning an event, all aspects from the physical space to the welcoming atmosphere should be consider. Students should be asked to go through training on inclusive language and how to confront peers on non-inclusive language when it comes to disability. Campus wide lectures and programming should target students without disabilities allowing for opportunities to engage in materials, educational trainings, and learn about the disabled community, as many students hold strong stereotypes and misconceptions about disabled individuals.

One thing that was evident throughout the participants narratives was the need for connection, inclusion, and a sense of belonging, within the campus community. For students who have already developed great advocacy skills, it is encouraged that they 
seek out opportunities to get involved on their college campus by asking to serve on different committees, providing feedback openly with others when something is not accessible, and sharing personal thoughts, feelings, and perspectives with institutional leaders who create change.

There is power in numbers and advocating for change is no different. It is encouraged that students empower each other, through support, and mentorship. Creating student lead organizations for disabled students, not only provides a space for community, but for their voices, perspectives, and agenda to be vocal and persistent. Students want more interaction with other athletes who had similar disabilities either through peer mentor programs, or student lead clubs. Students wanted an opportunity to engage with students who have similar challenges and go through similar struggles. Rallying together to advocate for a cause and equal access and educate others within the community is essential. More times than not, students are ashamed of their disabled identity, something that needs to be kept hidden or a secret and it is time to normalize what it means to have a disability.

\section{Limitations}

As with all research studies, there are limitations to consider. In this study there are several limitations pertaining to recruitment and limitations relating to diversity within the population of participants who volunteered. It is important to consider that this research originally set out to recruit participants athletically competing at institutions in the Power 5 conferences, but after considering to expand this requirement to include nonPower 5 conferences, lead to the inclusion of FBS institutions. This decision created a larger gap in comparison as Power 5 schools typically have more funding and resources 
compared to other NCAA D1 schools outside of those conferences. As originally expected, students reported vastly different experience due to their institutional funding and financial revenue. Lack of funding leads to varying experiences which is evident in some of the responses provided by participants, especially those at non-Power 5 institutions. For example, Earl directly mentioned in his interview that if his athletic department were provided with the same funding that Power 5 conferences receive, his school would be able to offer better resources. Jamie did not directly mention finances; however, her disability services department is still operating without technological advances, which could be due to lack of funding and resources.

When addressing the limitations related to recruitment it is important to consider two specific factors, the athletic perspective relating to the NCAA and disability context relating to laws and comfort of professionals. I found that many professionals (academic advisors/counselors or learning specialists) were hesitant to pass along the research opportunity. A few professionals explained via email that the hesitancy derived from the fact that this research provided an optional monetary incentive. The NCAA has strict rules under "extra benefits". Although the NCAA bylaw 16.11.1.6.2 states students may receive benefits for participating in research, either lead by or under the supervision of a faculty member with IRB approval, professionals still wanted to clear the research through their compliance office, which is understandable. However, none of these professionals who shared this concern followed back up with information after the request once it was sent to compliance.

In addition, some professionals expressed concern about FERPA by discussing the research with students they knew who had disabilities. When talking about disabilities 
professionals may feel restricted and safeguard students with disabilities due to the ADA and other federal laws. Another perspective is the fact that some professionals may not have known how to go about discussing the opportunity with students, especially if they do not have language or discuss disability with their student caseload. Some professionals from private institutions shared that they have departmental policies against sharing research outside of the institution to protect their athletes. Although athletic departments are trying to protect their student's athletes, they may be stifling their voices from being heard.

The second largest limitation is the lack of diversity within the participants demographic surrounding race, level in school, and overall ability to advocate and communicate for their needs. Most of the participants described themselves as advocates and felt comfortable speaking up for their needs when it came to their academics. Therefore, this research is missing a large population of students on college campuses who are not registered with their institutions disability support services or do not feel comfortable disclosing their disability as openly as these participants, so the research is limited in its participants views which lean towards having experience and comfort in sharing ones disability in exchange for accommodations.

Four out of the five participants were White and had a documented disability on file with their athletic department or disability support services. One participant who identified as Black, had never been "medically" diagnosed, which provided a completely different perspective. Studying disability is complicated because as explained by Evans and colleagues (2017), there are variations in a student's impairment, choices, and environments. The variation causes rich individual narratives, but cause difficulty to 
streamline common experiences among all participants due to their college campus culture, impairments or abilities, and decision-making processes which lead to their choices around self-disclosure and self-advocacy. There is a lack in diversity, as Black male college athletes' voices are not provided thoroughly throughout this research, and there is limiting gap of the second and third year collegiate experience for college athletes with a disability.

\section{Future Research}

With little knowledge and gaps in the literature surrounding learning disabled college athletes, and after analyzing the findings from this study, there are different realms in which future research can explore. The suggestions below are not an exhaustive list of directions, but rather some ways in which this specific research study can be expanded. The following suggestions examine the research from various perspectives.

This research presented is limited as the students who opted into participate view themselves as advocates and have a wide range of skill development and experience in advocacy and self-disclosing their disability. However, there are many students who are uncomfortable speaking about their disability with others and have not developed the confidence to advocate for their potential needs. One approach to collecting a wider range of responses would entail a quantitative approach, such as offering survey questions, where students may be more inclined to answer questions anonymously.

Most of the participants in this study identified as White. More inclusion and targeted recruitment of students from a variety of ethnic backgrounds would be beneficial and would allow for a greater representation of experiences, culture, and world views. In addition, when going through the data there were some codes and overlapping 
experiences that only pertained to participants with $\mathrm{ADHD}$, and others that only pertained to participants with a learning disability. Although these are often clumped together due to their high incidence rate, it would be helpful to separate the disabilities even further, if possible. For example, students with ADHD have the option to medicate whereas learning disabilities do not require or offer medication to assist with potential challenges. Furthermore, ADHD is viewed by others in our society as more acceptable compared to a learning disability, such as dyslexia. Conducting research solely on one impairment might provide even further insight and direction.

One finding throughout this study examined peer interactions and stereotype threat between college athletes with disabilities and their peers. More research should consider peer interaction and their support or hinderance to the college experience. In addition, more work needs to examine the intersecting identities of college athletes with a learning challenge and take that a step further to explore stereotype threat for men of color. It is known that the majority of Power 5 football and men's basketball rosters are Black men, and it is suggested that a significant amount of this same population receives assistance for learning or ADHD challenges that influence their academic success. Further research needs to allow this specific population to have a voice in the literature so words can be put into action.

All participants at one point or another throughout their interview spoke about their family and how they helped build confidence, provided a model of self-advocacy, or helped shaped their students beliefs and perspectives on what it means to have a disability. When it comes to academic success and perspective on disability, all participants spoke about their parents playing an active role. This included the way Don, 
Jamie, and Alex talked about discussing their disability and academic success and triumphs with their families, to the way Emily and Earl viewed their disability based on their childhood and family's experiences. Emily and Earl both touched on how their families rejected or hesitated to label or view their child as "different" than what society deems "normal". Future research should consider community cultural wealth (Yosso, 2005) more specifically the connection between aspirational or familial capital and how this is connected back to the lives of college athletes with disabilities.

Although students were the focus of this research study, and student voice is extremely valuable, research focusing on professionals in the field is critical, especially focusing on athletic academic counselor and learning specialists. It is also recommended that when institution, department, or personnel implements any targeted support services, data should be collected to help inform best practices through assessment and evaluation. This data can also be published and should be continuously examined, letting both the data provided in numbers and students perspective lead the initiative.

Finally, it is critical for future researchers to consider best practices on how they should go about crafting research that is inclusive to all participants. This begins with doing research "with" rather "on" students with disabilities. In addition, studies with the disabled community should consider allowing participants to play an active role in the research process. Researchers should consider focusing on a specific impairment as students with ADHD and learning disabilities shared vastly different unique experiences such as medication for ADHD, or their confidence in academics related to specific learning impairments. Finally, research and materials need to be provided in accessible 
format, and accessibility should be at the forefront of all recruitment materials, data collection instruments and documentation or forms that will be completed by participants.

\section{Conclusion}

The goals of this research study were to provide student voice and perspective, offer recommendations for professionals and organizations associated with college athletics, while contributing to the research through a social justice perspective. This study aimed to examine the lived experiences of college athletes with learning disabilities and/or ADHD surrounding self-disclosure, advocacy, and academic success. This study provided a narrative and revealed a shared phenomenon amongst participants which demonstrated self-disclosure of a disability considers individuals reactions and perceptions, self-advocacy is accomplished by being vocal and persistent and perceptions of academic support are centered around rapport and relationships. The findings and recommendations of this study should help students feel a sense of community and normalcy within their shared experiences. Practitioners and individuals who have influence of higher education universities or the organizations that dictate policies or procedures should consider how they can become more inclusive in their practices and overall support for college athletes with nonapparent disabilities.

Conducting this research has not only challenged my thinking about how society views disabilities on a larger conceptual level but it has also provided me an opportunity to reconsider how I personally interpret my own impairment within different environments and contexts within higher education. As my research evolved, I too, grew and learned with the process. I am more cognizant and aware of how I can be more inclusive, and previous research, theories, and frameworks have provided great insight 
into how societal "norms" continue to dominate our thinking and actions or lack thereof. I hope research and leaders in higher education continues to make this "invisible" identity more visible, ensuring disabled students have a voice and are considered in all decisions.

The title of this research begins with "The Ball is in Your Court". The reasoning for this title is not only a play on words relating to athletics, but to consider how we all contribute to perpetuated systems held in place that oppress students and individuals with disabilities. We all play a role no matter how little or large in taking action to change the way we think, navigate our world, and ensure that every student is included. This is not an issue that only affects the disabled; inclusion and universal design cannot be achieved without everyone creating change within their own personal life and reflecting on how they view and navigate their own world and how that affects others with varying impairments. Considering personal unconscious bias and taking the time to educate is a starting point, but I think we can all dig deeper to create larger systematic change in our culture. The goal is to provide a space where we can all be provided an equitable experience and not be viewed as "different" or "abnormal" because we have varying abilities and different ways of navigating our world. We should aim to create an inclusive environment where no one feels segregated, excluded, or embarrassed due to their abilities. Individuals, institutional systems, and our society at large have a long way to go to achieve this goal, but it starts with awareness and realizing our individual roles and how we can influence change. So now the ball is in your court... what are you going to do to create non-disabling environments? 


\section{REFERENCES}

Abell, V. L. (2000). 2000-2001 NCAA Division I manual. Indianapolis, IN: The National Collegiate Athletic Association.

Adams, K. S., \& Proctor, B. E. (2010). Adaptation to college for students with and without disabilities: Group differences and predictors. Journal of Postsecondary Education and Disability, 22(3), 166-184.

Adams, W.C. (2015). Conducting semi-structured interviews. In Newcomer, K.E., Hatry, H.P., \& Wholey, J.S (Eds.), Handbook of practical program evaluation, (pp. 492505). Hoboken, NJ: John Wiley \& Sons.

Addis, M. E., \& Mahalik, J. R. (2003). Men, masculinity, and the contexts of help seeking. American Psychologist, 58, 5-14.

American Psychiatric Association. (2013). Diagnostic and statistical manual of mental disorders: DSM-5 (5th ed). Washington, D.C: American Psychiatric Association.

Americans with Disabilities Act of 1990, 42 U.S.C. (1990). Retrieved from http://www.ada.gov/2010_regs.htm.

Assouline, S. G., \& Whiteman, C. S. (2011). Twice-exceptionality: Implications for school psychologists in the post-IDEA 2004 era. Journal of Applied School Psychology, 27(4), 380-402.

Bailey, S. (2017). A Comparison of academic and athletic performance in the NCAA. College Student Journal, 51(2), 173-182.

Baker, K. Q., Boland, K., \& Nowik, C. M. (2012). Survey of faculty and student perceptions of persons with disabilities. Journal of Postsecondary Education and Disability, 25(4), 309-329.

Baldridge, D. C., \& Veiga, J. F. (2001). Toward a greater understanding of the willingness to request an accommodation: Can requesters' beliefs disable the Americans with Disabilities Act? Academy of Management Review, 26(1), 85-99. 
Banks, J., \& Hughes, M. S. (2013). Double consciousness: Postsecondary experiences of African American males with disabilities. Journal of Negro Education, 82(4), 368-381.

Barkley, R. A., Fletcher, K., Fischer, M., \& Smallish, L. (2003). Does the treatment of attention-deficit/hyperactivity disorder with stimulants contribute to drug use/abuse? A 13-year prospective study. Pediatrics, 111, 97-109. 338, b1955.

Barnard, L., \& Lan, W. Y. (2007). Faculty attitudes towards persons with disabilities when controlling for diversity attitudes. International Journal of Diversity in Organisations, Communications, and Nations, 7(1), 1-9.

Barnard-Brak, L., Lectenberger, D., \& Lan, W. Y. (2010). Accommodation strategies of college students with disabilities. The Qualitative Report, 15(2), 411-429.

Barnard-Brak, L., Sulak, T., Tate, A., \& Lechtenberger, D. (2010). Measuring college students' attitudes toward requesting accommodations: A national multiinstitutional study. Assessment for Effective Intervention, 35(3), 141-147.

Barnhill, C. R., \& Turner, B. A. (2013). Broken promises: The effect of psychological contract violation on student-athlete trust and intentions to leave their team. Journal of Intercollegiate Sport, 6, 179-195.

Beamon, K. (2012). “I'ma Baller": Athletic identity foreclosure among AfricanAmerican former student-athletes. Journal of African American Studies, 16(2), 195-208.

Beamon, K. (2014). Racism and stereotyping on campus: Experiences of African American male student-athletes. The Journal of Negro Education, 83(2), 121-134.

Bell, L. F. (2009). Examining academic role-set influence on the student-athlete experience. Journal of Issues in Intercollegiate Athletics, 19(4), 19-41.

Benford, R. D. (2007). The college sports reform movement: Reframing the "edutainment" industry. The Sociological Quarterly, 48(1), 1-28.

Benner, P. (1984). From novice to expert: Excellence \& power in clinical nursing practice. Menlo Park, CA: Addison-Wesley.

Bennett, R. A. III., Hodge, S. R., Graham, D. L., \& Moore, J. L. III. (2015). Black males and intercollegiate athletics: An exploration of problems and solutions (Vol. Diversity in Higher Education (Vol. 16)). Bingley: Emerald Group Publishing.

Benson, M. (1994). Executive summary of reports 91-01 to 91-06 (NCAA research report 91-07). Overland Park, KS: National Collegiate Athletic Association. 
Berger, R. J., \& Lorenz, L. S. (Eds.) (2015). Disability and qualitative inquiry: Methods for rethinking an ableist world. Burlington, VT: Ashgate Publishing Company.

Bernard, H. R. (2002). Research methods in anthropology: Qualitative and quantitative approaches (3rd ed.). Walnut Creek, CA: Alta Mira Press.

Bethel, B., Biffle, E., \& Scragg, B., (2012). Defining the profession: Establishing professional standards for learning specialists. Retrieved from https://www.chronicle.com/blogs/players/files/2012/06/DefiningLS.pdf.

Bowen, W. G., \& Levin, S. A. (2011). Reclaiming the game: College sports and educational values. Chicago, IL: Princeton University Press.

Brauer, M., Judd, C. M., \& Jacquelin, V. (2001). The communication of social stereotypes: The effects of group discussion and information distribution on stereotypic appraisals. Journal of Personality and Social Psychology, 81(3), 463.

Brewer, B. W., Van Raalte, J. L., Petitpas, A. J., Bachman, A. D., \& Weinhold, R. A. (1998). Newspaper portrayals of sport psychology in the United States, 19851993. The Sport Psychologist, 12(1), 89-94.

Brinckerhoff, L. C., Shaw, S. F., \& McGuire, J. M. (1992). Promoting access, accommodations, and independence for college students with learning disabilities. Journal of Learning Disabilities, 25(7), 417-429.

Broughton, E., \& Neyer, M. (2001). Advising and counseling student athletes. New Directions for Student Services, 93, 47-53.

Burgstahler, S. E. (2007). Applications of universal design in education. Seattle: University of Washington.

Burgstahler, S. E. (2008). Universal design of instruction: From principles to practice. In S. E. Burgstahler \& R. C. Cory (Eds.), Universal design in higher education: From principles to practice (pp. 23-43). Cambridge, MA: Harvard University Press.

Burmeister, E., \& Aitken, L. M. (2012). Sample size: How many is enough? Australian Critical Care, 25(4), 271-274.

Burroughs, K. M. (1997). Learning disabled student athletes: a sporting chance under the ADA? The Journal of Contemporary Health Law and Policy, 14(1), 57-91.

Byers, W., \& Hammer, C. H. (1997). Unsportsmanlike conduct: Exploiting college athletes. Ann Arbor, MI: University of Michigan Press. 
Calmore, J. (1992). Critical race theory, Archie Shepp, and fire music: Securing an authentic intellectual life in a multicultural world. Southern California Law Review, 65, 2129-2231.

Carodine, K., Almond, K. F., \& Gratto, K. K. (2001). College student athlete success both in and out of the classroom. New Directions for Student Services, 93, 19-33.

Carter, N., Bryant-Lukosius, D., DiCenso, A., Blythe, J., \& Neville, A., J. (2014). The use of triangulation in qualitative research. Oncology Nursing Forum, 41, 545547.

Casuso-Holgado, M. J., Cuesta-Vargas, A. I., Moreno-Morales, N., Labajos-Manzanares, M. T., Barón-López, F. J., \& Vega-Cuesta, M. (2013). The association between academic engagement and achievement in health sciences students. BMC Medical Education, 13(1), 33.

Cawthon, S. W., \& Cole, E. V. (2010). Postsecondary students who have a learning disability: Student perspectives on accommodations access and obstacles. Journal of Postsecondary Education and Disability, 23(2), 112-128.

Center for Applied Special Technology (CAST). (2012a). About UDL. Retrieved from http://www.udlcenter.org/aboutudl/whatisudl

Center for Applied Special Technology (CAST). (2012b). UDL guidelines: Theory and practice version. Retrieved from http://www.udlcenter.org/aboutudl/udlguidelines theorypractice.

Clark, M., \& Parette, P. (2002). Student athletes with learning disabilities: A model for effective supports. College Student Journal, 36(1), 47-61.

Cohen, M., Kahn, D., \& Steeves, R. (2000). Hermeneutic phenomenology research: A practical guide for nurse researchers. London, England: Sage Publications.

College teams exploit new rule for 'learning disabilities'. (2009, December 28). USA TODAY, p. 8A.

Collier, R. (2012). Person-first language: What it means to be a" person". Canadian Medical Association. Journal, 184(18), E935.

Collins, M. E., \& Mowbray, C. T. (2005). Higher education and psychiatric disabilities: National survey of campus disability services. American Journal of Orthopsychiatry, 75(2), 304-315.

Comeaux, E. (2008). Black males in the college classroom: A quantitative analysis of student athlete-faculty interactions. Challenge, 14(1), 2. 
Comeaux, E. (2011). A study of attitudes toward college student-athletes: Implications for faculty-athletics engagement. Journal of Negro Education, 80, 521-532.

Comeaux, E. \& Harrison, C.K. (2007). Faculty and male student-athletes: Racial differences in the environmental predictors of academic achievement. Race, Ethnicity and Education, 10(2), 199-214.

Comeaux, E., \& Harrison, C. K. (2011). A conceptual model of academic success for student-athletes. Educational Researcher, 40(5), 235-245.

Cooper, J. N. (2012). Personal troubles and public issues: A sociological imagination of Black athletes' experiences at Predominantly White Institutions in the United States. Sociology, 2(3), 261-271.

Cooper, J. N., \& Hawkins, B. (2014). The transfer effect: A critical race theory examination of Black male transfer student athletes' experiences. Journal of Intercollegiate Sport, 7(1), 80-104.

Corbin, J., \& Strauss, A. (2008). Basics of qualitative research: Techniques and procedures for developing grounded theory (Vol. 3). Thousand Oaks: Sage Publications.

Corrigan, P. (2000). Mental health stigma as social attribution: Implications for research methods and attitude change. Clinical Psychology, Science and Practice, 7(1), 4867.

Corrigan, P., \& Matthews, A. (2003). Stigma and disclosure: Implications for coming out of the closet. Journal of Mental Health, 12(3), 235-248.

Cortiella, C., \& Horowitz, S. H. (2014). The state of learning disabilities: Facts, trends and emerging issues. New York, NY: National Center for Learning Disabilities. Retrieved from http://www.ncld.org/types-learning-disabilities/what-is-ld/stateof-learning disabilities

Cory, R. C. (2011). Disability services offices for students with disabilities: A campus resource. New Directions for Higher Education, 154(154), 27-36.

Council III, M. R., \& Gardner III, R. (2018). Developing effective self-advocacy skills in student- athletes with disabilities. In M. R. Council III, S. R. Hodge, \& R.A. Bennett III, (Eds.). The collegiate athlete at risk: Strategies for academic support and success. Charlotte, NC. Information Age Publishing Inc.

Crawford, V. (2002). Embracing the monster: Overcoming the challenges of hidden disabilities. Baltimore: Paul H. Brooks Publishing. 
Creswell, J. W., \& Miller, D. L. (2000). Determining validity in qualitative inquiry. Theory into Practice, 39(3), 124-130.

Creswell, J. W., \& Poth, C. N. (2017). Qualitative inquiry and research design: Choosing among five approaches. Thousand Oak, CA: Sage Publications.

Cummings, R., Maddox, C. D., \& Casey, J. (2000). Individualized transition planning for students with learning disabilities. The Career Development Quarterly, 49, 60-72.

Cypress, B. S. (2017). Rigor or reliability and validity in qualitative research: Perspectives, strategies, reconceptualization, and recommendations. Dimensions of Critical Care Nursing, 36(4), 253-263.

DaDeppo, L. M. (2009). Integration factors related to the academic success and intent to persist of college students with learning disabilities. Learning Disabilities Research \& Practice, 24(3), 122-131.

Daly-Cano, M., Vaccaro, A., \& Newman, B. (2015). College student narratives about learning and using self-advocacy skills. Journal of Postsecondary Education and Disability, 28(2), 213-227.

Davis, K. (2006). In the penalty box: The push for academic reform leaves some schools lagging. Diverse Issues in Higher Education, 23(4), 24-26.

Davis, L.J. (2011) Why is disability missing from the discourse on diversity? Chronicle of Higher Education. 25 September 2011. Available online at

http://chronicle.com/article/Why-is-Disability-MissingFrom/129088/.

Debrand, C. C., \& Salzberg, C. L. (2005). A validated curriculum to provide training to faculty regarding students with disabilities in higher education. Journal of Postsecondary Education and Disability, 18(1), 49-61.

De Cesarei, A. (2014). Disclosure of disability by university students: Development of a study protocol. Open Journal of Social Sciences, 2(08), 71-76.

deJong, M., \& Schellens, P. (1998). Focus groups or individual interviews?: A comparison of text evaluation approaches. Technical Communication, 45, 77-88.

Delgado, R., \& Stefancic, J. (2013). Critical race theory: The cutting edge. Philadelphia, PA: Temple University Press.

Denbo, S. (2003). Disability lessons in higher education: Accommodating learning disabled students and student athletes under the Rehabilitation Act and the Americans with Disabilities Act. American Business Law Journal, 41, 145. 
Denhart, H. (2008). Deconstructing barriers: Perceptions of students labeled with learning disabilities in higher education. Journal of Learning Disabilities, 41(6), 483-497.

Denzin, N. K. (1978). Triangulation: A case for methodological evaluation and combination. In N. K. Denzin (Ed.), Sociological methods (2nd ed., pp. 339- 357). New York, NY: McGraw-Hill.

DeSensi, J. T. (2014). Sport: An ethos based on values and servant leadership. Journal of Intercollegiate Sport, 7(1), 58-63.

DiCenso, A., Guyatt, G., \& Ciliska, D. (2005). Evidence-based nursing: A guide to clinical practice (pp. 120-135). St. Louis, MO: Elsevier Mosby.

Dowrick, P. W., Anderson, J., Heyer, K., \& Acosta, J. (2005). Postsecondary education across the USA: Experiences of adults with disabilities. Journal of Vocational Rehabilitation, 22(1), 41-47.

Duffy, J. T., \& Gugerty, J. (2005). The role of disability support services. In E. E. Getzel and P. Wehman (Eds.), Going to college: Expanding opportunities for people with disabilities (pp. 89-115). Baltimore, MD: Brookes Publishing.

Dybwad G. \& Bersani H. (1996) New voices: Self-advocacy by people with disabilities. Cambridge, MA: Brookline Books.

Eckes, S. E., \& Ochoa, T. A. (2005). Students with disabilities: Transitioning from high school to higher education. American Secondary Education, 33(3), 6-20.

Engstrom, C. M., \& Sedlacek, W. E. (1991). A study of prejudice toward university student-athletes. Journal of Counseling \& Development, 70(1), 189-193.

Engstrom, C. M., Sedlacek, W. E., \& McEwen, M. K. (1995). Faculty attitudes toward male revenue and nonrevenue student-athletes. Journal of College Student Development, 36(3), 217-227.

Erlandson, D. A., Hartis, E. L., Skipper, B. L., \& AlIen, S. D. (1993). Doing naturalistic inquiry: A guide to methods. Newbury Park, CA: Sage Publications.

Etikan, I., Musa, S. A., \& Alkassim, R. S. (2016). Comparison of convenience sampling and purposive sampling. American Journal of Theoretical and Applied Statistics, $5(1), 1-4$.

Evans, N. J., \& Broido, E. M. (2011, November 14). Social involvement and identity involvement of students with disabilities. Poster presented at the Association for the Study of Higher Education conference, Charlotte, NC. 
Evans, N. J., Broido, E. M., Brown, K. R., \& Wilke, A. K. (2017). Disability in higher education: A social justice approach. San Francisco, CA: John Wiley \& Sons.

Ferrante, A. P., Etzel, E., \& Lantz, C. (1991). Counseling college student-athletes: Issues and interventions. Morgantown, WV: Fitness Information Technology.

Ferris, E., Finster, M., \& McDonald, D. (2004). Academic fit of student-athletes: An analysis of NCAA division IA graduation rates. Research in Higher Education, $45(6), 555-575$.

Fletcher, J. M., Lyon, G. R., \& Fuchs, L. S. (2006). Learning disabilities: From identification to intervention. New York, NY: Guilford Press.

Foley, B. J., Minick, M. P., \& Kee, C. C. (2002). How nurses learn advocacy. Journal of Nursing Scholarship, 34, 181-186.

Fontana, A., \& Frey, J. H. (2000). The interview: From structured questions to negotiated text. Handbook of Qualitative Research, 2(6), 645-672.

Forman, A. E., Baker, P. M., Pater, J., \& Smith, K. (2011). Beautiful to me: Identity, disability, and gender in virtual environments. International Journal of E-Politics (IJEP), 2(2), 1-17.

French, S., \& Swain, J. (1997). Changing disability research: Participating and emancipatory research with disabled people. Physiotherapy, 83(1), 26-32.

Friedensen, R., McCrae, B., \& Kimball, E. (2017). Using qualitative research to document variations in student experience. In E. Kimball \& K. Loya (Eds.), Using qualitative research to promote organizational intelligence (pp. 53-64). San Francisco, CA: Jossey-Bass.

Fry, M. (2010). Creating a positive climate for young athletes from Day 1. Journal of Sport Psychology in Action, 1, 33-41.

Fusch, P., \& Ness, L. (2015). Are we there yet? Data saturation in qualitative research. The Qualitative Report, 20, 1208-1416.

Gansemer-Topf, A. M., \& Schuh, J. H. (2006). Institutional selectivity and institutional expenditures: Examining organizational factors that contribute to retention and graduation. Research in Higher Education, 47(6), 613-642.

Gaston-Gayles, J. L. (2004). Examining academic and athletic motivation among student athletes at a Division I university. Journal of College Student Development, 45(1), $75-83$. 
Gaston-Gayles, J. G. (2009). The student athlete experience. New Directions for Institutional Research, 144, 33-41.

Gentles, S. J., Charles, C., Ploeg, J., \& McKibbon, K. (2015). Sampling in qualitative research: Insights from an overview of the methods literature. The Qualitative Report, 20(11), 1772-1789.

Gerber, P. J., \& Price, L. A. (2003). Persons with learning disabilities in the workplace: What we know so far in the Americans with Disabilities Act era. Learning Disabilities Research \& Practice, 18(2), 132-136.

Getzel, E. E. (2008). Addressing the persistence and retention of students with disabilities in higher education: Incorporating key strategies and supports on campus. Exceptionality, 16(4), 207-219.

Getzel, E. E., \& Wehman, P. (2005). Going to college: Expanding opportunities for people with disabilities. Baltimore, MD: Brookes.

Getzel, E. E., \& Thoma, C. A. (2008). Experiences of college students with disabilities and the importance of self-determination in higher education settings. Career Development for Exceptional Individuals, 31, 77-84.

Goldstein, S. (2007). Understanding AD/HD and occurring conditions. ATTENTION! 13(6), 42-44.

Gordon, M., \& Keiser, S. (Eds.). (2000). Accommodations in higher education under the Americans with Disabilities Act (ADA): A no-nonsense guide for clinicians, educators, administrators, and lawyers. New York, NY: Guilford Press.

Gould, D. (2016). Quality coaching counts. The Phi Delta Kappan, 97(8), 13-18.

Graham, S. A. (1999). Transition plans for student athletes with learning disabilities Baylor, TX: Baylor University.

Grandy, J., Lough, N., \& Miller, C. (2016). Improving student-athlete academic success: evaluation of learning support tools utilized by academic advisors for athletics. Journal for the Study of Sports and Athletes in Education, 10(3), 199217.

Greenbaum, B., Graham, S., \& Scales, W. (1995). Adults with learning disabilities: Educational and social experiences during college. Exceptional Children, 61(5), 460-471.

Gulas, I. (1974). MMPI low-point codes for a "normal" young adult population: A normative study. Journal of Clinical Psychology, 30, 77-78. 
Gunn, E. L., \& Eddy, J. P. (1989). Student services for intercollegiate athletes. College Student Affairs Journal, 9(3), 36-44.

Guralnick, M. J. (1999). Second-generation research in the field of early intervention. In M. Guralnick (Ed.), The effectiveness of early intervention (pp. 3-22). Baltimore, MD: Paul Brookes.

Hadley, W. M. (2006). LD students' access to higher education: Self-advocacy and support. Journal of Developmental Education, 30(2), 10-16.

Hadley, W. M. (2011). College students with disabilities: A student development perspective. New Directions for Higher Education, 154, 77-81.

Hammersley, M., \& Atkinson, P. (1995). Insider accounts: Listening and asking questions. Ethnography: Principles in Practice, 2, 124-156.

Harmon, N. (2010, January-February). Overscheduled and overcommitted: The lives of student. [Electronic version]. About Campus, 14(6), 26-29.

Harper, S. R. (2006). Black male students at public universities in the U.S.: Status, trends and implications for policy and practice. Washington, DC: Joint Center for Political and Economic Studies.

Harper, S. R. (2009). Niggers no more: A critical race counternarrative on Black male student achievement at predominantly White colleges and universities. International Journal of Qualitative Studies in Education, 22(6), 697-712.

Harris, H. L., Altekruse, M. K., \& Engels, D. W. (2003). Helping freshman student athletes adjust to college life using psychoeducational groups. Journal for Specialists in Group Work, 28(1), 64-81.

Harrison, K. C., Comeaux, E., \& Plecha, M. (2006). Faculty and male football and basketball players on university campuses: An empirical investigation of the "intellectual" as mentor to the student athlete. Research Quarterly for Exercise and Sport, 77(2), 277-284.

Hartman, R. C. (1993). Transition to higher education. New Directions for College Student Services, 64, 31-43.

Hartmann, T. (2003). The Edison gene: ADHD and the gift of the hunter child. Rochester, VT: Park Street Press.

Hawkins, B. J. (2010). The new plantation: Black athletes, college sports, and predominantly White NCAA institutions. New York, NY: Palgrave Macmillan. 
Henry, W., Fuerth, K., \& Figliozzi, J. (2010). Gay with a disability: A college student's multiple cultural journey. College Student Journal, 44(2), 377-388.

Herbert, J. T., Welsh, W., Hong, B. S. S., Soo-Yong, Byun, Atkinson, H. A., \& Kurz, C. A. (2014). Persistence and graduation of college students seeking disability support services. Journal of Rehabilitation, 80(1), 22-32.

Hill, K., Burch-Ragan, M., \& Yates, D. Y. (2001). Current and future issues and trends facing student-athletes and athletic programs. In M. F. Howard-Hamilton \& S. K. Watt (Eds.), Student services for athletes: New Directions for Student Services, 93, 65-80.

Hishinuma, E. S., \& Fremstad, J. S. (1997). NCAA college freshmen academic requirements: Academic standards or unfair roadblocks for students with learning disabilities? Journal of Learning Disabilities, 30(6), 589-598.

Hodes, J. S., James, T., Martin, G., \& Milliner, K. (2015). Go for the win: A collaborative model for supporting student-athletes. Learning Assistance Review, 20(1), 47-60.

Hollis, L. P. (2001). Service ace? Which academic services and resources truly benefit student athletes. Journal of College Student Retention: Research, Theory \& Practice, 3(3), 265-284.

Houck, C. K., Asselin, S. B., Troutman, G. C., \& Arrington, J. M. (1992). Students with learning disabilities in the university environment: A study of faculty and student perceptions. Journal of Learning Disabilities, 25(10), 678-684.

Howard-Hamilton, M. F., \& Sina, J. A. (2001). How college affects student athletes. New Directions for Student Services, 2001(93), 35-45.

Howard-Hamilton, M. F, Cuyjet, M. J., \& Cooper, D. (2011). Understanding multiculturalism and multicultural competence among college students. In M. J. Cuyjet, M. F. Howard-Hamilton, \& D. L. Cooper (Eds.). Multiculturalism on campus: Theory, models, and practices for understanding diversity and creating inclusion (pp. 2-18). Sterling, VA: Stylus.

Huff, A. S. (2009). Designing for research for publication. Thousand Oaks, CA: Sage Publications.

Huger, M. S. (2011). Fostering a disability-friendly institutional climate. New Directions for Student Services, 2011(134), 3-11. 
Hughes, C., \& Williams-Graham, J. (1994). To disclose or not to disclose: That is the question. Columbia, MO: Missouri State Department of Elementary and Secondary Education, Jefferson City, Division of Special Education. (ERIC Document Reproduction Service No. ED377600).

Huml, M. R., Hancock, M. G., \& Bergman, M. J. (2014). Additional support or extravagant cost?: Student-athletes' perceptions on athletic academic centers. Journal of Issues in Intercollegiate Athletics, 7, 410-430.

Iaccarino, M. A., Fitzgerald, M., Pulli, A., Woodworth, K. Y., Spencer, T. J., Zafonte, R., \& Biederman, J. (2018). Sport concussion and attention deficit hyperactivity disorder in student athletes: A cohort study. Neurology: Clinical Practice, 8(5), 403-411.

Irick, E. (2011). Student-athlete participation: NCAA sports sponsorship and participation rates report. Retrieved from http://www.nwcaonline.com/nwcawebsi ite/docs/saving-wrestlingfiles/pdf-.pdf?sfvrsN $=0$.

Jackson, R. L., Drummond, D. K., \& Camara, S. (2007). What is qualitative research? Qualitative Research Reports in Communication, 8(1), 21-28.

Janiga, S. J., \& Costenbader, V. (2002). The transition from high school to postsecondary education for students with learning disabilities: A survey of college service coordinators. Journal of Learning Disabilities, 35(5), 463-470.

Jolly, C. J. (2008). Raising the question \# 9 is the student-athlete population unique? And why should we care? Communication Education, 57(1), 145-151.

Jones, S. R. (1996). Toward inclusive theory: Disability as social construction. NASPA Journal, 33(4), 347-354.

Jordan, J. M., \& Denson, E. L. (1990). Student services for athletes: A model for enhancing the student-athlete experience. Journal of Counseling \& Development, 69(1), 95-97.

Judd, C. M., \& Park, B. (1993). Definition and assessment of accuracy in social stereotypes. Psychological Review, 100(1), 109-128.

Kallio, H., Pietilä, A. M., Johnson, M., \& Kangasniemi, M. (2016). Systematic methodological review: developing a framework for a qualitative semi-structured interview guide. Journal of Advanced Nursing, 72(12), 2954-2965.

Kamusoko, S. D., \& Pemberton, C. L. A. (2013). Student-athlete wellbeing and persistence: An in-depth look at student-athlete perceptions. Journal for the Study of Sports and Athletes in Education, 7, 41-61. 
Kanahara, S. (2006). A review of the definitions of stereotype and a proposal for a progressional model. Individual Differences Research, 4, 306-321.

Kaplin, W. A., \& Lee, B. A. (2013). Law of higher education (5th ed.). Somerset, NJ: John Wiley \& Sons.

Kaplowitz, M. (2000). Statistical analysis of sensitive topics in group and individual interviews. Quality \& Quantity, 34, 419-431.

Kaplowitz, M., \& Hoehn, J. (2001). Do focus groups and individual interviews reveal the same information for natural resource valuation? Ecological Economics, 36, 237247.

Kelly, C. A., Ketcham, C. J., Patel, K., \& Hall, E. E. (2018). Test setting and ADHD influence baseline concussion testing neurocognitive performance in collegiate student-athletes: 1967 Board \# 228 May 31 3. Medicine \& Science in Sports \& Exercise, 50(5S), 476.

Kranke, D., Jackson, S. E., Taylor, D. A., Anderson-Fye, E., \& Floersch, J. (2013). College student disclosure of non-apparent disabilities to receive classroom accommodations. Journal of Postsecondary Education and Disability, 26(1), 3551 .

Kuhn, T. L. (2008). Historical foundations of academic advising. In V. N. Gordon, W. R. Habley, \& T. J. Grites (Eds.), Academic advising: A comprehensive handbook (pp. 3-16). San Francisco, CA: Jossey-Bass.

Kuo, J., Hagie, C., \& Miller, M. (2004). Encouraging college student success: The instructional challenges, response strategies, and study skills of contemporary undergraduates. Journal of Instructional Psychology, 31, 60-71.

Kurth, N., \& Mellard, D. (2006). Student perceptions of the accommodation process in postsecondary education. Journal of Postsecondary Education and Disability, 19(1), 71-84.

Kvale, S. (1996). Interviews: An introduction to qualitative research interviews. Thousand Oaks, CA: Sage Publications.

Lafrenière, M. K., Jowett, S., Vallerand, R. J., \& Carbonneau, N. (2011). Passion for coaching and the quality of the coach-athlete relationship: The mediating role of coaching behaviors. Psychology of Sport \& Exercise, 12, 144-152.

Lally, P. S., \& Kerr, G. A. (2005). The career planning, athletic identity, and student role identity of intercollegiate student athletes. Research Quarterly for Exercise and Sport, 76(3), 275-285. 
Lawrence, S. M., Harrison, C. K., \& Stone, J. (2009). A day in the life of a male college athlete: A public perception and qualitative campus investigation. Journal of Sport Management, 23, 591-614.

Lehmann, J. P., Davies, T. G., \& Laurin, K. M. (2000). Listening to student voices about postsecondary. Teaching Exceptional Children, 32(5), 60-65.

Levine, J., Etchison, S., \& Oppenheimer, D. M. (2014). Pluralistic ignorance among student-athlete populations: a factor in academic underperformance. Higher Education, 68(4), 525-540.

Lewis, A., \& Porter, J. (2004). Interviewing children and young people with learning disabilities*: guidelines for researchers and multi-professional practice. British Journal of Learning Disabilities, 32(4), 191-197.

Lincoln, Y. S., \& Guba, E. G. (1985). Effective evaluation. New York, NY: Jossey-Bass.

Lund, S. (2019). A Comparison of College Student-Athletes With Attention-Deficit Hyperactivity Disorder (ADHD) and Nonathletes With ADHD: Academic Adjustment, Severity of Mental Health Concerns, and Complexity of Life Concerns. Norfolk, VA: Old Dominion University.

Lux, S.J. (2016). The lived experiences of college students with a learning disability and/or 201 attention deficit hyperactivity disorder. Ames, IA: Iowa State University.

Lynch, R. T., \& Gussel, L. (1996). Disclosure and self-advocacy regarding disabilityrelated needs: Strategies to maximize integration in postsecondary education. Journal of Counseling \& Development, 74(4), 352-357.

Madaus, J. W. (2008). Employment self-disclosure rates and rationales of university graduates with learning disabilities. Journal of Learning Disabilities, 41(4), 291299.

Mahalik, J. R., Good, G. E., \& Englar-Carlson, M. (2003). Masculinity scripts, presenting concerns, and help seeking: Implications for practice and training. Professional Psychology: Research and Practice, 34(2), 123-131.

Maher, A. R. (2014). From scattered to centered: Understanding and overcoming $A D H D$. Eau Claire, WI: PESI Publishing \& Media.

Manderino, L. M., Zachman, A. M., \& Gunstad, J. (2018). Novel ImPACT validity indices in collegiate student-athletes with and without histories of ADHD or academic difficulties. The Clinical Neuropsychologist, 1-12. 
Marshak, L., Van Wieren, T., Ferrell, D. R., Swiss, L., \& Dugan, C. (2010). Exploring barriers to college student use of disability services and accommodations. Journal of Postsecondary Education and Disability, 22(3), 151-165.

Marshall, C. \& Rossman, G. (2006). The how of the study: Building the research design. In C. Marshall \& G. Rossman (Eds.), Designing qualitative research (pp. 51-96). Thousand Oaks, CA: Sage Publications.

Martin, B. E., Harrison, C. K., Stone, J., \& Lawrence, S. M. (2010). Athletic voices and academic victories: African American male student-athlete experiences in the Pac-Ten. Journal of Sport and Social Issues, 34(2), 131-153.

Martin, J., Van Dycke, J., Greene, B., Gardner, J., Christensen, W., Woods, L. (2006). Direct observation of teacher-directed IEP meetings: Establishing the need for student IEP meeting instruction. Exceptional Children, 72,187-200.

Mason, C., Field, S., \& Sawilowsky, S. (2004). Implementation of self-determination activities and student participation in IEPs. Exceptional Children, 70(4), 441-451.

Mason, A., \& Mason, M. (2005). Understanding college students with learning disabilities. Pediatric Clinics, 52(1), 61-70.

Mathison, S. (1988). Why triangulate? Educational Researcher, 17(2), 13-17.

May, A. L., \& Stone, C. A. (2010). Stereotypes of individuals with learning disabilities: Views of college students with and without learning disabilities. Journal of Learning Disabilities, 43(6), 483-499.

McGuire, J. M. (1988). An approach to meeting the needs of the LD student in a two-year college setting. In C. Mangrum \& S. Strichart (Eds.), College and the learning disabled student. (2nd. ed.) (pp. 229-236). Philadelphia, PA: Grune and Stratton.

Meabon, D. L., \& Schuh, J. H. (1994). Keeping Your Institution off the NCAA Sanctions List: Issues for student affairs administrators. NASPA Journal, 31(3), 217-224.

Meekosha, H. \& Shuttleworth, R. (2009). What's so "critical” about critical disability studies? Australian Journal of Human Rights, 15(1), 47-75.

Megivern, D., Pellerito, S., \& Mowbray, C. (2003). Barriers to higher education for individuals with psychiatric disabilities. Psychiatric Rehabilitation Journal, 26, 217-231.

Melendez, M. C. (2006). The influence of athletic participation on the college adjustment of freshmen and sophomore student athletes. Journal of College Student

Retention: Research, Theory \& Practice, 8(1), 39-55. 
Mellard, D. F., Hall, J. P., \& Parker, K. (1999). Assisting adult educators in preparing individuals with disabilities for employment. American Rehabilitation, 25(3), 2431.

Menke, D. J. (2016). Inside the bubble: college experiences of student-athletes in revenue-producing sports. Journal for the Study of Sports and Athletes in Education, 10(1), 16-32.

Merriam, S. B., \& Tisdell, E. J. (2015). Qualitative research: A guide to design and implementation. San Francisco, CA: John Wiley \& Sons.

Meyer, S. K. (2005). NCAA academic reforms: Maintaining the balance between academics and athletics. Phi Kappa Phi Forum, 85(3), 15-18.

Miles, M. B., Huberman, A. M., \& Saldaña, J. (2014). Qualitative data analysis: A methods sourcebook (3rd ed.). Los Angeles, CA: Sage Publications.

Milsom, A., \& Hartley, M. (2005). Assisting students with learning disabilities transitioning to college: What school counselors should know. Professional School Counseling, 8(5), 436-441.

Mithaug, D. (1996). Equal opportunity theory. Thousand Oaks, CA: Sage Publications.

Monda, S. J. (2011). At risk college athletes and academic achievement: Experiences of first year football players. Poster presented at the NCAA research symposium, Indianapolis, IN.

Mull, C., Sitlington, P. L., \& Alper, S. (2001). Postsecondary education for students with learning disabilities: A synthesis of the literature. Exceptional Children, 68, 97118.

Murray, C., Flannery, B. K., \& Wren, C. (2008). University staff members' attitudes and knowledge about learning disabilities and disability support services. Journal of Postsecondary Education and Disability, 21(2), 73-90.

Murray, C., Lombardi, A., \& Kosty, D. (2014). Profiling adjustment among postsecondary students with disabilities: A person-centered approach. Journal of Diversity in Higher Education, 7(1), 31-44.

Murty, K. S., \& Roebuck, J. B. (2015). Deviant exploitation of black male student athletes on white campuses. Deviant Behavior, 36(6), 429-440.

N4A Committee on Learning Disabilities. (1998). Services for student-athletes with learning disabilities. Survey results May 1998. [On-line]. Available: http://www.nfoura.org/Committees/Cold/surveymay99.html. 
N4A. (2013). Best practices for promoting and maintaining a culture of student-athlete success, accountability, and academic integrity. Westlake, OH: Author.

National Collegiate Athletic Association. (2014). Football Bowl Subdivision Membership Requirements, Frequently Asked Questions. Retrieved from: https://www.ncaa.org/sites/default/files/Football\%20Bowl\%20Subqa\%2012\%208 $\% 2014 . p d f$

National Collegiate Athletic Association (2017a, May) Interassociation consensus Document: mental health best practices. Understanding and supporting studentathletes mental wellness. Retrieved from: http://www.ncaa.org/sport-scienceinstitute/mental-health-best-practices.

National Collegiate Athletic Association. (2017b, August, 7) Social Environments Study. Retrieved from: http://www.ncaa.org/about/resources/research/ncaa-socialenvironments-study.

National Collegiate Athletic Association (2017c, December, 1). Ole Miss lacked institutional control in football program. Retrieved from: http://www.ncaa.org/aou t/resources/media-center/news/ole-miss-lacked-institutional-control-football program.

National Collegiate Athletic Association. (2019a). 2019-2020 NCAA Division I manual. Indianapolis: IN: National Collegiate Athletic Association.

National Collegiate Athletic Association (2019b). Educational-impacting disability. Retrieved from: http://www.ncaa.org/student-athletes/future/education-impactingdisabilities.

National Collegiate Athletic Association (2019c, January 31). Former Missouri tutor completed coursework for 12 student-athletes. Retrieved from: http://www.ncaa.org/about/resources/media-center/news/former-missouri-tutorcompleted-coursework-12-student-athletes.

National Collegiate Athletic Association. (2019d). The Student-Athlete Experience. Retrieved from: http://www.ncaa.org/student-athletes.

National Collegiate Athletic Association. (2019e). What is the NCAA. Retrieved from: http://www.ncaa.org/about/resources/media-center/ncaa-101/what-ncaa.

National Joint Commission on Learning Disabilities. (1990). Definition of learning disabilities. Retrieved June, 2019, from https://njcld.files.wordpress.com/2018/10/learning-disabilities-issues-ondefinition-1990.pdf 
National Joint Committee on Learning Disabilities. (2007). The documentation disconnect for students with learning disabilities: Improving access to postsecondary disability services. Learning Disability Quarterly, 30(4), 265-274.

Naylor, A. H. (2007). The coach's dilemma: balancing playing to win and player development. Journal of Education, 187(1), 31-48.

Newman, L. (2005). Changes in postsecondary education participation of youth with disabilities. Journal for Vocational Special Needs Education, 27(2), 30-38.

Nezu, C., Nezu, A., \& Arean, P. (1991). Assertiveness and problem-solving training for mildly mentally retarded persons with dual diagnoses. Research in Developmental Disabilities, 12, 371-386.

Nind M. (2009) Conducting qualitative research with people with learning, communication and other disabilities: Methodological challenges. National Centre for Research Methods, pp. 24. (ESRC National Centre for Research Methods Review Paper).

Njororai, W.W. S. (2012). Challenges of being a black student athlete on U.S. college campuses. Journal of Issues in Intercollegiate Athletics, 5, 40-63.

Nwadike, A. C., Baker, A. R., Brackebusch, V. B., \& Hawkins, B. J. (2015). Institutional racism in the NCAA and the racial implications of the " 2.3 or take a knee legislation”. Marquette Sports Law. Review, 26(2), 523-543.

O'Shea, A., \& Meyer, R. H. (2016). A qualitative investigation of the motivation of college students with nonvisible disabilities to utilize disability services. Journal of Postsecondary Education and Disability, 29(1), 5-23.

Odom, S. L., Brantlinger, E., Gersten, R., Horner, R. H., Thompson, B., \& Harris, K. R. (2005). Research in special education: Scientific methods and evidence-based practices. Exceptional Children, 71(2), 137-148.

Olney, M. F., \& Kim, A. (2001). Beyond adjustment: Integration of cognitive disability into identity. Disability \& Society, 16(4), 563-583.

Ostiguy, B. J., Peters, M. L., \& Shlasko, D. (2016). Ableism. In M. Adams \& L. A. Bell (Eds.), Teaching for diversity and social justice (3rd ed., pp. 299-337). New York, NY: Routledge.

Pate, J., Stokowski, S., \& Hardin, R. (2011). Third time's a charm: The case of Tennessee's four junior football players who endured three different head coaches in three seasons. Journal of Issues in Intercollegiate Athletics, 4, 354-369. 
Pearson, H. (2010). Complicating intersectionality through the identities of a hard of hearing Korean adoptee: An autoethnography. Equity and Excellence in Education, 43(3), 341-356.

Parsons, J. (2013). Student athlete perceptions of academic success and athlete stereotypes on campus. Journal of Sport Behavior, 36(4), 400-416.

Pascarella, E. T., \& Terenzini, P. T. (2005). How college affects students: A third decade of research. San Francisco, CA: Jossey Bass.

Patton, M. Q. (1999). Enhancing the quality and credibility of qualitative analysis. Health Services Research, 34, 1189-1208.

Peña, E. V. (2014). Marginalization of published scholarship on students with disabilities in higher education journals. Journal of College Student Development, 55(1), 3040.

Peña, E. V., Stapleton, L. D., \& Schaffer, L. M. (2016). Critical perspectives on disability identity. New Directions for Student Services, 2016(154), 85-96.

Petronio, S. (2002). Boundaries of privacy: Dialectics of disclosure. Albany, NY: State University of New York Press.

Petronio, S., Martin, J., \& Littlefield, R. (1984). Prerequisite conditions for selfdisclosing: A gender issue. Communication Monographs, 51(3), 268-273.

Polakow, V. (1993). Lives on the edge: Single mothers and their children in the other America. Chicago IL: University of Chicago Press.

Polkinghorne, D. E. (1989). Phenomenological research methods. In R. S. VaUe \& S. Hailing (Eds.), Existential-phenomenological perspectives in psychology (pp. 4160). New York, NY: Plenum Press.

Potuto, J. J. R., \& O'Hanlon, J. (2007). National study of student-athletes regarding their experiences as college students. College Student Journal, 41(4), 947-966.

Quick, D., Lehmann, J., \& Deniston, T. (2003). Opening doors for students with disabilities on community college campuses: what have we learned? What do we still need to know? Community College Journal of Research \& Practice, 27(910), 815-827.

Rao, S. (2004). Faculty attitudes and students with disabilities in higher education: A literature review. College Student Journal, 38(2), 191-199. 
Raskind, M. H., Goldberg, R. J., Higgins, E. L., \& Herman, K. L. (1999). Patterns of change and predictors of success in individuals with learning disabilities: Results from a twenty-year longitudinal study. Learning Disabilities Research \& Practice, 14(1), 35-49.

Raue, K., \& Lewis, L. (2011). Students with disabilities at degree-granting postsecondary institutions (No. NCES 2011-018). Washington, DC: U.S. Government Printing Office. Retrieved from U.S. Department of Education, National Center for Education Statistics website https://nces.edu.gov/pubsearch/pubsinfo.asp?pubid= 2011018.

Reardon, C. L., \& Factor, R. M. (2010). Sports psychiatry: A systematic review of diagnosis and medical treatment of mental illness in athletes. Sports Medicine, 40(11), 961-980.

Reusen, A., \& Bos, C. (1994). Facilitating student participation in individualized education programs through motivation strategy instruction. Exceptional Children, 60, 466-476.

Richards, L. \& Morse, J.M. (2013a). Coding. Chapter 6. In qualitative methods, $3^{\text {rd }}$ ed. (pp. 149-168). Los Angeles, CA: Sage Publications.

Richards, L. \& Morse, J.M. (2013b). The integrity of qualitative research. Chapter 2. In Qualitative methods, $3^{\text {rd }}$ ed. (pp. 23-48). Los Angeles, CA: Sage Publications.

Riddell, S., \& Weedon, E. (2014). Disabled students in higher education: Discourses of disability and the negotiation of identity. International Journal of Educational Research, 63, 38-46.

Ridpath, B. D. (2010). Perceptions of NCAA Division I athletes on motivations concerning the use of specialized academic support services in the era of the Academic Progress Rate. Journal of Issues in Intercollegiate Athletics, 3, 253271.

Ridpath, M. (2014). In Brown, G. T., Hainline, B., Kroshus, E., \& Wilfert, M. (Eds.). Mind, body and sport: Understanding and supporting student-athlete mental wellness. Retrieved from http://www.ncaa.org/health-and-safety/sport-scienceinstitute/introductionmind-body-and-sport

Rishe, P. J. (2003). A reexamination of how athletic success impacts graduation rates Comparing student-athletes to all other undergraduates. American Journal of Economics and Sociology, 62(2), 407-427.

Roulston, K. (2010). Reflective interviewing: A guide to theory and practice. London, England. Sage Publications. 
Rubin, L. M., \& Moses, R. A. (2017). Athletic subculture within student-athlete academic centers. Sociology of Sport Journal, 34(4), 317-328.

Russell, C., Gregory, D., Ploeg, J., DiCenso, A., \& Guyatt, G. (2005). Qualitative research. In A. DiCenso, G. Guyatt, \& D. Ciliska (Eds.), Evidence-based nursing: A guide to clinical practice (pp. 120-135). St. Louis, MO: Elsevier Mosby.

Saldaña, J. (2011). The coding manual for qualitative researchers. Thousand Oaks, CA: Sage Publications.

Salzberg, C. L., Peterson, L., Debrand, C. C., Blair, R. J., Carsey, A. C., \& Johnson, A. S. (2002). Opinions of disability service directors on faculty training: The need, content, issues, formats, media, and activities. Journal of Postsecondary Education and Disability, 15(2), 101-14.

Salzer, M. S., Wick, L. C., \& Rogers, J. A. (2008). Familiarity with and use of accommodations and supports among postsecondary students with mental illnesses. Psychiatric Services, 59(4), 370-375.

Sanderson, A. R., \& Siegfried, J. J. (2015). The case for paying college athletes. Journal of Economic Perspectives, 29(1), 115-38.

Satterfield, J., Croft, C., \& Godfrey, M. (2010). Whose responsibility is it anyway: The student-athlete? Academic Leadership: The Online Journal, 8(1), 34.

Schulman, J. L., \& Bowen, W. G. (2001). The game of life: College sports and educational values. Princeton, NJ: Princeton University Press.

Shaw, S. F., \& Dukes, L. L. (2001). Program standards for disability services in higher education. Journal of Postsecondary Education and Disability, 14(2), 81-90.

Shaw, S. F., Keenan, W. R., Madaus, J. W., \& Banerjee, M. (2010). Disability documentation, the Americans with Disabilities Act Amendments Act, and the summary of performance: How are they linked? Journal of Postsecondary Education and Disability, 22(3), 142-150.

Shaw, R. A. (2011). Employing universal design for instruction. In M. S. Huger (Ed.), Fostering the increased integration of students with disabilities (New Directions for Student Services, no. 134, pp. 21-33). San Francisco, CA: Jossey-Bass.

Shriberg, A., \& Brodzinski, F. R. (1984). Rethinking services for college athlete. New directions for student-athletes in division I revenue producing sports. Sociology of Sport Journal, 9, 48-59.

Shropshire, K. L., \& Williams Jr, C. D. (2017). The miseducation of the student athlete: How to fix college sports. Philadelphia, PA: Wharton Digital Press. 
Siegfried, J. J., \& Burba, M. G. (2004). The college football association television broadcast cartel. The Antitrust Bulletin, 49(3), 799-819.

Silver, L. (2006). The misunderstood child. New York, NY: Three Rivers Press.

Simons, H. D., Bosworth, C., \& Fujita, S. (2007). The athlete stigma in higher education. College Student Journal, 47, 251-273.

Simons, H. D., Van Rheenen, D., \& Covington, M. V. (1999). Academic motivation and the student athlete. Journal of College Student Development, 40, 151-162.

Singer, J. N. (2005). Understanding racism through the eyes of African American male student-athletes. Race Ethnicity and Education, 8(4), 365-386.

Smart, J. (2001). Disability, society, and the individual. Gaithersburg, MD: Aspen.

Smith, S. D. (1999). Examining the role of Attention-Deficit/Hyperactivity Disorder (ADHD) in the life experiences of University Student-Athletes. Corvallis, OR: Oregon State University

Snyder, P. L. (1996). Comparative levels of expressed academic motivation among Anglo and African American university student-athletes. Journal of Black Studies, 26(6), 651-667.

Solórzano, D. G., \& Delgado Bernal, D. (2001). Examining transformational resistance through a critical race and LatCrit theory framework: Chicana and Chicano students in an urban context. Urban Education, 3, 308-342.

Sommo, A., \& Chaskes, J. (2013). Intersectionality and the disability: Some conceptual and methodological challenges. Research in Social Science and Disability, 7, 4759.

Stake, R. E. (1995). The art of case study research. Thousand Oaks, CA: Sage Publications.

Staurowsky, E. J., \& Sack, A. L. (2005). Reconsidering the use of the term studentathlete in academic research. Journal of Sport Management, 19(2), 103-116.

Steele, C. M. (1997). A threat in the air: How stereotypes shape the intellectual identities and performance of women and African Americans. American Psychologist, 52, 613-629.

Steinberg, M. A., Walther, C., Herbst, M., West, J., Wingler, D., \& Smith, J. (2018). Learning specialists in college athletics: Who are they and what do they do? Journal of Higher Education Athletics \& Innovation, 1(4), 77-118. 
Steinfeldt, J. A., Steinfeldt, M. C., England, B., \& Speight, Q. L. (2009). Gender role conflict and stigma toward help-seeking among college football players. Psychology of Men \& Masculinity, 10(4), 261.

Stokowski, S. E. (2013). I know I can learn. The experiences of NCAA Division I - FBS student-athletes with learning disabilities and/or ADHD in higher education. Knoxville, TN: University of Tennessee.

Stokowski, S. E., Blunt-Vinti, H., Hardin, R., Goss, B. D., \& Turk, M. (2017). I know I can learn: The perceptions of NCAA Division I football college athletes with learning disabilities. Journal of Issues in Intercollegiate Athletics, 2017 Special Issue, 95-118.

Stokowski, S. E., \& Huffman, L. T. (2014). Sport participation motivations of studentathletes with learning disabilities. Research Quarterly for Exercise and Sport, 85(S1), A124.

Stokowski, S., Goldsmith, A., Croft, C., Hutchens, S., \& Fridley, A. (2020). The impact of football on student-athletes with education-impacting disabilities. Journal for the Study of Sports and Athletes in Education, 14(1), 1-18.

Stokowski, S., \& Ferguson, T. (2020). Student-Athlete, Black Football Student-Athletes with Education-Impacting Disabilities. In NASPA Knowledge Community Publication. NASPA, Washington, DC.

Strauss, A. (1987) Qualitative analysis for social scientists. Cambridge, England: Cambridge University Press.

Swadener, B. B. (2010). "At risk" or "at promise"?: From deficit constructions of the "other childhood" to possibilities for authentic alliances with children and families. International Critical Childhood Policy Studies, 3, 7-29.

Swadener, B. B., \& Lubeck, S. (Eds.). (1995). Children and families "at promise”: Deconstructing the discourse of risk. Albany, NY: SUNY Press.

Swadener, B. B., \& Niles, K. (1991). Children and families "at-promise" making homeschool community connections. Democracy in Education, 5(3), 13-18.

Taleb, N. N. (2007). The black swan: The impact of the highly improbable (Vol. 2). New York: Random House.

Test, D. W., Fowler, C. H., Wood, W., Brewer, D. M., \& Eddy, S. (2005). A conceptual framework of self-advocacy for students with disabilities. Remedial and Special Education, 26(1), 43-54. 
Thoma, C. A., \& Wehmeyer, M. L. (2005). Self-determination and the transition to postsecondary education. In E. E. Getzel \& P. Wehman (Eds.), Going to college: Expanding opportunities for people with disabilities (pp. 49-68). Baltimore, MD: Brookes.

Thompson, A. (2013). Social class and learning disabilities: Intersectional effects on college students in New York City. Research in Social Science and Disability, 7, 267-292.

Thompson, J., Petronio, S., \& Braithwaite, D. O. (2012). An examination of privacy rules for academic advisors and college student-athletes: A communication privacy management perspective. Communication Studies, 63(1), 54-76.

Thompson, M. V. (2012). Creating a culture of inclusion: Shifting the disability frame. ACPA Developments, 10(1). Retrieved from http://www2.myacpa.org/developments/spring-2012/creating-a-culture-ofinclusion-the-disability-frame/2306

Tierney, W. (1993). Building communities of difference: Higher education in the twentyfirst century. South Hadley, MA: Bergin and Garvey.

Trainin, G., \& Swanson, H. L. (2005). Cognition, metacognition, and achievement of college students with learning disabilities. Learning Disability Quarterly, 28(4), 261-272.

Trainor, A. A. (2005). Self-determination perceptions and behaviors of diverse students with LD during the transition planning process. Journal of Learning Disabilities, $38(3), 233-249$.

Trainor, A., \& Graumann, K. D. (2012). Reviewing qualitative research in the social sciences: A guide for researchers and reviewers. New York, NY: Routledge.

Trammell, J. (2009). Red-shirting college students with disabilities. Learning Assistance Review, 14(2), 21-31.

Trammell, J., \& Hathaway, M. (2007). Help-seeking patterns in college students with disabilities. Journal of Postsecondary Education and Disability, 20(1), 5-15.

Treme, J., \& Burrus, R. T. (2016). NCAA basketball: when does recruiting talent translate into wins for power conferences? Journal of Economics and Finance, 40(4), 735-753.

Troiano, P. F., Liefeld, J. A., \& Trachtenberg, J. V. (2010). Academic support and college success for postsecondary students with learning disabilities. Journal of College Reading and Learning, 40(2), 35-44. 
Tuffrey-Wijne, I., Bernal, J., \& Hollins, S. (2008). Doing research on people with learning disabilities, cancer and dying: ethics, possibilities and pitfalls. British Journal of Learning Disabilities, 36(3), 185-190.

U.S. Department of Education, National Center for Education Statistics. (2013). Table 269: Number and percentage distribution of students enrolled in postsecondary institutions, by level, disability status, and selected student characteristics: 200304 and 2007-08. In U.S. Department of Education, National Center for Education Statistics (Ed.), Digest of Education Statistics (2012 ed.). Retrieved from http://nces.ed.gov/programs/digest/d12/tables/dt12_269.asp

U.S. Department of Education, National Center for Education Statistics. (2014). Table 311.10: Number and percentage distribution of students enrolled in postsecondary institutions, by level, disability status, and selected student characteristics: 200708 and 2011-12. In U.S. Department of Education, National Center for Education Statistics (Ed.), Digest of Education Statistics (2013 ed.). Retrieved from http://nces.ed.gov/programs/digest/d13/tables/dt13_311.10.asp

U.S. Government Accountability Office. (2009). Higher education and disability: Education needs a coordinated approach to improve its assistance to schools in supporting students. Washington, DC: Government Printing Office. Retrieved from http://www.gao.gov/new.items/d1033.pdf.

Vaccaro, A., Kimball, E. W., Wells, R. S., \& Ostiguy, B. J. (2015). Researching students with disabilities: The importance of critical perspectives. New Directions for Institutional Research, 2014(163), 25-41.

van Manen, M. (2014). Phenomenology of practice: Meaning giving methods in phenomenological research and writing. Walnut Creek, CA: Left Coast Press.

Van Reusen, A. K., Bos, C. S., Schumaker, J. B., \& Deshler, D. D. (1994). The selfadvocacy strategy for education and transition planning. Lawrence, KS: Edge Enterprises.

Vickers, M. Z. (2010). Accommodating college students with learning disabilities: ADD, $A D H D$, and dyslexia. Raleigh, NC: John W. Pope Center for Higher Education Policy. Retrieved from http://www.popecenter.org/acrobat/vick ers-mar2010.pdf.

Walker, Y. N. (2004). Playing the game of academic integrity vs. athletic success: The Americans with Disabilities Act (ADA) and intercollegiate student-athletes with learning disabilities. Marquette Sports Law Review, 15, 601.

Walling, L. L. (1996). Hidden abilities in higher education: New college students with disabilities. (Monograph Series 21). Columbia, SC: National Resource Center for The Freshman Year Experience and Students in Transition. 
Watson, J. C. (2005). College student-athletes' attitudes toward help-seeking behavior and expectations of counseling services. Journal of College Student Development, 46(4), 442-449.

Watson, J. C. (2006). Student-athletes and counseling: Factors influencing the decision to seek counseling services. College Student Journal, 40(1) 35-42.

Watt, S. K., \& Moore, J. L. (2001). Who are student athletes? In M. F. Howard-Hamilton \& S. K. Watt (Eds.), Student services for student athletes. New Directions for Student Services, no. 93. San Francisco, CA: Jossey-Bass.

Wehmeyer, M., \& Lawrence, M. (1995). Whose future is it anyway? Promoting student involvement in transition planning. Career Development for Exceptional Individuals, 18, 69-83.

Weiss, M. P. (2011). Supporting student athletes with disabilities: A case study. Journal of Postsecondary Education and Disability, 24(2), 161-163.

Weston, M. A. (1999). Academic standards or discriminatory hoops leaning-disabled student-athletes and the NCAA initial academic eligibility requirements. Tennessee Law Review, 66(4), 1049-1126.

Weston, M. A. (2005). The intersection of sports and disability: Analyzing reasonable accommodations for athletes with disabilities. St. Louis University Law Journal, 50(137), 137-163.

Williams, P., \& Shoultz, B. (1982). We can speak for ourselves. Bloomington, IN: Indiana University Press.

Wilson, K., Getzel, E., \& Brown, T. (2000). Enhancing the post-secondary campus climate for students with disabilities. Journal of Vocational Rehabilitation, 14(1), $37-50$.

Wilson, M. (2017). NCAA Division I football coaching contracts: A comparative analysis of incentives for athletic and academic team performance from 2006, 2009, and 2011. Journal of Contemporary Athletics, 11(4), 237-255.

Wolniak, G. C., Pierson, C. T., \& Pascarella, E. T. (2001). Effects of intercollegiate athletic participation on male orientations toward learning. Journal of College Student Development, 42(6), 604-24.

Wolverton, B. (2008, September 5). Spending plenty so athletes can make a grade. The Chronicle of Higher Education, A3-A10. 
Wolverton, B. (2014, December 11). Payments for athletes? Check. Players with balanced lives? Not so much. Chronicle of Higher Education. Retrieved from http://chronicle.com /article/Payments-for-Athletes-Check/150807.

Wolverton, B. (2016, February 28). The hottest hire in athletics? Learning specialists. The Chronicle of Higher Education, 62(25), A14.

Wrisberg, C. A., \& Martin, S. B. (1994, October). Attitudes of African-American and Caucasian athletes towards sport psychology consultants. Paper presented at the meeting of Association for the Advancement of Applied Sport Psychology, Incline Village, NV.

Yopyk, D. A., \& Prentice, D. A. (2005). Am I an athlete or a student? Identity salience and stereotype threat in student-athletes. Basic and Applied Social Psychology, 4, 329 -336 .

Yosso, T. J. (2000). A critical race and LatCrit approach to media literacy: Chicanalo resistance to visual microaggressions. Unpublished doctoral dissertation, University of California, Los Angeles.

Yosso, T. J. (2005). Whose culture has capital? A critical race theory discussion of community cultural wealth. Race, Ethnicity and Education, 8(1), 69-91.

Zimbalist, A. (1999) Unpaid professionals: Commercialism and conflict in big-time college sports. Princeton, NJ: Princeton University Press. 
Appendix A

Semi-Structured Interview Protocol

\section{RQ2: What does this process of self-disclosure look like for college athletes with learning disabilities and/or ADHD?}

In your own words, how would you describe your disability?

Describe how your disability affect your college experience, if at all?

How does your athletic participation influence your college experience, if at all?

Have you ever felt stereotyped based on one or more of your identities?

If so, can you explain the experience? What did you feel and by whom?

In what academic situations do you disclose your disability? (Faculty, peers, academic support)

In what athletic situations do you feel the need to disclose your disability? (coach, trainer)

Can you describe a time you felt pressured to disclose your disability?

In what academic situations do you knowingly choose not to self-disclose and why?

Before deciding to self-disclose information about your disability, what to do you consider?

After disclosing your disability how did you feel and what are the reactions of others?

Have you ever disclosed your disability to your coach? Please explain why or why not.

\section{RQ3: How do college athletes with learning disabilities and/or ADHD advocate for their academic success?}

How would you define being an advocate for something or someone?

In what ways do you ensure your needs are met in regard to your academic success?

How comfortable do you feel making your own decisions in your college life?

How do you stand up for yourself in environments or spaces where you do not have power?

How much knowledge do you have in regard to laws and services related to your disability?

Who or where do you go to gain more information in regard to your disability?

Describe a time when you stood up for something you needed to help you succeed academically. What did that look like? How did it feel? What about a time related to athletics?

Who do you communicate your needs too in regard to your disability? In what situations or contexts? What makes you feel comfortable? What makes you feel resistant?

How did you learn to communicate or advocate for your needs?

How comfortable do you feel advocating for others? What does this look like?

\section{RQ1: In what ways do college athletes with learning disabilities and/or ADHD describe academic support within their campus community?}

What types of support do you personally use to help you succeed academically?

How often do you use or interact with these support services that are available?

Who is your support system when it comes to academics and how do they support you?

When it comes to your academic success, where do you feel the least supported?

What could your university do differently to better support your needs?

What choices do you make in relation to your academics that help you succeed?

How can colleges better support college athletes with disabilities?

What can athletic departments do to better support college athletes with disabilities?

What type of support would you want to see implemented to help college athletes with disabilities navigate their transition to college? 
Appendix B

Demographic Data Sheet

Please answer the following questions to the best of your ability. Under pseudonym, please DO NOT put your legal name, instead please create a fictional name of your choosing. If you choose to leave the space blank, a name will be provided to you by the researcher.

Pseudonym:

Conference:

Year in School:

Gender:

Race/Ethnicity:

Age:

Sport:

Major:

Disability: ADHD Learning Disability Unknown Other

Did you receive disability services in high school?

Yes No

Are you registered with Disability Services on your campus? $\quad$ Yes $\quad$ No

How long have you known about your disability?

What year were you diagnosed?

"Self-Advocacy is learning how to speak up for yourself, making your own decisions about your own life, learning how to get information so that you can understand things that are of interest to you, finding out who will support you in your journey, knowing your rights and responsibilities, problem solving, listening and learning, reaching out to others when you need help and friendship, and learning about self-determination."

- Center for Parent Information and Resources

Please use the following scale: $(1=$ extremely uncomfortable: $10=$ extremely comfortable $)$ ?

Based on the definition above, how comfortable do you feel self-advocating?
1
2
3
4
5
6
7
8
10

How comfortable do you feel speaking up for your needs?
1
2
3
4
5
6
7
8
10

How comfortable do you feel reaching out to others when you are in need?
1
2
3
4
5
6
7
8
9
10 


\section{Appendix C \\ Subject Recruitment Email}

Good morning

My name is Stephanie O'Donnell and I am a current Ph.D. student working under the supervision of Professor Amy Hirschy ( ), from the University of Louisville, in the Counseling and Personnel Services (College Student Personnel) program. I am conducting research on current NCAA DI college athletes with learning disabilities and/or ADHD and their collegiate experience.

I was reaching out to see if you could send the following message (after the signature) to some current students you think would be interested in participating. Another option is to print out the attached flier and publicize the opportunity in your office space.

If you are not the appropriate person to contact to have this message sent out, please feel free to forward this on to whoever that person may be. If you have any further questions or concerns, please contact me at or

Thank you,

Stephanie O'Donnell

Dear Student,

My name is Stephanie O'Donnell and I am a current graduate student working under the supervision of Professor Amy Hirschy (_) at the University of Louisville. I am conducting research on current NCAA DI college athletes with learning disabilities and/or ADHD and their collegiate experience.

As a former student who participated in athletics with a disability, I am interested in hearing your story and experiences on your college campus. Participation in this research study would help inform how learning specialists, academic counselors or advisors, and other administrators or faculty can better the collegiate experience for athletes with nonvisible disabilities. I am seeking 6 to 10 current college athletes with learning disabilities and/or ADHD from a variety of NCAA Division I institutions and athletic teams to discuss their collegiate experience.

- I am looking to conduct a one-time, audio recorded, 90-minute interview via phone or video chat.

- Questions will focus on understanding how you view academic support, self-disclosure (sharing your disability with others), and self-advocacy (speaking up for your needs).

- You will be compensated $\mathbf{\$ 2 0 . 0 0}$ for your time which is in compliance with NCAA bylaw 16.11.1.6.2.

- Your confidentiality will be strictly safeguarded in this study, which includes not informing your coach, athletic staff, and academic administrators that you are participating.

If you are interested in more information or would like to participate, please contact Stephanie O’Donnell via email at or via phone 
Appendix D

Recruitment Flier

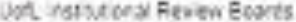

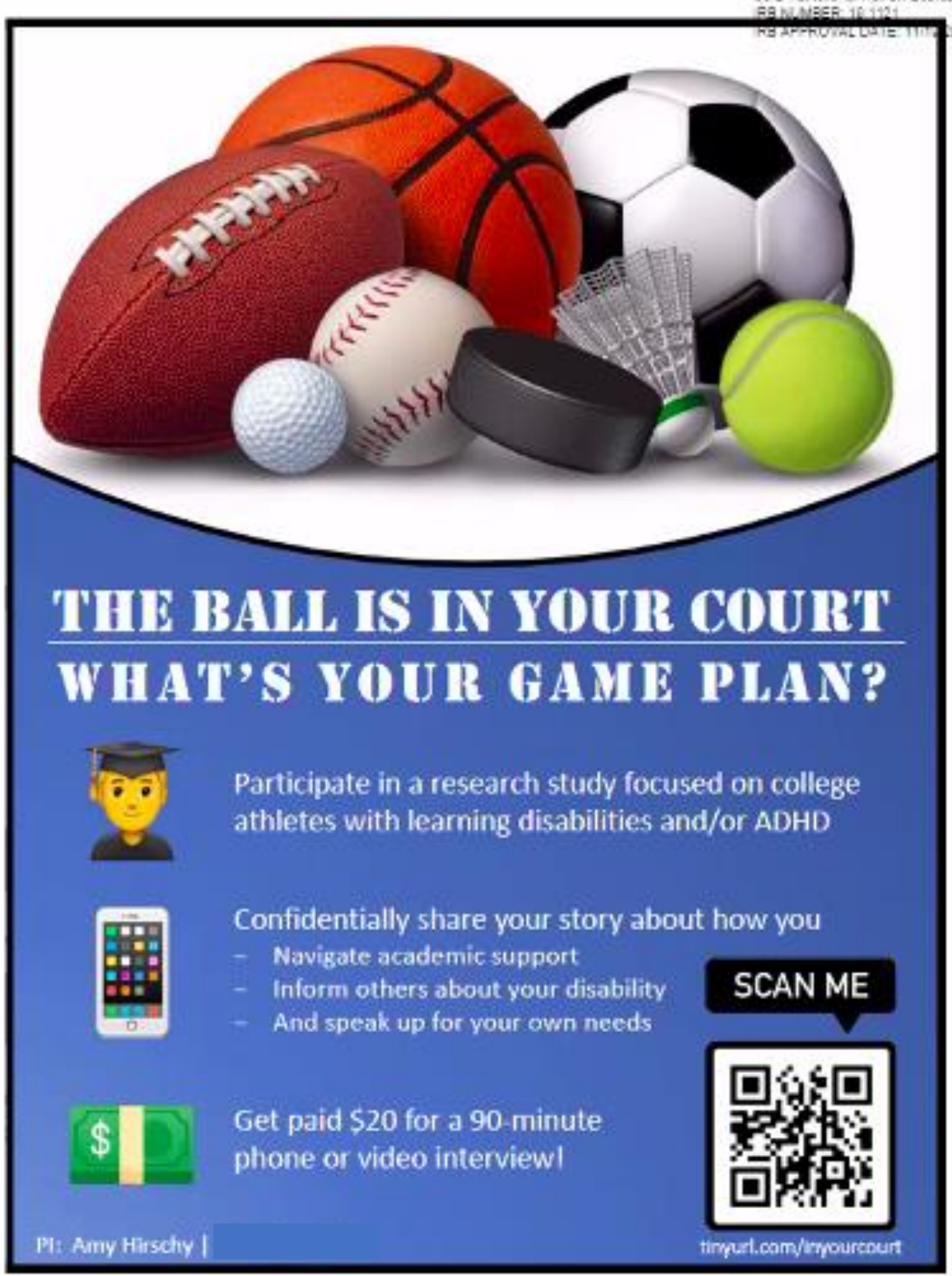


Appendix E

Preamble

The Ball Is In Your Court: A Phenomenological Study Examining College Athletes with Learning Disabilities and/or ADHD on College Campuses

UofL Institutional Review Boards

IRB NUMBER: 19.1121

IRB APPROVAL DATE: 11/19/2019

Date: November 1, 2019

Dear College Athlete:

You are being invited to participate in a research study by answering questions provided by email in the attached demographic sheet followed by an audio recorded, one on one, 90-minute interview conducted via phone or video chat. This study is seeking 6 to 10 current NCAA Division I college athletes with learning disabilities and/or ADHD from a variety of Power 5 conference institutions and athletic teams to discuss their collegiate experience. This study can help inform college professionals on the specific academic needs of students when it comes to sharing their disability and speaking up for their needs.

This study is conducted by Dr. Amy Hirschy of the University of Louisville and $\mathrm{Ph}$.D. doctoral candidate Stephanie O'Donnell. There are no known risks for your participation in this research study. The information collected may not benefit you directly. In compensation for your time and effort, you will receive $\$ 20.00$ in the following weeks after the interview has been completed. This is in compliance with NCAA bylaw 16.11.1.6.2. The information learned in this study may be viewed as beneficial and informative to others within the profession. The information you provide will be used towards completion of dissertation work and potential publication. Your completed demographic sheet and interview will be stored electronically online through the University of Louisville's encrypted password protected storage system.

Since you will be paid by prepaid card for you time, inconvenience, or expense while you are in the study, the University of Louisville may collect your name, address, social security number, and keep records of how much you are paid. You may or may not be sent a Form 1099 by the University. This will only happen if you are paid $\$ 600.00$ or more in on year by the University. This will not include payments you may receive as reimbursement for actual expenses based on receipts or actual miles traveled. We are required by the Internal Revenue Service to collect this information and you may need to report the payment as income on your taxes. You can still be in the study even if you do not want to be paid. Individuals from the Department of Counseling \& Human Development, the Institutional Review Board (IRB), the Human Subjects Protection Program Office 
(HSPPO), and other regulatory agencies may inspect these records. In all other respects, however, the data will be held in confidence to the extent permitted by law. Should the data be published, your identity will not be disclosed.

Taking part in this study is voluntary. By answering questions on the initial demographic sheet, you agree to take part in this research study. You do not have to answer any questions that make you uncomfortable. If you decide to be in this study you may stop taking part at any time.

If you decide not to be in this study or if you stop taking part at any time, you will not lose any benefits for which you may qualify.

If you have any questions, concerns, or complaints about the research study, please contact:

\section{Dr. Amy Hirschy}

Stephanie O'Donnell
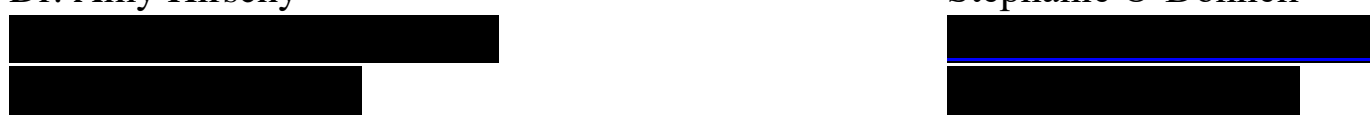

If you have any questions about your rights as a research subject, you may call the Human Subjects Protection Program Office at (502) 852-5188. You can discuss any questions about your rights as a research subject, in private, with a member of the Institutional Review Board (IRB). You may also call this number if you have other questions about the research, and you cannot reach the research staff, or want to talk to someone else. The IRB is an independent committee made up of people from the University community, staff of the institutions, as well as people from the community not connected with these institutions. The IRB has reviewed this research study.

If you have concerns or complaints about the research or research staff and you do not wish to give your name, you may call 1-877-852-1167. This is a 24 hour hot line answered by people who do not work at the University of Louisville.

Sincerely,

Stephanie O'Donnell

Dr. Amy Hirschy
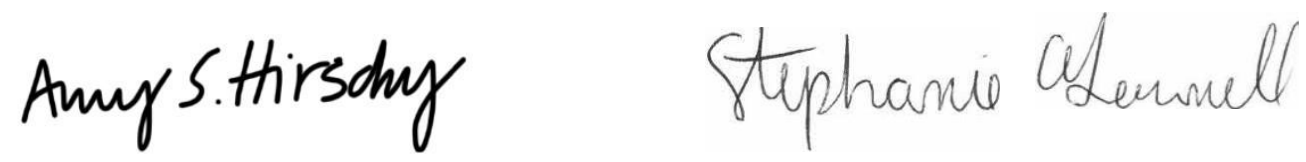


\section{CURRICULUM VITAE}

\section{Stephanie O’Donnell}

\section{$\underline{\text { Education }}$}

University of Louisville; Louisville, KY

Doctor of Philosophy: Counseling \& Student Personnel Services

December 2020

Dissertation: The Ball is in Your Court: A Phenomenological Study Examining College Athletes with

Learning Disabilities and/or ADHD on College Campuses

\section{Clemson University; Clemson, SC}

Graduate Certification: Athletic Leadership

May 2019

University of Alabama; Tuscaloosa, AL

Master of Arts: School Counseling

May 2017

Master of Arts: Higher Education Administration

May 2016

Keene State College; Keene, NH

Bachelor of Science: Elementary Education

May 2013

Bachelor of Arts: Gender and Psychological Development

May 2013

\section{University of Kentucky; Lexington, KY}

National Student Exchange Program

Fall 2010

\section{Higher Education Experience}

\section{University of Louisville; Louisville, Kentucky}

Quality Enhancement Plan Graduate Assistant: Delphi Center

August 2018-December 2019

- Provided administrative assistance for the executive director of the quality enhancement plan

- Co-chaired the student advisory team committee, meeting once a month

- Analyzed and interpreted assessment, data, and instruments related to teaching and learning

- Conducted benchmarking pertaining to teaching and learning, and quality enhancement plans

- Implemented and maintained marketing strategies for the quality enhancement plan

General Studies Instructor: Student Success and Exploratory Advising August 2019-October 2019

- Facilitated lessons and assessments for a group of 16 students through exploration and development

- Provided educational opportunities for students to transition and navigate their first year through college

\section{University of Kentucky; Lexington, Kentucky}

Resident Director: Residence Life

September 2017-July 2018

- Supervise a group of 9 student staff members, 1 full-time office assistant and 250 residents

- Conduct academic conversations with students on academic probation

- Collaborate with departments on campus and provide referrals to residents

- Engage in partnership with Living Learning Partners and Peer Mentors

- Serve on several committees to enhance university and department mission and goals 
- Supervised a group of 10 resident advisors, 5 freshman advisors, and 480 residents

- Implemented and conducted several professional development, team building and training opportunities

- Collaborated with departments on campus and provide referrals to residents

- Managed and conducted administrative tasks and conduct hearings with residents

- Communicated with parents and students on unvisited policies

- Supported residents and student staff through conflict, mediation, and crisis management

- Served in an on-call rotation, and respond to emergencies, and crisis response

- Facilitated roommate mediations, and staff conflicts

- Utilized Habitudes, to provided leadership development

Summer Graduate Assistant: Housing and Residential Communities

May 2015-July 2015

- Managed and supervised a group of 13 orientation assistants and 3 summer resident advisors

- Provided customer service experience working with parents, residents, and future students

- Created weekly schedules for student staff members as well as handled operational tasks

- Trained all student staff members on housing policies, procedures, and orientation information

- Contacted and organized all keys, parking passes, and information for camps and conferences

Community Service Intern: Center for Sustainable Service and Volunteerism May 2015-July 2015

- Designed and implemented a community service model for Housing and Residential Communities

- Planned seven different community service outreach programs to fit the unique needs of residents

- Communicated and outreached to various departments on campus and within the community

- Marketed the events in several different strategic ways throughout campus (i.e. technology)

Assumption College; Worcester, Massachusetts

National Orientation Directors Association (NODA): Orientation Intern

May 2016-June 2016

- Trained and led 20 Orientation Leaders and 6 Executive members through student and parent orientations

- Developed diverse training sessions for staff to effectively ran orientation throughout the summer sessions

- Produced and evaluated online assessment surveys to evaluate and enhance future sessions

- Managed and operated orientation food budget throughout training and orientation sessions

Keene State College; Keene, New Hampshire

Resident Hall Assistant: Residential Life

August 2011-December 2012

- Created a living learning community and with 50 sophomore, transfer, and international students

- Facilitated programs to enhance study skills, and academic support

- Guided transfer and international students, providing resources and transitional support

- Served on call, facilitated roommate mediations, and responded to crisis, and emergencies

Summer Conference Worker

May 2012-August 2012

- Managed administrative tasks such as checking in and out conference guests, and provided information

- Served on-call, provided customer service to guests, and prepared residence rooms for conference

Teacher Associate for Intro to Education: Education Department

January 2011-December 2012

- Co-instructed and oversaw anywhere from 5 students to 12 students in a course

- Prepared and implemented lesson plans, activities, group discussions and assessments

- Graded assessment tools, and provided one-hour study sessions for students weekly

\section{Athletic Academic Services}

\section{University of North Carolina; Chapel Hill, North Carolina}

Assistant Learning Specialist: Academic Support Programs

August 2020-Present

- Provide comprehensive academic support to a designated caseload one-on-one and in small groups

- Support the tutoring services program by scheduling/canceling sessions, hiring and evaluating tutors

- Provide strategic tools to enhance students learning, organization, and time management skills

- Guide students through learning various assistive technology strategies to enhance their learning

- Review and propose changes to initial "at-risk" evaluation document

- Assist in initial disability screenings for students refereed for evaluation and accommodations 
University of Central Florida; Orlando, Florida

Assistant Athletic Academic Advisor: Academic Support

January 2020-May 2020

- Monitored and managed academic progress for a caseload of 16 athletes and football defensive walk-ons

- Conducted and monitored team and group study-hall twice a week for 75 minutes

- Worked one-on-one with student-athletes on developing academic skills

- Compiled and maintained reports such as study hall, grades, eligibility, class checking, and coaches report

- Academically advised caseload of students through multi-term registration

University of Louisville; Louisville, Kentucky

Thorntons Academic Center of Excellence

Athletic Academic Support Intern

January 2019-December 2019

- Assisted with administrative tasks, such as book distribution, book vouchers, and grade reports

- Created a learning assistant manual and resource documents for academic advisors from across campus

- Reviewed degree audits for the registrar's office, ensuring credits hours are accurate for all students

- Collaborated with learning specialist to review documents and aid in assessments

Athletic Academic Learning Assistant

January 2019-May 2019

- Worked individually with students, ranging from 30 minutes once a week to one hour three times a week

- Guided students through study skills, organization, time-management, and learning strategies

- Aided students in completing objective-based study hall

- Researched and conducted presentation on writing skills and reading comprehension

Athletic Academic Tutor

August 2018-December 2019

- Tutored approximately three students per week in humanities, sports administration, and psychology

- Abided by NCAA, FERPA, ACC, and institutional policies and regulations

- Developed an understanding of and utilize EAB, GradesFirst, and TeamWorks software

- Promoted educational pedagogy suited for each individual tutorial meeting

University of Kentucky; Lexington, Kentucky

Internship: Center for Academic \& Tutorial Services (CATS)

January 2018-June 2018

- Observed, shadowed, and interacted with athletes, academic counselors, and graduate assistants

- Learned NCAA regulations on eligibility, recruitment, academics, and financial aid

- Tracked student athlete's attendance, tutoring sessions, and academic grades

\section{School Counseling Experience}

\section{Tuscaloosa City Schools; Tuscaloosa, Alabama}

School Counseling Internship: Northridge High School

January 2017-April 20017

- Experienced 300 hours in a high school, 180 observable hours, and 120 direct, hands-on experience

- Collaborated and communicated with coaches, teachers, and administrators on student progress

- Met bi-weekly with students one on one, to discuss academic progress and career trajectories

- Assisted with career counseling and higher education preparation

School Counseling Internship: Tuscaloosa Magnet School- Elementary

January 2017-April 2017

- Experienced 300 hours in an elementary school, 180 observable hours, and 120 direct, hands-on

- Created and implemented classroom, group, and individualized guidance lessons based on ASCA

School Counseling Practicum: Tuscaloosa Magnet School- Middle

August 2016-November 2016

- Experienced 130 hours in a middle school, 66 observable hours, and 63 direct, hands-on experience

- Completed over 22 direct individual counseling sessions with undergraduate and graduate students

- Assisted with 10 hours of group counseling sessions and 15 hours in career counseling

\section{K-12 Teaching Experience}

The University of Alabama; Tuscaloosa, Alabama

The University of Alabama CrossingPoints

March 2015-March 2016

College of Education and the Tuscaloosa County School Systems providing transitional services for

students with disabilities 18-21 
- Volunteered three hours a week working with exceptional children ages 18-21

- Participated in recreational, academic, job placement and daily living skills

Keene State College; Keene, New Hampshire

Student Teaching; Wheelock Elementary School

- Taught and managed a kindergarten classroom of fifteen students

January 2013-May 2013

- Created lesson plans implementing the common core with New Hampshire standards

- Provided 600 hours, and three solo weeks of teaching

\section{AmeriCorps Service}

City Year Boston, AmeriCorps; English High School, Boston, MA

August 2013-June 2014

Education nonprofit organization uniting young people for a full year of service keeping students in school and on track to graduate

- Provided 10,000 plus hours of service to Boston community through educational and physical service

- Mentored a cohort of $10^{\text {th }}$ grade special education students in attendance, behavior, and coursework

- Organized initiatives and evaluated student data on retention as attendance coordinator

- Provided individual interventions, modeling response to intervention at levels tier two and three

- Collaboratively worked with staff, teachers, and administrators in Early Warning Indicator meetings

- Created individualized educational plans for students slipping off track, and in danger of failing

- Communicated with parents on students' academic progress, attendance, and behavior

- Provided tutoring services and collaborated with the Boston Scholar Athletes program

\section{Committee Work}

University of Louisville; Louisville, Kentucky

ADA Compliance Committee

October 2018-December 2019

- Serve as a student representative, collaborating with faculty, staff and administrators

- Discuss pressing issues surrounding accessibility and access on campus

\section{The University of Alabama; Tuscaloosa, Alabama}

Housing and Residential Communities

Training Committee: Housing \& Residential Communities

October 2016-January 2017

- Created and executed Community Director Spring training

- Collaborated with other professionals from campus to create informative presentations

- Developed a diversity and social justice workshop for graduate students

Search Committee for Area Coordinator

November 2016-January 2017

- Served on a search committee to help find an area coordinator for Housing \& Residential Communities

- Dedicated several hours and weeks throughout the process to rank applicants, and conduct interviews

Manual and Training Committee

January 2015-December 2016

- Designed and implemented a housing manual to assist student staff members through training

- Created unique, engaging training opportunities for student staff members

- Evaluated prior assessments and evaluations to recreate learning outcomes for training sessions

Residential Curriculum Committee

August 2015-December 2016

- Researched and provided feedback on language used within the development of curriculum outcomes

- Generated assessment tools to evaluate the outcome of Residential Curriculum

Recruitment and Selection Committee

September 2014-May 2016

- Participated in the process of hiring professional and student staff members

- Organized recruitment strategies for student staff members and graduate assistants

- Interviewed and engaged with potential professional staff member candidates when on campus

\section{Higher Education Administration \& Student Affairs}

Higher Education Organization Committee

October 2014-May 2016

- Created and maintained alumni relations with the department of higher education

- Provided transitional support for students entering into the program of higher education 
- Served as the community and service outreach partner to the city of Tuscaloosa, AL

- Planned community building activities for the department of higher education

Search Committee for Coordinator of Informal Recreations

- Served on a search committee to help find a coordinator for information recreations

- Met several times throughout the process to look over resumes, and conduct phone interviews

- Provided feedback on candidates on campus interviews, and ability to fit the dynamics of the department

\section{Keene State College; Keene, New Hampshire}

All Access Committee

January 2010-May 2013

- Advocated to ensure a safe and inclusive campus for the disabled

- Evaluated data and discussed higher education documents, and articles

- Collaborated with other professional higher education staff

Global Education Ambassador

January 2011-May 2013

- Promoted, persuaded, and informed students about National Student Exchange

- Interacted with international students, as an initial contact person

\section{Professional Memberships}

National Association for Academic Advisors of Athletics (N4A)

National Academic Advising Association (NACADA)

March 2018-Present
August 2019-Present

\section{Certifications}

National Certified Counselor Certification (NCC)

New Hampshire Teaching Certification; Elementary Education K-8

Alteristic Green Dot Certification: Violence Prevention Strategies

November 14, 2017

September 6, 2015

July 2018

\section{Service, Activities, and Honors}

Chi Sigma Iota: Counseling Professional Honor Society; University of Alabama April 2015-May 2017 Assistant Cheerleading Coach; English High School Boston, MA Kappa Delta Pi: Epsilon Pi Education Honor Society; Keene State College National Colligate Honors Society; Keene State College Admissions Tour Guide; Keene State College

Keene State College Cheerleading; Keene State College

September 2013-January 2014

September 2012-May 2013

January 2011-May 2013

September 2009-May 2013

September 2009-May 2013

\section{Presentations}

Under Construction: Building Strong Relationship for Effective Tutoring; NCLCA 2019 October 4, 2019

The Leadership Compass: Who am I as a Leader?; NCLCA 2019

N4A National Conference 2019; Orlando, FL Research Poster Session

October 5, 2019

June 2019

N4A National Conference 2020; Las Vegas, NV Universal Design

June 2020

University of Alabama UA-Leads; Leadership Compass

Alabama NASPA 2015; Student Development Theory, Afro-America Gospel Choir

Higher Education; High Impact Practices: First-Generation Students \& Study Abroad

February 21, 2015

January 24, 2015

April 21, 2015

\section{Publications}

O'Donnell, S. (2020). (Review of the book The Collegiate Athlete4 at Risk: Strategies for Academic Support and Success, by M. R. Council III, S. R. Hodge, \& R. A. Bennett III). Journal of Issues in Intercollegiate Athletes 2020,13 i-iii i.

\section{Grants}

NCAA Graduate Grant 2019

Unfunded

University of Louisville Graduate School Counsel 2019

$\$ 500.00$ 